GA-A14147

UC-77

\title{
HTGR CONTAINMENT DESIGN OPTIONS: AN APPLICATION OF PROBABILISTIC RISK ASSESSMENT
}

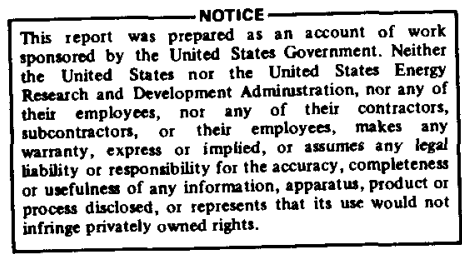

Prepared in part under

Contract EY-76-C-03-0167

Project Agreement No. 51

for the San Francisco Operations Office

U.S. Energy Research and Development Administration

GENERAL ATOMIC PROJECTS 3219 and 4223

\section{DATE PUBLISHED: AUGUST 1977}




\section{DISCLAIMER}

This report was prepared as an account of work sponsored by an agency of the United States Government. Neither the United States Government nor any agency Thereof, nor any of their employees, makes any warranty, express or implied, or assumes any legal liability or responsibility for the accuracy, completeness, or usefulness of any information, apparatus, product, or process disclosed, or represents that its use would not infringe privately owned rights. Reference herein to any specific commercial product, process, or service by trade name, trademark, manufacturer, or otherwise does not necessarily constitute or imply its endorsement, recommendation, or favoring by the United States Government or any agency thereof. The views and opinions of authors expressed herein do not necessarily state or reflect those of the United States Government or any agency thereof. 


\section{DISCLAIMER}

Portions of this document may be illegible in electronic image products. Images are produced from the best available original document. 


\title{
NOTICE
}

This report was prepared as an account of work sponsored by the United States Government. Neither the United States nor the United States Energy Research and Development Administration, nor any of their employees, nor any of their contractors, subcontractors, or their employees, makes any warranty, express or implied, or assumes any legal liability or responsibility for the accuracy, completeness or usefulness of any information, apparatus, product or process disclosed, or represents that its use would not infringe privately owned rights.

\author{
Printed in the United States of America \\ Available from \\ National Technical Information Service \\ U.S. Department of Commerce \\ 5285 Port Royal Road \\ Springfield, Virginia 22161 \\ Price: Printed Copy $\$ 6.75 ;$ Microfiche $\$ 3.00$ \\ $8,-4$
}


Form ERDA 426

$(2 \pi 5)$

ERDAM 3201

\section{U.S. ENERGY RESEARCH \& DEVELOPMENT ADMINISTRATION \\ MAJOR CONTRACTOR'S RECOMMENDATION FOR \\ DISPOSITION OF SCIENTIFIC AND TECHNICAL DOCUMENT}

* See Instructions on Reverse

1. ERDA Report No. GA-AI4147

2. Subject Category No. UC-77
3. Title HTGR CONTAINMENT DESIGN OPTIONS: AN APPLICATION OF PROBABILISTIC RISK ASSESSMENT.

EY-76-C-03-0167, PA 51

4. Type of Document (" $X$ " one)

D. Scientific and Technical Report

$\square$ b. Conference paper:

Title of conference

Date of conference

Exact location of conference

c. Other (Specify, Thesis, Translation, etc.)*

5. Copies Transmitted ("X" one or more)

a. Copies being transmitted for standard distribution by ERDA-TIC.

$\square$ b. Copies being transritted for special distribution per attached complete address list.*

$\square$ c. Two completely legible, reproducible copies being transmitted to ERDA-TIC.

6. Recommended Distribution (" $X$ " one)

$\bigotimes$ a. Normal handling (after Patent clearance): no restraints on distribution except as may be required by the security classification.

$\square$ b. Make available only to U.S. Government agencies and their contractors.

$\square$ c. Make available only within ERDA and to ERDA contractors.

$\square$ d. Make available only within ERDA.

$\square$ e. Make available only to those listed in item 12 below.

f. Other (Specify)*

7. Recommended Announcement (" $X$ " one)

Q a. Normal procedure may be followed.*

$\square$ b. Recommend following announcement limitations:

8. Reason for Restrictions Recommended in 6 or 7 above.

$\square$ a. Preliminary information.

$\square$ b. Prepared primarily for internal use.

$\square$ c. Other (Explain)

9. Patent Clearance ("X" one)

W. ERDA patent clearance has been granted by responsible ERDA patent group.

$\square$ b. Document has been sent to responsible ERDA patent group for clearance.

10. National Security Information (For classified document only; " $\mathrm{X}$ " one)

$\square$ a. Document does contain national security Information other than restricted data.

$\square$ b. Document does not contain national security information other than restricted data.

11. Copy Reproduction and Distribution

a. Total number of copies reproduced

b. Number of copies distributed outside originating organization

12. Additional Information or Remarks (Continue on separate sheet, if necessary)

13. Submitted by (Name and Position) (Please print or type)*

Jack E. Weaver, Manager, Document Center

14. Organization

General Atomic Company

15. Signature

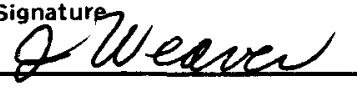




\section{INSTRUCTIONS}

Who uses this Form: All ERDA contractors except those specifically instructed by their ERDA contract administrator to use the shorter Form ERDA-427

When to Use: Submit one copy of this Form with each document which is sent to ERDA's Techncial Information Center (TIC) in accordance with the requirements of ERDA Manual Chapter 3201

Where to send: Forward this Form and the document(s) to

USERDA-TIC

P.O. Box 62

Oak Ridge, TN 37830

Item instructions:

Item 1. The furst element in the number shall be an ERDAapproved code to be determined as follows (a) The responsible field office may request TIC approval of a unique code for a contractor, e $g$, BNL, BMI, HNL, etc , (b) A program division may request TIC approval of a unıque code for a program or series of reports, e g, PNE, VUF, etc, (c) An operations office may instruct a contractor to use the code approved for the operations office, $1 \mathrm{e}$., COO, ORO, IDO, SRO, SAN, ALO, RLO, NVO, and (d) Program divisions shall use the code ERDA for reports which they themselves prepare unless there is reason to use some other approved code.

The code shall be followed by a sequential number, or by a contract number plus a sequential number, as follows (a) Contractors or programs with unique codes may complete the report number by adding a sequential number to the code, e g, H N L-101, HNL-102, etc, or PNE-1, PNE-2, etc, or they may add the identifying portion of the contract number and a sequential number, $e g, A B C-2105-1$, $\mathrm{ABC}-2105-2$, etc, (b) Contractors using the operations office code shall complete the report number by adding the identifying portion of the contract number and a sequential number, e.g, COO-2200-1, COO-2200-2, etc , (c) Subcontractor reports shall be identified with the code used by the prime contractor, and (d) Program divisions using the ERDA code shall complete the report number by ddding a sequential number which they request from the Library Branch, Division of Administrative Services

Item 2. Insert the appropriate subject category from TID-4500 ("Standard Distribution for Unclassified Scientific and Technical Reports") or M-3679 ("Standard Distribution for Classified Scientific and Technical Reports") far both classified and unclassified documents, whether or not printed for standard distribution

Item 3. Give title exactly as on the document itself unless title is classified In that case, omit title and state "classified title" in the space for item 3

Item 4. If box $c$ is checked, indicate type of item being sent, e.g., thesis, translation, etc

Item 5. a If box a is checked, the number of coples specified for the appropriate category or categories in M-3679 or TID-4500 shall be forwarded to TIC for distribution.

b If box b is checked, complete address list must be provided TIC. c If box $\mathrm{c}$ is checked, at least one copy shall be original ribbon or off set and be completely legible A clear carbon copy is acceptable as a second reproducible copy

Item 6. If box a is checked for an unclassified document, it may be distributed by TIC (after patent clearance) to addressees listed in TID -4500 for the appropr vate subject category, to libraries in the U.S. and abroad, which through purchase of microfiche maintain collections of ERDA reports, and to the National Technical Information Service for sale to the public.

If box a is checked for a classified document, it may be distributed by TIC to addressees listed in M-3679 for the appropriate subject category

If a box other than a is checked, the recommended limitation will be followed unless TIC receives other instructions from the responsible ERDA program division

Box $f$ may be checked in order to specify special instructions, such as "Make avalable only as specifically approved by the program division," etc

Item 7. a. Announcement procedures are normally determined by the distribution that is to be given a document. If box a in item 6 is checked for an unclassified document, it will normally be listed in the weekly "Accessions of Unlımited Distribution Reports by TIC" (TID-4401) and may be abstracted in "Nuclear Scrence Abstracts" (NSA).

A classified document, or an unclassified document for which box b, c, d, e, or $f$, in item 6 is checked, may be cited with appropriate subject index terms in "Abstracts of Limited Distribution Reports" (ALDR)

b. If the normal announcement procedures described in $7 \mathrm{a}$ are not appropriate check $7 \mathrm{~b}$ and indicate recommended announcement limitations

Item 8. If a box other than a is checked in item 6 , or if $7 \mathrm{~b}$ is checked, state reason for the recommended restriction, e.g., "preliminary information," "prepared primarily for internal use," etc

Item 9. It is assumed that there is no objection to publication from the standpoint of the originating organization's patent interest Otherwise explain in item 12

Item 10. If box a is checked, document cannot be made avallable to Access Permit holders (Code of Federal Regulations, 10 CFR, Part 25, subpart 25.6), if box b is checked, TIC will determine whether or not to make it avallable to them

Item 11. Self explanatory

Item 12. Use this space if necessary to expand on answers given above, e g , item $6 f$ and item 8

Item 13. Enter name of person to whom inquiries concerning the recommendations on this Form may be addressed

Item 14-16. Self explanatory 
This report was prepared by the Safety and Reliability Branch of the Plant Engineering Division under the supervision of $V$. Joksimovic, Branch Manager, and D. D. Orvis, Section Leader.

Coordinating Author:

C. E. B1iss

Contributors:

A. W. Barse11

F. S. Dombek

G. W. Hannaman

D. D. Orvis

T. Pasternak

Acknowledgment: The following persons have also assisted in the preparation of this report:

I. T. Buechler

R. K. Deremer

J. H. Jaeger

G. T. Loh

T. Taniguchi 
$\bullet$

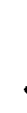

.

.

. 


\section{ABSTRACT}

Through the use of probabilistic risk assessment (PRA), it is possible to quantitatively evaluate the radiological risk associated with a given reactor design and to place such risk into perspective with alternative designs. This report investigates the merits of several containment alternatives for the HTGR from the viewpoints of economics and licensability, as well as public risk. The quantification of cost savings and public risk indicates that presently acceptable public risk can be maintained and cost savings of $\$ 40$ milition can result from use of a vented confinement for the HTGR. On the basis of these investigations further R\&D guidelines for HTGR safety research are suggested which augment the $R \& D$ recommendations reported in the "HTGR Accident Initiation and Progression Analysis Status Report." 
○ 


\section{GLOSSARY}

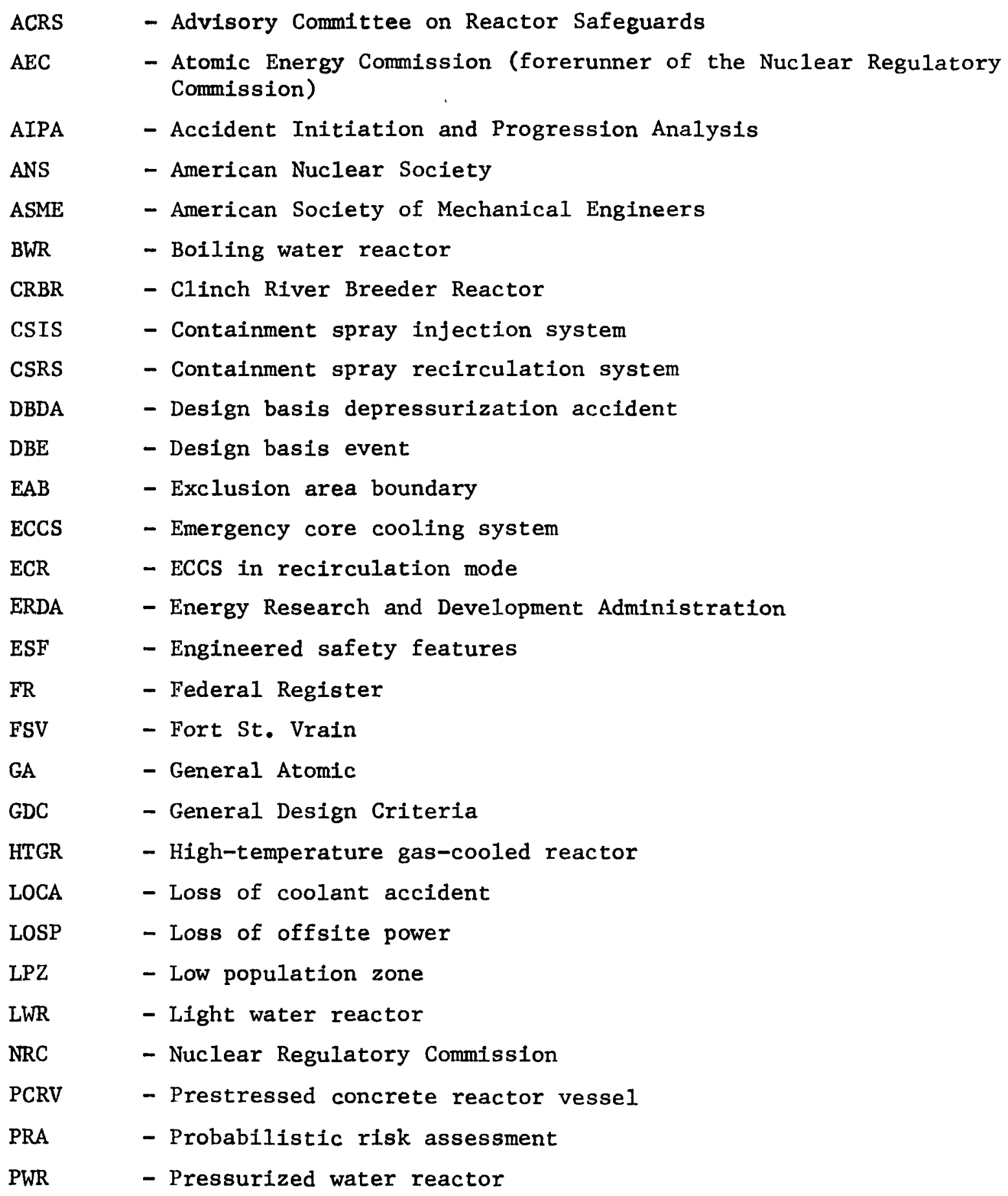




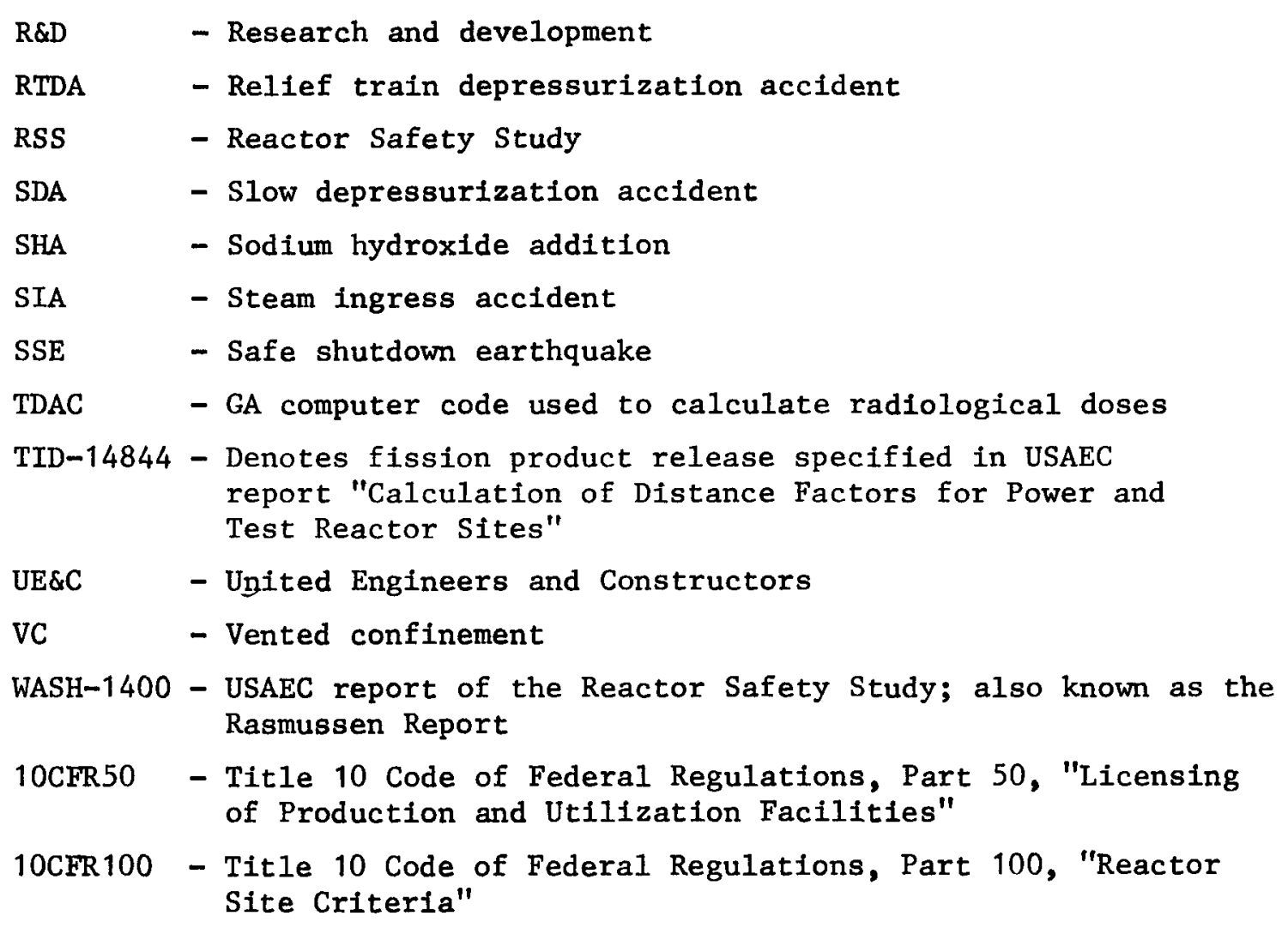


CONTENTS

ABSTRACT . . . . . . . . . . . . . . . . . . . . . . v v

GLOSSARY . . . . . . . . . . . . . . . . . . . . vii

1. INTRODUCTION . . . . . . . . . . . . . . . . . . . . 1-1

References . . . . . . . . . . . . . . . . . . . . 1-3

2. SUMMARY AND CONCLUSIONS . . . . . . . . . . . . . . . 2-1

2.1. Summary . . . . . . . . . . . . . . . . . 2-1

2.2. Basic Conclusions ............... . . 2-3

References . . . . . . . . . . . . . . . . . . 2-4

3. DEFINITION OF DESIGN OPTIONS . . . . . . . . . . . . . 3-1

3.1. Reference Design (Conventional Containment). . . . . . 3-1

3.2. Unlined Containment . . . . . . . . . . . . . 3-1

3.3. Reclosable Vented Containment . . . . . . . . . . 3-3

3.4. Filtered Vented Containment . . . . . . . . . . . 3-3

3.5. Reclosable Vented Confinement . . . . . . . . . . 3-3

3.6. Vented Confinement . . . . . . . . . . . . 3-4

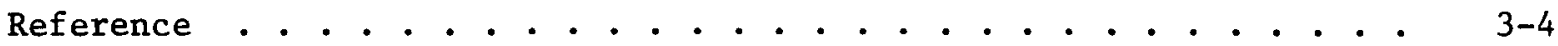

4. COST ASSESSMENTS . . . . . . . . . . . . . . . . . 4-1

4.1. Introduction . . . . . . . . . . . . . . . . . 4-1

4.2. Cost Savings For Unlined Containment . . . . . . . . . 4-2

4.3. Cost Savings For Reclosable Vented Containment . . . . . 4-2

4.4. Cost Savings For Filtered Vented Containment . . . . . . 4-4

4.5. Cost Savings For Reclosable Vented Confinement . . . . . 4-4

4.6. Cost Savings For Vented Confinement . . . . . . . . . 4-7

4.7. Summary of Cost Results . . . . . . . . . . . . 4-7

References......................... 44-10

5. PROBABILISTIC RISK ASSESSMENT FOR CONTAINMENT DESIGN OPTIONS. • 5-1

5.1. Probabilistic Risk Assessment For The HTGR With Vented Confinement .............. . . 5-4

5.1.1. Risk Assessment Associated With Representative Initiating Events . . . . . . . . . 5 5-7 
5.2. Probabilistic Risk Assessment of a PWR With

Conventional Containment . . . . . . . . . . 5-29

5.2.1. PWR Accident Sequence Selection . . . . . . 5-29

5.2.2. Consequence Modeling for PWRs . . . . . . 5-32

5.2.3. Loss of Offsite Power (PWR) . . . . . . . 5-35

5.2.4. Large Loss-of-Coolant Accident (LOCA) . . . . 5-35

5.2.5. Smal1 LOCA S 1 (2- to 6-in.-Diameter Break) . 5-39

5.2.6. Smal1 LOCA $S_{2}(1 / 2$ - to 2-in.-Diameter Break) . . 5-41

5.3. Comparison of Risks for HTGR-VC and PWR With

Conventional Containment . . . . . . . . . . . 5-43

5.3.1. Median Value Risk Envelope Comparison . . . . 5-43

5.3.2. Complementary Cumulative Distribution Curve
Comparisons . . . . . . . . . 5-45

5.4. Summary of Probabilistic Risk Assessment . . . . . . 5-55

References ...................... . 5-57

6. LICENSING CONSIDERATIONS . . . . . . . . . . . . . 6-1

6.1. Historical Perspective For HTGR Containment Licensing. . 6-1

6.1.1. Evolution of HTGR Containment Provisions . . . . 6-2

6.1.2. Evolution of the General Design Criteria . . . 6-6

6.1.3. Potential Impact of Probabilistic Risk

Assessment on Licensing of Containment

Options . . . . . . . . . . . . . 6-12

6.2. Seismic Design Considerations ........... . 6-15

6.2.1. Design to Seismic Category I . . . . . . 6-15

6.2.2. Two-Tier Leak Rate Approach ........ . 6-16

6.2.3. "Site Suitability Source Term" Approach . . . . 6-16

6.2.4. Consideration of Alternate Factors . . . . . 6-17

6.2.5. Conclusions Regarding Seismic Considerations . . 6-17

6.3. Licensing of Containment Options . . . . . . . . 6-17

6.3.1. Licensing of Unlined Containment . . . . . . 6-18

6.3.2. Licensing of Reclosable Vented Containment . . 6-35

6.3.3. Licensing of Reclosable Vented Confinement . . 6-43

6.3.4. Licensing of Vented Confinement ....... 6-45

6.4. Summary of Licensing Considerations . . . . . . . 6-49

References . . . . . . . . . . . . . . . . 6-50 
7. RESEARCH AND DEVELOPMENT SUGGESTIONS . . . . . . . . . . . 7-1

7.1. Introduction . . . . . . . . . . . . . . 7-1

7.2. R\&D Suggestions Derived From Unlined Containment Considerations .............. . . 7-1

7.3. R\&D Suggestions Derived From Other Containment Options ................... 7-3

References ..................... . . . . . . . . .

APPENDIX A: UNCERTAINTIES IN DOSE CONSEQUENCES . . . . . . . . . A A

APPENDIX B: ATMOSPHERIC DISPERSION ASSUMPTIONS AND PARAMETER SELECTIONS FOR PWR CONSEQUENCE ANALYSIS . . . . . . B-1

FIGURES

3-1. Containment design options . . . . . . . . . . . . 3-2

5-1. AIPA risk analysis methodology . . . . . . . . . . 5-6

5-2. Event tree for loss of offsite power for vented confinement . . . . . . . . . . . . . . 5-9

5-3. Risk plot for loss of offsite power . . . . . . . . . 5-12

5-4. Event tree for rapid PCRV depressurization with vented $5-14$

5-5. Risk plot for rapid PCRV depressurization . . . . . . 5-15

5-6. Event tree for slow PCRV depressurization with vented confinement . . . . . . . . . . . . . 5-17

5-7. Risk plot for slow PCRV depressurization . . . . . . . 5-18

5-8. Event tree for relief train spurious depressurization of PCRV with vented confinement . . . . . . . . . 5-20

5-9. Risk plot for relief train spurious depressurization of PCRV .................. . . 5-22

5-10. Event logic tree for steam ingress . . . . . . . . . 5-24

5-11. Risk plot for steam ingress . . . . . . . . . . . 5-26

5-12. Summary risk plot of dominant sequences for HTGR with
vented confinement . . . . . . . . . . . . . 5-27

5-13. Risk plot for loss of offsite power for PWR . . . . . . 5-37

5-14. Risk plot for large LOCA event for PWR . . . . . . . . 5-38

5-15. Risk plot for PWR $S_{1}$ LOCA event (2 in. -6 in. diameter). . 5-40

5-16. Risk plot for PWR $\mathrm{S}_{2}$ LOCA event (1/2 in. - 2 in. $5-42$ 
5-17. Risk summary comparison of dominant sequences for PWR and HTGR with vented confinement . . . . . . . . . . . 5-44

5-18. Summary cumulative risk comparison between HTGR-VC and PWR with conventional containment . . . . . . . . . . 5-47

5-19. Loss of offsite power transients: cumulative risk comparison between HTGR-VC and PWR with conventional containment . . . . . . . . . . . . . . . . . . . .

5-20. Spectrum of primary coolant system depressurization events: cumulative risk comparison between HTGR-VC and PWR with conventional containment . . . . . . . . . . 5-52

5-21. Design basis events: cumulative risk comparison between HTGR-VC and PWR with conventional containment . . . . . . 5-54

6-1. DBDA dose parameter tree for vented design options (direct release to environment assumed) .. . . . . . . . 6-38

6-2. Alternatives for acceptable DBDA results for vented design options ...................... . 6-40

A-1. Probability density function (pdf) for iodine escape (nonplateout) fraction from PCRV . . . . . . . . . . . .

A-2. Representation of fission product processes in the containment

4-1. Cost savings for unlined containment . . . . . . . . 4-3

4-2. Cost savings for reclosable vented containment . . . . . . . 4-5

4-3. Cost savings for reclosable vented confinement . . . . . . . 4-6

4-4. Cost savings for vented confinement . . . . . . . . . . 4-8

4-5. Summary of cost savings for containment options versus reference design .. . . . . . . . . . . . . . 4-9

5-1. HTGR vented confinement dominant risk branch probabilities. - 5-8

5-2. HTGR dominant risk sequence dose summary 30 day, $2500 \mathrm{~m} \mathrm{LPZ}$ doses....................... 5 5-11

5-3. PWR dominant accident sequences versus release categories . . 5-30

5-4. Key to PWR accident sequence symbols . . . . . . . . . . 5-31

5-5. Summary of input data to PWR consequence analysis . . . . . . 5-33

5-6. Median 30-day integrated dose at $2500 \mathrm{~m}$ for PWR release categories ................ . . 5-34 
TABLES (continued)

5-7. Risk for PWR accident sequences . . . . . . . . . . . 5-36

6-1. Evolution of HTGR containment provisions . . . . . . . 6-3

6-2. Dose calculation parameters . . . . . . . . . . . 6-19

6-3. Dose consequences for DBDA release to unlined containment . . 6-24

6-4. Dose consequences for time-dependent TID-14844 release to unlined containment . . . . . . . . . . . . 6-25

6-5. Median dose consequences for core heatup from current AIPA analysis. . . . . . . . . . . .... . 6-27

6-6. Dose consequences for time-dependent TID-14844 release to unlined containment ( $1.5 \% /$ day containment leak rate and

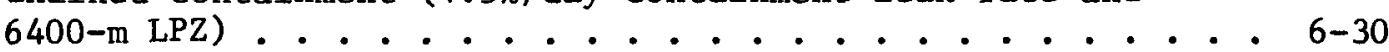

6-7. Dose consequences for time-dependent TID-14844 release to unlined containment (1.5\%/day containment leak rate with nonpermuted meteorology) .. . . . . . . . 6-32

6-8. Dose consequences for time-delayed TID-14844 release to unlined containment (finite PCRV-to-containment transport rate and $1.5 \% /$ day containment leak rate). . . . . . . 6-34

6-9. Dose consequences for DBDA release to vented containment or confinement ............... . 6-37

6-10. Dose consequences for time-dependent TID-14844 release to reclosable vented containment ... . . . . . . . 6-42

6-11 Dose consequences for time-dependent TID-14844 release to reclosable vented confinement . . . . . . . . . 6-46

A-1. Uncertainty factor summary . . . . . . . . . . . . A-2 


\section{INTRODUCTION}

In the United Kingdom, France, and, to a lesser extent, Germany, the inherent safety of gas-cooled reactors has long been recognized and accepted as a valid trade-off for engineered safety features (ESFs). Inherent safety was also recognized in British and French Magnox reactors exported to Spain, Italy, and Japan. The Fort St. Vrain HTGR was licensed in the United States with a reclosable vented confinement, in recognition of its moderate core power level and remote stte and also partly in recognition of the safety inherent in a design incorporating a prestressed concrete reactor vessel (PCRV). It was apparent for some time, therefore, that certain engineered safety features included in the present HTGR design, largely because of U. S. light water reactor (LWR) licensing precedents, might not be truly cost effective, because of the strong effect of inherent HTGR safety features in reducing public risk. Through the use of probabilistic risk assessment ( $P R A$ ), however, it is possible to quantitatively evaluate the radiological risk associated with a given reactor design and to place such risk into perspective with alternate designs. Two broadbased studies of reactor safety which employ the PRA methodology have been undertaken in the U. S., namely the Reactor Safety Study (RSS) for LWRs and the HTGR Accident Initiation and Progression Analysis (AIPA) Study.

The first significant application of the PRA methodology to nuclear power reactors in the United States was the RSS, an assessment of public risk from LWR accidents together with a comparison of these risks with those associated with other man-caused and natural events. The final report of this study was published in October 1975 in a twelve-volume document, WASH-1400 (Ref. 1-1), commonly referred to as the Rasmussen Report. 
The AIPA Program is a probabilistic risk assessment of the HTGR being performed by General Atomic (GA) and funded by the Energy Research and Development Administration (ERDA). The study was reported in a sevenvolume status report (Ref. 1-2), which has been reviewed by a number of organizations including NRC personnel and their contractors (National Labs). The responses to comments received have been published as Volume VIII of the Status Report (Ref. 1-3).

These two studies provided a new level of insight into the safety considerations for nuclear power plants. The results of the RSS show that overall public risks, including latent effects, from LWR accidents are comparable to or lower than other man-caused hazards. From the results of the AIPA study, it is apparent that public risks from an HTGR design, which has been reviewed by the NRC and ACRS via the Summit and Fulton construction permit applications (Refs. 1-4, 1-5), compare favorably with the results of the RSS.

The primary initial objective of the AIPA study was to identify areas where safety research and development (R\&D) should be directed for the HTGR. The safety R\&D decision criteria (Ref. 1-6) developed jointly by ERDA and GA for the AIPA study necessitated a comparison to the RSS results. A preliminary comparison of LWR safety and HTGR safety, as assessed in these two reports, suggested HTGR containment design as an area in which further design option scrutiny was warranted. This possibility was determined on the basis that HTGR containment criteria could be relaxed, resulting in significant cost savings and providing an apparently acceptable risk level. Hence, an HTGR containment design options study was initiated, supported by GA with partial ERDA funding as part of the AIPA study. This plan was also consistent with another of the initial AIPA objectives, use of PRA as a safety design optimization tool. (Volume III of Ref. 1-2 contains results of previous efforts to use PRA as a design optimization tool; this containment study illustrates more comprehensively how this can be accomp1ished.) 
Recently, the objective of AIPA has been redirected toward generating information necessary to license the HTGR on its own merit rather than on LWR precedents. The containment design options study reported here also supports this redirected AIPA study obfective.

Consistent with these AIPA objectives, the purpose of this report is to document the work performed for the containment design options study and thereby (1) to show the cost differences for the various containment options considered, (2) to establish, through probabilistic risk assessment, the effect that different containment designs have upon the public risk, (3) to assess the requirements and potential problems for licensing of various HTGR containment options, and (4) to derive further R\&D guidelines supporting the viable containment options.

\section{REFERENCES}

1-1. "The Reactor Safety Study -- An Assessment of Accident Risks in U. S. Commercial Nuclear Power Plants," USAEC Report WASH-1400, October 1975.

1-2. "HTGR Accident Initiation and Progression Analysis Status Report," ERDA Report GA-A13617, v. I-VII, General Atomic Company, October 1975 to February 1976.

1-3. "HTGR Accident Initiation and Progression Analysis Status Report," ERDA Report GA-A13617, v. VIII, General Atomic Company, January 1977.

1-4. "Summit Power Station Preliminary Safety Analysis Report," Delmarva Power and Light Company, August 1973.

1-5. "Fulton Generating Station Units 1 and 2, Preliminary Safety Analysis Report," Philadelphia Electric Company, November 1973.

1-6. Newby, Glen A., U. S. Energy Research and Development Administration letter to Herbert J. C. Kouts of Nuclear Regulatory Commission, March $18,1976$. 
2. SUITARY AND CONCLUSIONS

\subsection{SURMARY}

This report investigates the merits of several containment alternatives for the HTGR from the viewpoints of economics, public risk, and licensability. On the basis of these investigations, further R\&D guidelines for HTGR safety research are suggested which augment the R\&D recommendations reported in Ref. $2-1$.

In Section 3, a number of alternative containment concepts for the HTGR are proposed for detailed investigation including unlined containment, two types of vented containment, and two types of simple confinement buildings.

In Section 4, estimates of direct cost differences for the alternative designs compared to conventional contalnment are presented, ranging from $\$ 5.38$ million savings for a prestressed concrete unlined containment to $\$ 12.83$ million savings for a reinforced concrete vented confinement building. With consideration of indirect costs, contingencies, escalation, and interest during construction, the estimates of total cost savings range from $\$ 13.59$ million for unlined containment to $\$ 40.38$ million for vented confinement.

Section 5 contains comparisons of the risk from the HTGR with vented confinement versus the rlsk from a representative LWR as defined by the RSS (Ref. 2-2). The risk from an HTGR with vented confinement appears comparable to that from a representative PIR over the low and intermediate consequence range, but the HTGR appears to demonstrate a significant risk advantage in the higher consequence range. Other HTGR containment options, 
which further reduce the consequences for a given accident sequence, compare even more favorably. The difference in risk is attributed to inherent HTGR safety characteristics. The most important inherent safety features are (1) various aspects of the core design including the high core heat capacity, low core power density, fuel element design, and the selection of ceramic materials that maintain their integrity at high temperatures, (2) the low stored energy and inert properties of helium as the primary coolant, and (3) to a somewhat lesser extent, the PCRV.

Section 6 addresses licensing considerations. A review of past domstic HTGR experience shows no firm precedent requiring a specific type of containment for the HTGR. Meeting the exposure guidelines of 10CFR 100 (Ref. 2-3) for an appropriate spectrum of accident conditions is proposed as a reasonable basis for licensing consideration of alternative containment concepts, consistent with the apparent Nuclear Regulatory Commission (NRC) [Atomic Energy Commission (AEC)] intent in the LWR-based development of the general design criteria of 10CFR50, Appendix A. Based on obtainable building leak rates, dose consequences for an appropriate spectrum of accident conditions are demonstrated to be within the 10 CFR100 exposure guidelines for unlined containment, reclosable vented containment, and reclosable vented confinement. The conditions for which acceptability can be demonstrated become respectively more restrictive, however. Dose consequences within the 10CFR100 exposure guidelines appear to be impractical for vented confinement if assessment of consequences is performed strictly in accordance with traditional licensing-type assumptions. It is noted, however, that the NRC has recently used and endorsed the use of probabi1istic risk assessment techniques as an additional safety evalulation tool in the regulatory process. By use of this safety evaluation tool, the HTGR with vented confinement would appear to be acceptable.

Final1y, R\&D suggestions are proposed in Section 7 to provide further guidance for safety R\&D. It is suggested that additional containment leakage data be obtained for unlined containment and that experience with nonmetallic containment lining materials be verified. Existing work on 
validation of the GA model for fission product release and transport to the containment following various core heatup sequences should be continued.

\subsection{BASIC CONCLUSIONS}

The following overall conclusions have been derived from this study:

1. From past domestic HTGR experience, there is no firm regulatory precedent which dictates the use of a specific containment design for the HTGR. (While European and British gas-cooled reactor experience has not been reported herein, it should be noted that European and British gas-cooled reactors have generally been licensed without containment buildings.)

2. Cost savings assessments narrow the consideration of alternatives to vented confinement, reclosable vented confinement, and unlined cont ainment.

3. The results of the AIPA study (Ref, 2-1) and the RSS (Ref. 2-2) have enabled a quantification of containment options which demonstrates that alternative HTGR containment/confinement concepts appear to present acceptable risk and, based on cost studies, offer total investment cost savings of as much as $\$ 40$ million compared to conventional containment.

4. In light of the evaluations presented herein, it appears that considerations of the health and safety of the public could be more uniformly addressed and economically balanced by using probabilistic risk assessment techniques as part of licensing evaluations.

5. Based solely on considerations of probabilistic risk assessment, an HTGR with vented confinement appears to be a viable concept. 
6. An HTGR incorporating any of the other alternatives considered in this study would yield lower risk than would an HTGR with vented confinement and, therefore, would appear to be even more readily acceptable in a PRA-based 1icensing evaluation.

7. Unlined containment maintains dose consequences for an appropriate spectrum of accident conditions to within the 10 CFR 100 exposure guidelines (assuming the predicted design leak rate and representative site conditions), allowing consideration of this alternative within the traditional licensing framework. However, if the unlined containment design leak rate is assumed to be considerably greater than the predicted value, then either siting conditions more favorable than the representative site are required, or a more flexible interpretation of licensing practices must prevail, allowing consideration of features unique to the HTGR.

8. A potential exploitation of inherent HTGR safety is urban siting. Use of unlined containment does not preclude the possibility of urban siting for the HTGR, since, for an HTGR with unlined containment at a site with favorable meteorology, acceptable doses could still be demonstrated at site boundaries less than $500 \mathrm{~m}$ exclusion area boundary $(\mathrm{EAB})$ and $2500 \mathrm{~m}$ low population zone (LPZ).

REFERENCES

2-1. "HTGR Accident Initiation and Progression Analysis Status Report," ERDA Report GA-A13617, v. IV, General Atomic Company, December 1975.

2-2. "The Reactor Safety Study -- An Assessment of Accident Risks in U.S. Commercial Nuclear Power Plants," USAEC Report WASH-1400, October 1975.

2-3. "Reactor Site Criteria," Code of Federal Regulations, Title 10, Part 100. 


\section{DEFINITION OF DESIGN OPTIONS}

Several types of containment or confinement bulldings can be considered for HTGRs, and several of these have been studied in the past. For this study, the intent was to choose containment options that offer potential economic benefit while maintaining an acceptable low level of public risk. The purpose of this section is to define and describe the containment alternatives selected for study.

\subsection{REFERENCE DESIGN (CONVENTIONAL CONTAINMENT)}

For the proposed Summit and Fulton HTGRs, a conventional, high-pressure, steel-lined containment with a cleanup (recirculation) system was specified. This containment was designated as the reference design for this study, and evaluation of alternative concepts was based on comparison with this type of containment. Figure 3-1(a) presents a conceptual diagram of the reference design. Also shown are the alternatives considered in this study [Fig. 3-1(b) through (f)].

\subsection{UNLINED CONTAINMENT}

The first alternative considered was an unlined containment [Fig. 3-1(b)]. This is a pressure-retaining concrete containment, designed to withstand the effects of the most severe rupture of the primary or secondary coolant systems. An unlined containment consists of a domed concrete cylindrical shell similar to a conventional containment, except that no interior metallic liner is provided. The interior concrete surface of the building is coated with a vinyl or epoxy material, whose function is to reduce the building leak rate and to facilitate postaccident decontamination. A containment recirculation system is provided. 


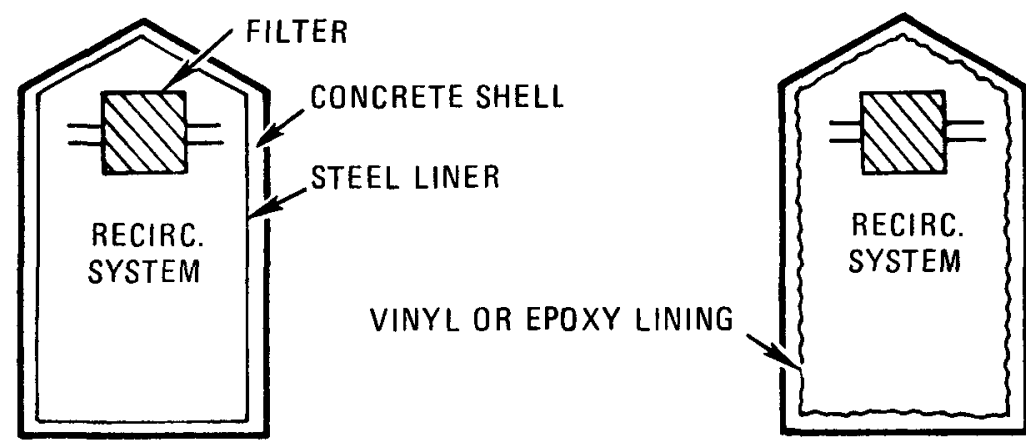

(a) LINED CONTAINMENT

(b) UNLINED CONTAINMENT

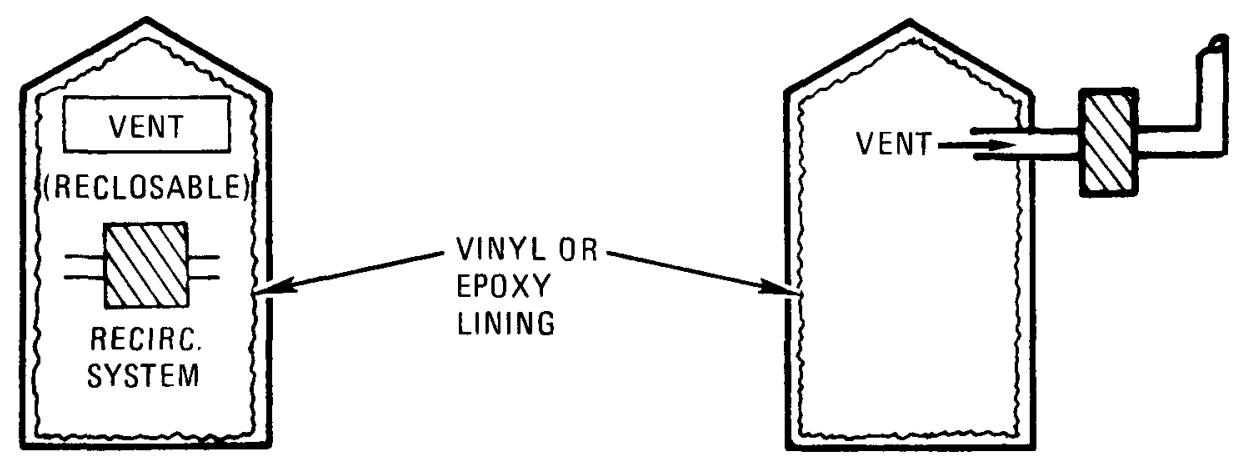

(c) RECLOSABLE VENTED CONTAINMENT

(d) FILTERED VENTED CONTAINMENT

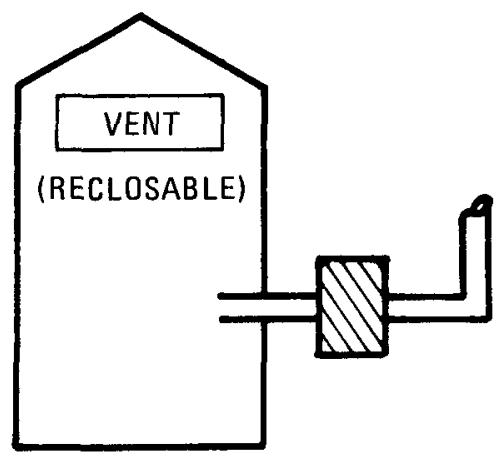

(e) RECLOSABLE VENTED CONFINEMENT

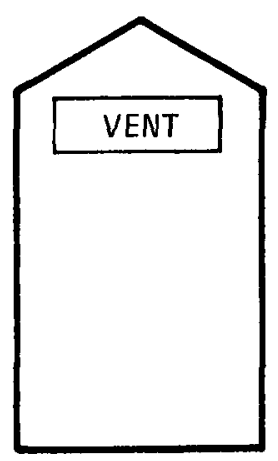

(f) VENTED CONFINEMENT

Fig. 3-1. Containment design options 


\subsection{RECLOSABLE VENTED CONTAINIENT}

The second alternative considered was a reclosable vented containment [Fig. 3-1(c)]. This concept is like an unlined containment; however, it requires only a modest design pressure since venting of the containment atmosphere is allowed following blowdown associated with rupture of the primary or secondary coolant system boundaries. Following blowdown, the vent system can be reclosed by automatic or remote manual valves. In the closed condition, the vented reclosable containment acts as an intact permanent barrier to the long-term release of fission products. As with conventional and unlined containments, a recirculation system would be provided to remove fission products from the containment atmosphere.

\subsection{FILTERED VENTED CONTAINIINT}

Another alternative concept was filtered vented containment, shown in

Fig. 3-1(d). For this concept, the containment atmosphere can be vented to the environment only through a filter system that removes most of the fission products. In the cost assessment (see Section 4), it was found that the cost of a filter bank capable of accommodating a primary system depressurization was prohibitive. Consequently, this concept was not considered further.

\subsection{RECLOSABLE VENTED CONFINEMENT}

A fourth alternative [Fig. 3-1(e)] was reclosable vented confinement, which is the concept used for the Fort St. Vrain HTGR. For a confinement concept, many design features that are provided to minimize leakage would be eliminated. Savings occur for deletion of the metallic or nonmetallic building liner and for the piping and electrical systems which penetrate the building walls, since penetrations consist of a sleeve with packing material surrounding the process pipe. For sudden accidental depressurization of the primary or secondary system, the building design includes a 
reclosable vent, allowing venting of the bullding atmosphere directly to the environment. Following such depressurization (and for normal operation), the vent system is closed, and, in this configuration, the building is maintained at slightly subatmospheric pressure. Hence, building leakage, which is potentially greater than in a conventional containment building, occurs as inleakage, and fission products are removed by effluent filters.

\subsection{VENTED CONEINEYENT}

The final concept considered is vented confinement, shown conceptually in Fig. 3-1(f). With respect to leak rate and control of fission products released to the environment, this concept is evaluated as the design equivalent of a nonisolated containment as assessed in the AIPA study (Ref. 3-1). It is similar to the reclosable vented confinement (defined above), except that the building is not maintained subatmospheric and no effluent filter system is provided. Depletion of fission products occurs only by the natural means of decay, fallout, plateout, and holdup or retention in the PCRV and confinement building. Such a building would be the most economical alternative.

REFERENCE

3-1. "HTGR Accident Initiation and Progression Analysis Status Report," v. VI, Table 3-7, ERDA Report GA-A13617, General Atomic Company, January 1976. 


\section{COST ASSESSMENTS}

\subsection{INTRODUCTION}

The cost of electricity to the consumer is dictated in part by the installed cost of electrical generating capacity. Conventional containment for a nuclear plant is a high cost item, representing a significant contribution to the installed cost of the electrical generating capacity. In addition to direct material and labor costs for construction, estimates of the installed cost of generating capacity include indirect construction costs, contingencies, escalation, and interest during construction. To present a true picture of potential savings to the public, the cost assessments of containment options must therefore include all of these components of installed cost of generating capacity. Assessment of the containment options on this installed cost basis also creates a common basis for comparison, enabling quantification of cost savings due to shortening of the construction schedule for some of the options.

To accurately assess the direct material and labor requirements for the reference design (conventional steel-1ined containment) and for the various options, United Engineers and Constructors (UE\&C), an architectengineering firm, was retained under contract to GA. The results of their study are reported in Ref. 4-1.

In addition to direct material and labor costs of the building itself, some of the options involve other direct costs for required changes in plant system design. For instance, for the vented options, the core auxiliary cooling system (CACS) must be designed to operate at atmospheric pressure, without the benefit of containment backpressure. For a confinement building, the secondary coolant system piping design can be simplified. Some of these system changes will represent additional cost savings while 
others may involve a cost penalty. The assessment of net change in cost must necessarily include these considerations.

Since some of the cost data generated by UE\&C (Ref, 4-1) and by GA are considered proprietary, the cost savings for each alternative are characterized only by the cost differential (" $\Delta$ ") relative to the base case of conventional steel-lined containment. In the following subsections, the cost effects have been identified in tabular form, providing a consistent format for cost comparisons of the alternatives.

\subsection{COST SAVINGS FOR UNLINED CONTAINMENT}

In the cost study performed by UE\&C (Ref. 4-1), both reinforced concrete and prestressed concrete were considered for unlined containment. However, a higher leak rate for reinforced concrete and the difficulty of designing a reinforced concrete unlined containment that meets leakage requirements following a design basis earthquake ultimately led to the choice of prestressed concrete. Table 4-1 summarizes the cost savings for prestressed unlined containment. As shown in Table 4-1, no system changes are required for unlined containment. The deletion of the steel liner allows an estimated four-week savings in the critical path construction schedule. These effects lead to a $\$ 5.38$ million direct cost savings and a total cost savings of $\$ 13.59$ million for unlined containment. (Note: Consideration of mechanistic failures rather than PCRV penetration closure failure as the design basis for depressurization accidents enables a considerable reduction in the containment design pressure. For example, if the design pressure for unlined containment is reduced to nominally 29 psig, the direct cost savings would be $\$ 6.70$ million, and the total cost savings would be approximately $\$ 18.15$ million, compared to the reference design.)

\subsection{COST SAVINGS FOR RECLOSABLE VENTED CONTAINMENT}

The study performed by UE\&C (Ref. 4-1) considered both reinforced and prestressed concrete for use in a reclosable vented containment building. 
TABLE 4-1

COST SAVINGS FOR UNLINED CONTAINMENT

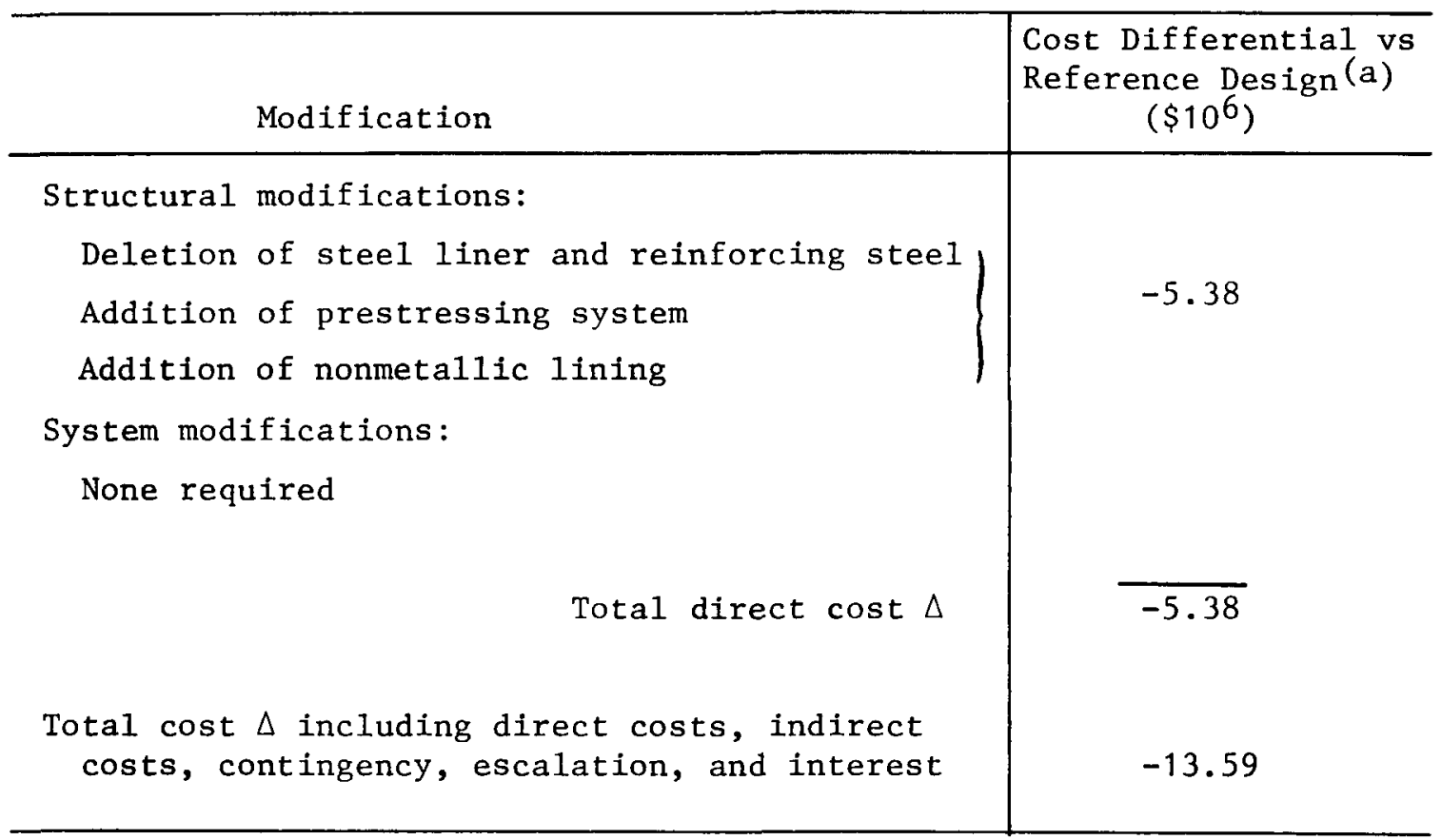

${ }^{\text {(a) }}$ Reference design $=$ conventional steel-lined containment. 
Venting of the building atmosphere during a pressure transient caused by primary or secondary system depressurization enables a building design pressure of 3.0 psig. As reported in Ref. 4-1, reinforced concrete containment buildings, even with modest design pressures, experience leak rates of the order of $6 \% /$ day. Since a reclosable vented containment must act as an unlined containment building when the vent system is closed, leak rates of this magnitude are unacceptable. Hence, prestressed concrete has been chosen for reclosable vented containment, enabling a lower leak rate which is necessary for acceptable siting event consequences (see Section $6.3 .2 .2)$.

The cost savings for prestressed concrete reclosable vented containment are given in Table 4-2. The elimination of a steel liner and reduced amount of reinforcing steel for the lower design pressure enable a reduction of $\$ 8.35$ million in the direct cost of the structure, yet the increased cost of an atmospheric core auxiliary cooling system (CACS) leads to an overall direct cost savings of $\$ 5.19 \mathrm{million}$. The total cost savings is $\$ 12.77$ m1lion.

\subsection{COST SAVINGS FOR FILTERED VENTED CONTAINMENT}

In Ref. 4-1, UE\&C reported that the cost of a filter bank capable of accommodating the blowdown from a DBDA is prohibitive. Hence, consideration of this alternative was discontinued, and no further cost assessments were performed.

\subsection{COST SAVINGS FOR RECLOSABLE VENTED CONFINEMENT}

For this type of confinement bullding, leakage occurs as inleakage since the building is maintained at subatmospheric pressure. Hence, reinforced concrete construction with attendant greater leakage than for prestressed concrete construction is acceptable. Cost savings are summarized in Table 4-3. In addition to the cost savings associated with reinforced construction at a reduced design pressure, other features that are provided to minimize leakage would be eliminated, allowing additional 


\begin{tabular}{|c|c|}
\hline Modification & $\begin{array}{l}\text { Cost Differential vs } \\
\text { Reference Design }(a) \\
\qquad\left(\$ 10^{6}\right)\end{array}$ \\
\hline \multicolumn{2}{|l|}{ Structural modifications: } \\
\hline \multicolumn{2}{|l|}{ Deletion of steel liner } \\
\hline \multicolumn{2}{|l|}{$\begin{array}{l}\text { Reduction in reinforcing steel for } \\
3.0 \text { psig design pressure }\end{array}$} \\
\hline \multicolumn{2}{|l|}{ Addition of vent system } \\
\hline \multicolumn{2}{|l|}{ Addition of nonmetallic lining } \\
\hline \multicolumn{2}{|l|}{ System modifications: } \\
\hline $\begin{array}{l}\text { Provision of CACS circulators designed } \\
\text { to atmospheric pressure }\end{array}$ & +3.17 \\
\hline Total direct cost $\Delta$ & -5.19 \\
\hline $\begin{array}{l}\text { Total cost } \Delta \text { including direct costs, } \\
\text { indirect costs, contingency, } \\
\text { escalation, and interest }\end{array}$ & -12.77 \\
\hline
\end{tabular}

(a) Reference design $=$ conventional steel-1ined containment . 
TABLE 4-3

COST SAVINGS FOR RECLOSABLE VENTED CONFINEMENT

\begin{tabular}{|c|c|}
\hline Modification & $\begin{array}{l}\text { Cost Differential vs } \\
\text { Reference Design (a) } \\
\qquad\left(\$ 10^{6}\right)\end{array}$ \\
\hline $\begin{array}{l}\text { Structural modifications: } \\
\text { Deletion of steel liner } \\
\text { Reduction in reinforcing steel for } 3.0 \text { psig } \\
\text { design pressure } \\
\text { Reduction in diameter } \\
\text { Modification of penetration system } \\
\text { Elimination of isolation valves } \\
\text { Deletion of recirculation system, addition } \\
\text { of exhaust system } \\
\text { Addition of vent system }\end{array}$ & -14.49 \\
\hline $\begin{array}{l}\text { System modifications: } \\
\text { Provision of CACS circulators designed to } \\
\text { atmospheric pressure }\end{array}$ & +3.17 \\
\hline $\begin{array}{l}\text { Tota1 direct cost } \Delta \\
\text { Tota1 cost } \Delta \text { including direct costs, indirect } \\
\text { costs, contingency, escalation, and interest }\end{array}$ & $\begin{array}{l}-11.33 \\
-34.87^{(b)}\end{array}$ \\
\hline
\end{tabular}

(a) Reference design = conventional steel lined containment.

(b) Cost savings for confinement-type buildings may be even greater, owing to the fact that building pressure testing and leakage testing could be greatly simplified or eliminated entirely. This could be worth as much as $\$ 500,000$ in direct costs plus up to 4 weeks savings in the critical path construction schedule. This has not been included in the savings quoted above because of uncertainty in future regulatory requirements for testing of such confinement-type buildings. 
savings. Piping and electrical penetrations would be replaced with standard sleeves similar to those used for fossil power plants. Since such a pipe sleeve does not act as an anchor as with containment penetrations, thermal pipe movement can be more readily accommodated, and as a result, building diameter can be reduced by $2 \mathrm{ft}$ compared to containment. Containment isolation valves in those systems that do not communicate with the primary coolant or confinement atmosphere can be eliminated. The containment atmosphere recirculation system would be deleted and replaced with an exhaust filtration system. As shown in Table 4-3, these design changes, offset by the cost increase for an atmospheric CACS, result in direct cost savings of $\$ 11.33$ million, which translates to a total cost savings of $\$ 34.87$ million.

\subsection{COST SAVINGS FOR VENTED CONFINEMENT}

As discussed in Section 3.6, this concept, the design equivalent of nonisolated containment as assessed in the AIPA study (Ref. 4-2), is similar to reclosable vented confinement except that the building is not maintained subatmospheric and an exhaust filtration system is not provided. The cost savings for vented confinement is summarized in Table 4-4. A direct cost savings of $\$ 12.83$ million is attainable, which translates to a total cost savings of $\$ 40.38$ million.

\subsection{SUMMARY OF COST RESULTS}

Table 4-5 presents a summary of both direct and total cost savings for each of the containment options. The data in this table help to narrow the consideration of alternatives. For example, reclosable vented containment can be deleted from serious consideration because it offers no economic incentive or licensing advantage over unlined containment. (A licensing assessment of reclosable vented containment is reported in Section 6 nevertheless, because this assessment was under way prior to completion of final economic evaluations.) 
TABLE 4-4

COST SAVINGS FOR VENTED CONFINEMENT

\begin{tabular}{|c|c|}
\hline Modification & $\begin{array}{l}\text { Cost Differential vs } \\
\text { Reference Design }(\mathrm{a}) \\
\qquad\left(\$ 10^{6}\right)\end{array}$ \\
\hline $\begin{array}{l}\text { Structural modifications: } \\
\text { Deletion of steel liner } \\
\text { Reduction in reinforcing steel for } 3.0 \text { psig } \\
\text { design pressure } \\
\text { Reduction in diameter } \\
\text { Modification of penetration system } \\
\text { Elimination of isolation valves } \\
\text { Deletion of recirculation system } \\
\text { Addition of vent system }\end{array}$ & -15.993 \\
\hline $\begin{array}{l}\text { System modifications: } \\
\text { Provision of CACS circulators designed to } \\
\text { atmospheric pressure }\end{array}$ & +3.17 \\
\hline $\begin{array}{l}\text { Tota1 direct cost } \Delta \\
\text { Total cost } \Delta \text { including direct costs, indirect } \\
\text { costs, contingency, escalation, and interest }\end{array}$ & $\begin{array}{l}-12.83 \\
-40.38^{(b)}\end{array}$ \\
\hline
\end{tabular}

(a) Reference design = conventional steel lined containment.

(b) Cost savings for confinement-type buildings may be even greater, owing to the fact that building pressure testing and leakage testing could be greatly simplified or eliminated entirely. This could be worth as much as $\$ 500,000$ in direct costs plus up to 4 weeks savings in the critical path construction schedule. This has not been included in the savings quoted above because of uncertainty in future regulatory requirements for testing of such confinement-type buildings. 
TABLE 4-5

SUMMARY OF COST SAVINGS FOR CONTAINMENT

OPTIONS VERSUS REFERENCE DESIGN(a)

\begin{tabular}{|c|c|c|}
\hline Option & $\begin{array}{l}\text { Direct Cost } \\
\text { Savings } \\
(\$ 106)\end{array}$ & $\begin{array}{c}\text { Total Investment } \\
\text { Cost Savings } \\
\left(\$ 10^{6}\right)\end{array}$ \\
\hline Conventiona1 stee1-1ined containment & 0 (base case) & 0 (base case) \\
\hline Un1ined containment $\left(\mathrm{P}_{\text {des }}=54.3 \mathrm{psig}\right)$ & 5.38 & 13.59 \\
\hline Unlined containment $\left(\mathrm{P}_{\text {des }}=28.6 \mathrm{psig}\right)$ & 6.70 & 18.15 \\
\hline Reclosable vented containment $\left(\mathrm{P}_{\mathrm{des}}=3\right.$ psig) & 5.19 & 12.77 \\
\hline Reclosable vented confinement $\left(\mathrm{P}_{\text {des }}=3\right.$ psig) & 11.33 & 34.87 \\
\hline Vented confinement $\left(\mathrm{P}_{\text {des }}=3\right.$ psig $)$ & 12.83 & 40.38 \\
\hline
\end{tabular}

(a) These cost savings represent a scoping study only; i.e; each building design has not been optimized. For example, the vented options could possibly be optimized by choice of a rectangular building rather than a right circular cylinder. However, such optimization, requiring detailed piping and cabling configurations, was beyond the scope of the study performed by UE\&C (Ref. 4-1). 
The data in Table 4-5 represent cost differentials for building and system modifications alone. These assessments do not include cost

increases for fuel design modifications necessary to reduce primary coolant activity, which would be a requirement for traditionally based licensing of the vented options (see Section 6.3.2.2). On a PRA evaluation basis, however, it appears that no reduction in primary circuit activity would be required for any of the vented design options. Hence, the cost penalty associated with reducing primary circuit activity was not assessed, and the amounts presented in Table 4-5 are taken as a true measure of the potential savings, even for the vented options.

REFERENCES

4-1. "General Atomic Company 3000 MW(t) HTGR Containment Alternatives Study Final Report," United Engineers and Constructors, Inc., Philadelphia, Pennsylvania, August 9, 1976.

4-2. "HTGR Accident Initiation and Progression Analysis Status Report," ERDA Report GA-A13617, v. VI, Table 3-7, General Atomic Company, January 1976. 


\section{PROBABILISTIC RISK ASSESSMENT FOR CONTAINMENT DESIGN OPTIONS}

The probabilistic risk assessment (PRA) techniques employed in the two major U.S. studies of thermal reactor safety [the RSS (Ref. 5-1) for LWRs and the AIPA Status Report (Ref. 5-2) for the HTGR] have been shown to afford a means for quantitatively assessing and comparing the risk associated with diverse reactor types and/or with other man-made or natural hazards. For example, the RSS compares the relative risk from PWRs and BWRs with each other and with other natural and man-made hazards. The methodology also provides a means for quantitatively evaluating varlous plant design configurations for an optimal design with respect to cost and risk to the public. The latter application of PRA was employed previously in AIPA in the design alternative evaluation for the HTGR moisture ingress protection system (Volume III, Section 5, Ref. 5-2). Similarly, the present study is an application of PRA to evaluate the feasibility of employing nonconventional containment to reduce HTGR plant costs.

Motivation for the present study became evident near the end of the preliminary AIPA study when, in accordance with the evolving R\&D decision criteria (Volume I, Section 3, Ref. 5 -2), the risk associated with an HTGR having a conventional containment was contrasted with that of the LWRs considered in the draft RSS. This comparison, based on single point (median) estimates of probability and consequence, indicated a margin between the risk envelope* for the conventional HTGR plant and the composite risk envelope for the LWRs considered in the RSS. It appeared that the HTGR with conventional containment may not be optimally cost effective

*The risk envelope results from connecting the maximum risk points on a probability versus consequence plot to illustrate a trend. There is no rigorous significance to the connecting lines themselves. 
with respect to public risk and that a safety-cost trade-off could be pursued.

The potential acceptability of nonconventional HTGR containment options was initially assessed from the Phase I AIPA results (Volume VI, Ref. 5-2) by considering the effect of different containment concepts on the highest risk point of the HTGR-AIPA risk envelope-that for sequence LOSP-BD, which results in an unrestricted core heatup. (See Volume IV of Ref. 5-2 for details on sequence designations.) This sequence is initiated by a loss of offsite power (LOSP) followed by a turbine-generator trip and failure of the on-site emergency power supply with consequent loss of all cooling modes for the reactor. In the Phase I analysis, this event sequence was determined to have a probability of about $10^{-6} / \mathrm{yr}$ and a consequence of about 40 man-rem based on a median population distribution interpolated from Table VI-6 of the draft version of WASH-1400 (Ref. 5-1). The use of a containment of lesser fission product retention capability would not affect the probability of the sequence but would result in increased consequence. For example, an increase in containment leak rate by an order of magnitude, as might be expected for unlined containment, would produce a proportional increase in consequences. Similarly, the risk associated with an LOSP sequence in a vented confinement could be determined by equating the consequence to that evaluated for the AIPA sequence that considered LOSP-BD plus failure of a containment isolation. This suggested that even with a vented confinement there would remain a margin between the risk envelope for the HTGR with vented confinement (HTGR-VC) and that for the LWRs treated in WASH-1400. This rough comparison along with expected economic incentives provided the motivation to inftiate a more comprehensive PRA to explore the risk associated with nonconventional HTGR containment.

In this detailed study of containment design options, risk is evaluated in terms of probability of occurrence and associated offsite dose consequences (rems) at the LPZ of $2500 \mathrm{~m}$, thereby eliminating any consideration of population distribution as required for determining man-rem. The 
evaluation is thus more amenable to correlation with offsite dose regulations for reactor siting. The overall risk stemming from a spectrum of initiating events is presented in two formats: (1) as risk (or P-C) plots of median-value probabilities and median-value consequences for high risk sequences, and (2) as complementary cumulative distribution curves showing the integral probability of exceeding a given consequence. The latter consider the uncertainty distributions for the sequence consequences in the integration procedure and are believed to provide a more comprehensive basis for risk evaluation.

At present there is no absolute standard of acceptable risk for probabilistic evaluation. In the absence of a risk criterion, ERDA has used WASH-1400 results as a "yardstick" for acceptance.* Likewise, the NRC has also considered the risk associated with LWRs to be an acceptable goal, as implied in correspondence regarding the Clinch River Breeder Reactor (Ref. 5-3). Therefore, as in the initial rough comparison described above, and consistent with a contractual commitment made at the outset of this study (Ref. 5-4), results of the RSS were employed in this study as a measure of current acceptability.

The probability data from the RSS for PWR accident sequences could be used directly. However, the RSS presents consequences in terms of resulting health effects and property damage rather than dose-versus-distance data. Therefore, to obtain PWR consequences in the form desired for comparison, i.e., as dose values at a 2500-m LPZ with atmospheric dispersion consistent with that used in the HTGR evaluation, it was necessary in the present study to calculate the PIVR dose consequences using source terms based on the fission product release levels published in the RSS.

*See, for example, the AIPA R\&D decision criteria (Volume I, Section 8, Ref. 5-2), which were developed jointly by ERDA and GA. In addition, an ERDA representative, Francis X. Gavigan, confirmed in a panel discussion at the Gatlinburg Conference on Nuclear Systems Reliability Engineering and Risk Assessment, June 20-24, 1977, that ERDA will be using the WASH-1400 envelope until a better acceptance criterion is defined. 
Although several nonconventional, cost-saving containment options are considered in this report (see Section 3), the PRA evaluation reported herein is limited to an assessment of only one option: the HTGR with vented confinement building (HTGR-VC). Among the options proposed in Section 3, the vented confinement represents the greatest departure from conventional containment and, therefore, affords the highest risk. Since the PRA results for the HTGR-VC indicate that the associated risk appears to be acceptable, the other less extreme containment options would also be acceptable, and there is no need to perform specific PRA to satisfy the objectives of this report.

In Section 5.1, pertinent PRA results from previous AIPA work, updated information, and modifications are brought together in a discussion of probabilistic risk analysis for HTGRs with vented confinement. Median point value risks are discussed in this section using the format of the P-C plot.

Using the same $\mathrm{P}-\mathrm{C}$ format, representative accident sequences for the PWR based on the results of the RSS are presented in Section 5.2. This section also compares the $\mathrm{P}-\mathrm{C}$ results for similar events in the HTGR-VC and PWR.

Section 5.3 is devoted to a comparison of risks of these two reactor systems. Complementary cumulative distribution curves are presented, as well as a summary P-C plot for representative accident sequences for the respective reactor types. These findings are summarized in Section 5.4.

\subsection{PROBABILISTIC RISK ASSESSMENT FOR THE HTGR WITH VENTED CONFINEMENT}

To a large extent, the application of PRA for the HTGR-VC utilizes analyses performed previously in the AIPA study (Ref. 5-2). Occurrence probabilities for sequences of interest were determined by modifications to the AIPA event trees as required for the containment design option; AIPA branch point probabilities as presented in the Status Report (Ref. 5-2) 
were generally employed directly. Consequence assessments in this study of vented confinement required some new analyses for depressurization accidents, whereas the consequences for core heatup events with HTGR-VC were an adaptation of the AIPA interim consequences for a nonisolated containment (see Volume VIII of Ref. 5-2).

To initiate this study, the AIPA methodology was surveyed for areas potentially affected by a change in containment design. The results of this survey for the vented confinement study are shown in Fig. 5-1. The cross-hatched blocks indicate all areas that were considered qualitatively for potential impact; the blocks labeled with deltas indicate where modifications in modeling or analyses were actually required.

At the left of Fig. 5-1 is the block "Initiating Event Selection," for which a change delta is shown. The significance of this delta is that all event sequences that had been shown previously to be insignificant with respect to dominant risk sequences could not be ignored with the vented confinement. Thus, it was necessary to reexamine the AIPA initiating event list for potentally important sequences that would require further development in event trees (the next block in Fig. 5-1).

The initiating event list was established by considering previously identified high risk events described in Volumes IV and VI of the AIPA Status Report as well as reviewing the initial list from Volume III for importance in the VC system.

As in the previous AIPA assessments, the loss of offstte power (LOSP) was found to be a representative initiator of core heatup sequences. Thus, the LOSP event is of major interest in determining the HTGR risk envelope, especially in the low probability, high consequence region.

Whereas the previous AIPA results indicated that reheater leaks were major contributors to risk, especially in the low or moderate consequence region, and tended to overshadow primary coolant system depressurization 


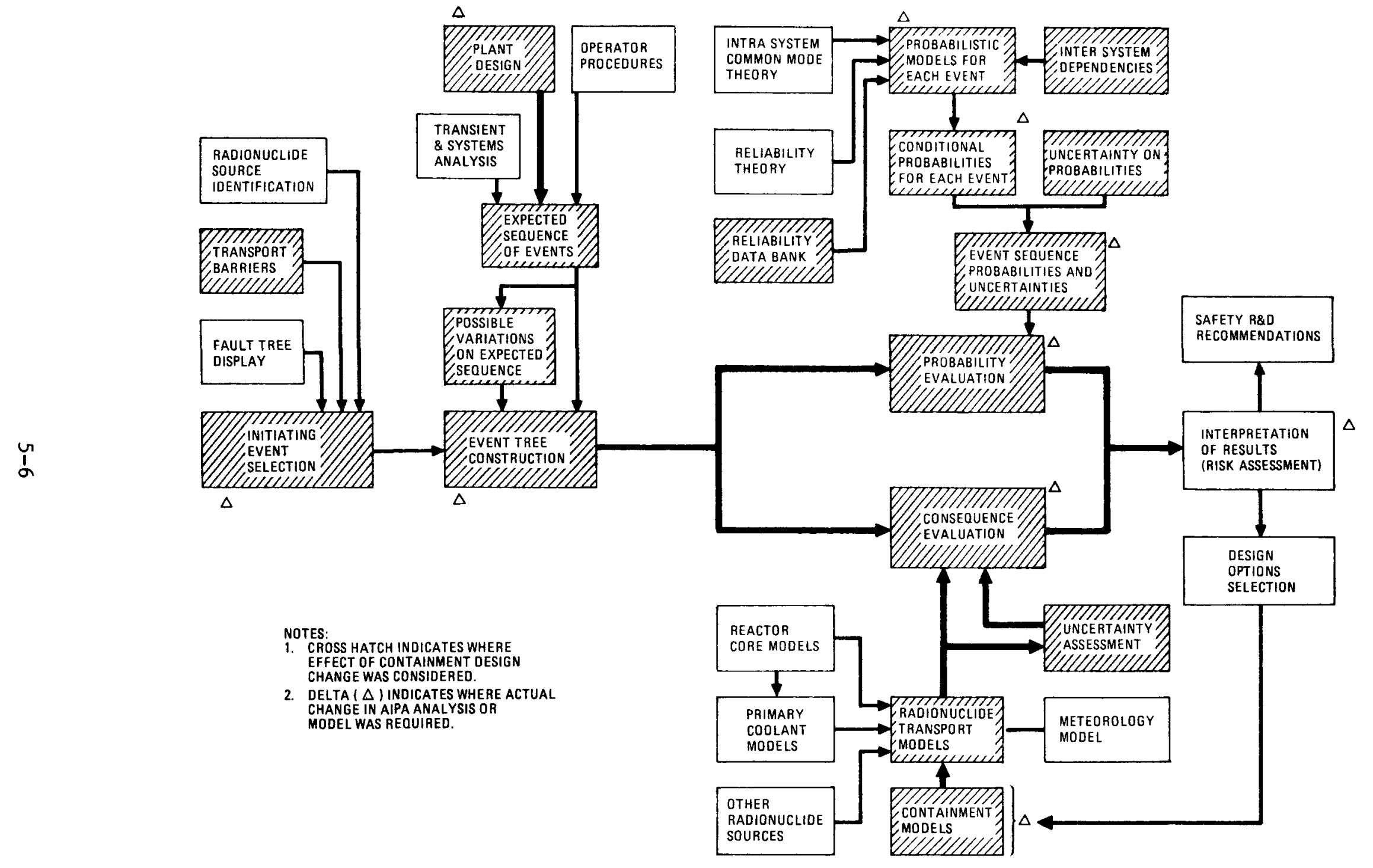

Fig. 5-1. AIPA risk analysis methodology 
events, this does not appear to be the case with vented confinement. With vented confinement, circulating fission products in the primary coolant would be released almost directly to the environment and the consequences would be significantly greater than with conventional containment. Similarly, water ingress events were reexamined in this study because they result in enhanced fission product release from the core and release from the PCRV by relief of overpressure. Table 5-1 summarizes the representative initiating events that were selected for establishing a risk envelope for an HTGR with vented confinement.

With respect to the consequence evaluation in Fig. 5-1, the block labeled "Containment Mode1s" has a delta to indicate the impact of the vented confinement on consequence modeling. As mentioned above, new consequence modeling was performed for depressurization events for the HTGR-VC. The effect of the venting was assumed to result in essentially instantaneous release from the confinement bullding and was modeled accordingly in the TDAC program. Consequence uncertainty factors were derived for the various initiating events as described in Appendix A.

For the accidents characterized by long-time release characteristics such as core heatup sequences, the releases were assumed to be equivalent to those from the HTGR with conventional containment with a failed isolation valve, which were previously assessed in the AIPA study. To be consistent with previous AIPA calculations, an atmospheric dispersion factor $(\chi / Q)$ of $8 \times 10^{-6} \mathrm{sec} / \mathrm{m}^{3}$ at $2500 \mathrm{~m}$ was assumed throughout. With these assumptions, the representative initiating events of Table 5-1 were evaluated for their effect on the vented confinement as described in the following sections.

\subsubsection{Risk Assessment Associated With Representative Initiating Events}

5.1.1.1. Loss of Offsite Power (LOSP). The event tree for the LOSP sequences for the vented confinement option is shown in Fig. 5-2. It is a revised version of that presented in Volume IV of the AIPA Status Report 
TABLE $5-1$

HTGR VENTED CONFINEMENT DOMINANT RISK BRANCH PROBABILITIES

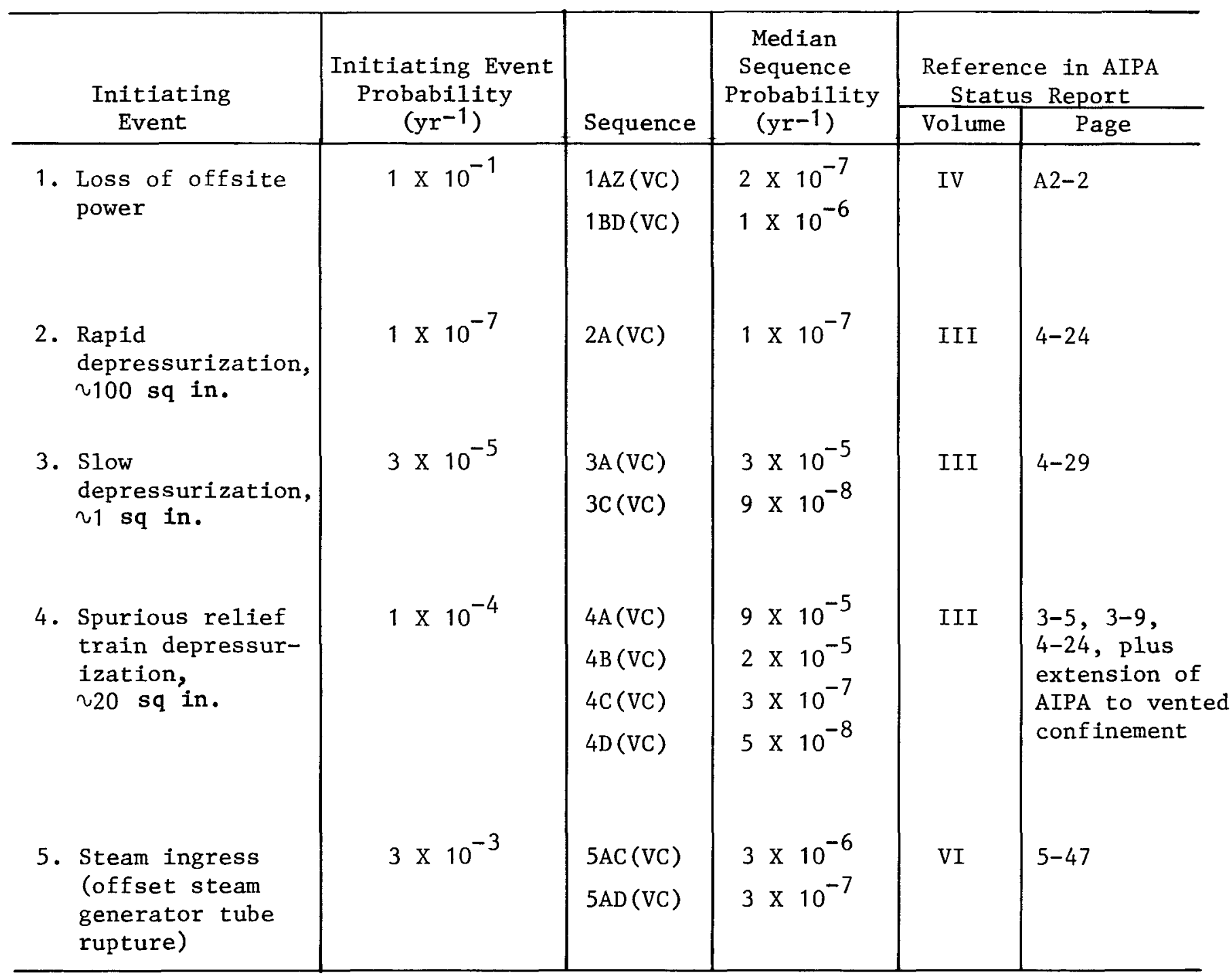




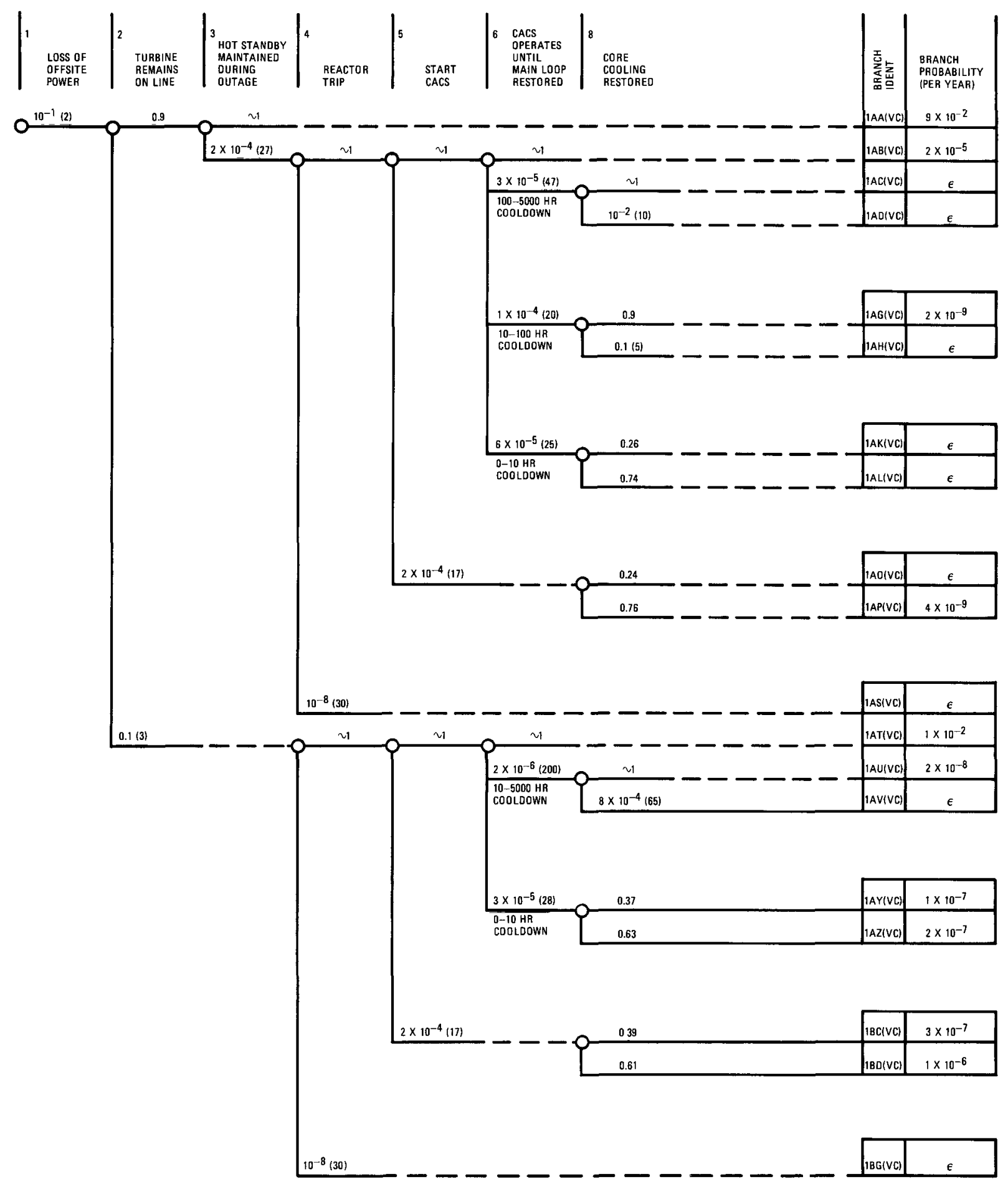

Fig. 5-2. Event tree for loss of offsite power for vented confinement 5-9 
for the conventional containment, appropriately modified by eliminating the branches denoting containment isolation and filtering capability. The sequences that follow loss of offoite power and terminate in hot standby or core cooldown by the CACS do not contribute to the public risk. However, sequences in which the CACS fails and cannot be repaired before the primary coolant system reaches temperatures beyond system cooling capability result in eventual core heatup, which may lead to the release of fission products to the environment. Therefore, the probabilities and consequences of these sequences are of interest for risk evaluation. As seen from Fig. 5-2, only Branches $1 \mathrm{AZ}(\mathrm{VC})$ and $1 \mathrm{BD}(\mathrm{VC})$ are sufficiently probable to contribute significantly to the risk of an LOSP-initiated core heatup event. Because Branch $1 \mathrm{AZ}(\mathrm{VC})$ includes a short time of core cooling, its consequences are somewhat less severe than those of $1 \mathrm{BD}(\mathrm{VC})$.

The consequences for these sequences for a plant with vented confinement (VC) are assumed to be equivalent to those calculated for similar event sequences with nonisolated containment. Therefore, the consequence for sequence $1 B D(V C)$ is assumed equal to that of AIPA Branch $B F$ as updated in Volume VIII. Consequences for Branch $1 \mathrm{AZ}(\mathrm{VC})$ were updated to be compatible with interim LOSP assumptions of Volume VIII by scaling the results for nonisolated containment Branch AN in Table 4-7 of Volume IV.

The probabilities of the dominant sequences are summarized in Table 5-1, and the consequences in terms of whole body gamma and inhalation thyroid doses with associated uncertainties are summarized in Table 5-2. Throughout this study, all sequence probabilities less than $10^{-9} / \mathrm{yr}$ are designated by epsilon $(\varepsilon)$ and are not developed further.

A graphical display of the whole body gamma risk associated with these representative sequences initiated by the LOSP event is shown in Fig. 5-3. The figure also provides a comparison with the risk points for corresponding sequences as previously calculated for the HTGR with conventional containment. The comparison indicates that use of VC would shift the maximum risk point from about $10^{-7}$ to $10^{-5}$ rem/yr. Median point risk 
TABLE 5-2

HTGR DOMINANT RISK SEQUENCE DOSE SUMMARY

30 DAY, $2500 \mathrm{M} \mathrm{LPZ}$

DOSES (UNCERTAINTY FACTOR) ${ }^{(a)}$

\begin{tabular}{|c|c|c|c|c|}
\hline $\begin{array}{c}\text { Initiating } \\
\text { Event }\end{array}$ & $\begin{array}{c}\text { Sequence } \\
\text { Designation }\end{array}$ & Whole Body & $\begin{array}{c}\text { Inhalation } \\
\text { Thyroid }\end{array}$ & Comment \\
\hline $\begin{array}{l}\text { Loss of offsite } \\
\text { power }\end{array}$ & $\begin{array}{ll}1 & \mathrm{AZ} \\
1 \mathrm{BD} & (\mathrm{vc})\end{array}$ & $\begin{array}{l}1.2(10) \\
1.4(10)\end{array}$ & $\begin{array}{ll}7.8 & (93) \\
9.7 & (93)\end{array}$ & Same as Interim LOSP BF \\
\hline $\begin{array}{l}\text { Rapid } \\
\text { depressurization } \\
(100 \text { sq in. DBDA })\end{array}$ & $2 A(v c)$ & $2.3 \times 10^{-2}(10)$ & $1.0(17)$ & \\
\hline $\begin{array}{l}\text { Slow } \\
\text { depressurization } \\
\left(\begin{array}{l}1 \mathrm{sq} \text { in.) }\end{array}\right.\end{array}$ & $3 A \& 3 C(v c)$ & $1.7 \times 10^{-2}(10)$ & $7.3 \times 10^{-1}$ (17) & \\
\hline $\begin{array}{l}\text { Spurious } \\
\text { relief train } \\
\text { depressurization } \\
(20 \mathrm{sq} \text { in.) }\end{array}$ & $\begin{array}{l}4 B \& 4 D(v c) \\
4 A \& 4 C(v c)\end{array}$ & $\begin{array}{l}2.3 \times 10^{-2}(10) \\
4.0 \times 10^{-3}(10)\end{array}$ & $\begin{array}{l}1.0(17) \\
2.0 \times 10^{-1}\end{array}$ & $\begin{array}{l}\text { Complete blowdown } \\
\text { Operator closes block valve }\end{array}$ \\
\hline $\begin{array}{l}\text { Steam } \\
\text { ingress } \\
\text { (offset steam } \\
\text { generator tube } \\
\text { failure) }\end{array}$ & $\begin{array}{l}5 \mathrm{AC}(\mathrm{vc}) \\
5 \mathrm{AD}(\mathrm{vc}) \\
5 \mathrm{AE}(\mathrm{vc})\end{array}$ & $\begin{array}{l}3.2 \times 10^{-2}(13) \\
2.7 \times 10^{-1}(13) \\
7.6 \times 10^{-1}(13)\end{array}$ & $\begin{array}{l}1.3 \times 10^{-1}(17) \\
7.3 \times 10^{-1}(17) \\
7.3 \times 10^{-1}(17)\end{array}$ & $\begin{array}{l}18 \% \text { relief at } 10 \text { min } \\
\text { Complete blowdown, block } \\
\text { valve closes } \\
\text { Complete blowdown and } \\
\text { hydrolysis release }\end{array}$ \\
\hline
\end{tabular}

(a) For derivation of uncertainty factors, see Appendix A. 


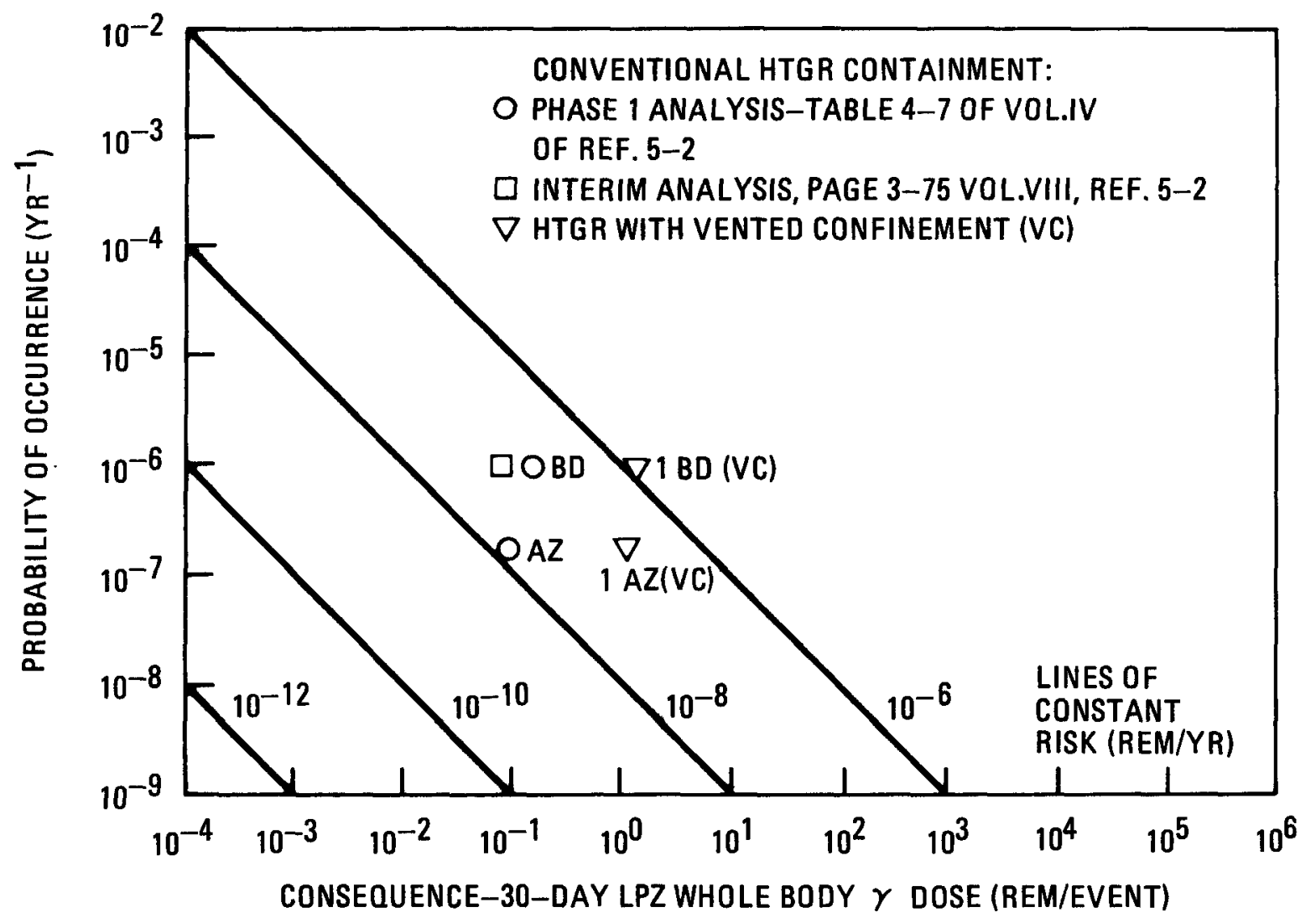

Fig. 5-3. Risk plot for loss of offsite power 
values associated with thyroid dose are not displayed graphically in this report. In Section 5.3, the risk for thyrold dose is developed in cumulative distribution curves.

5.1.1.2. Rapid Depressurization of Primary Coolant System. The event tree for rapid depressurization with the VC is shown in Fig. 5-4 as derived from the AIPA event tree for the same event with conventional containment. The AIPA event tree was modified by removing branch points associated with containment functions such as isolation and filtration of fission products during recirculation, which results in a very concise event tree.

Sequence $2 A(V C)$ of Fig. 5-4 represents the expected outcome of a failure of a PCRV penetration closure for which the maximum area for primary coolant depressurization is limited by flow restrictors to $100 \mathrm{sq}$ in. Fo1lowing the occurrence of rapid depressurization, the reactor is tripped and cooled down by the CACS. The consequence of this sequence is the release to the environment of primary coolant gasborne activity plus plateout or dustborne activity lifted off intemal PCRV surfaces.

Sequence $2 B(V C)$ represents rapid depressurization followed by failure of the CACS to provide cooldown and subsequent unrestricted core heatup with eventual release of the fission products initially bound in the core. Sequence $2 C(V C)$ represents the sequence in which rapid blowdown is followed by a failure to trip the reactor. The probabilities of Branches $2 \mathrm{~B}(\mathrm{VC})$ and $2 \mathrm{C}(\mathrm{VC})$ are so small that neither sequence is treated further.

The gasborne circulating activities, liftoff from plateout, and noble gases from decay of the remaining plateout activity combine to produce the whole body gamma dose. The thyroid dose is primarily due to the dust and the liftoff of the plateout activity. Consequences with uncertainty factors are sumarized in Table 5-2.

The median point value risk for the rapid depressurization events for HTGR-VC is compared in Fig. 5-5 with previous AIPA results for conventional 


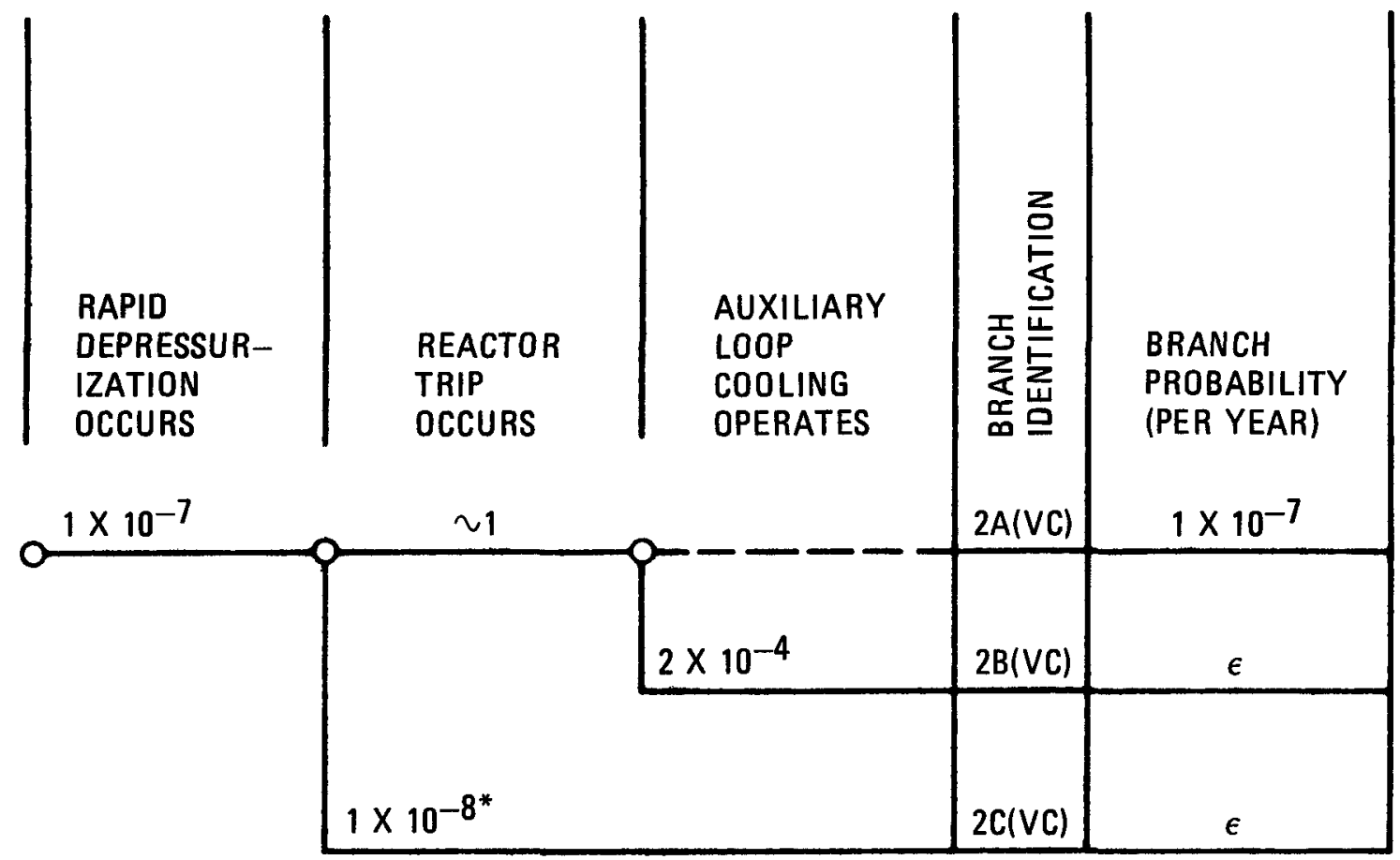

\section{*SEQUENCES BEYOND FAILURE TO TRIP REACTOR ARE NOT DEVELOPED}

THE NOTATION $\in$ DENOTES $<10^{-9}$

Fig. 5-4. Event tree for rapid PCRV depressurization with vented confinement 


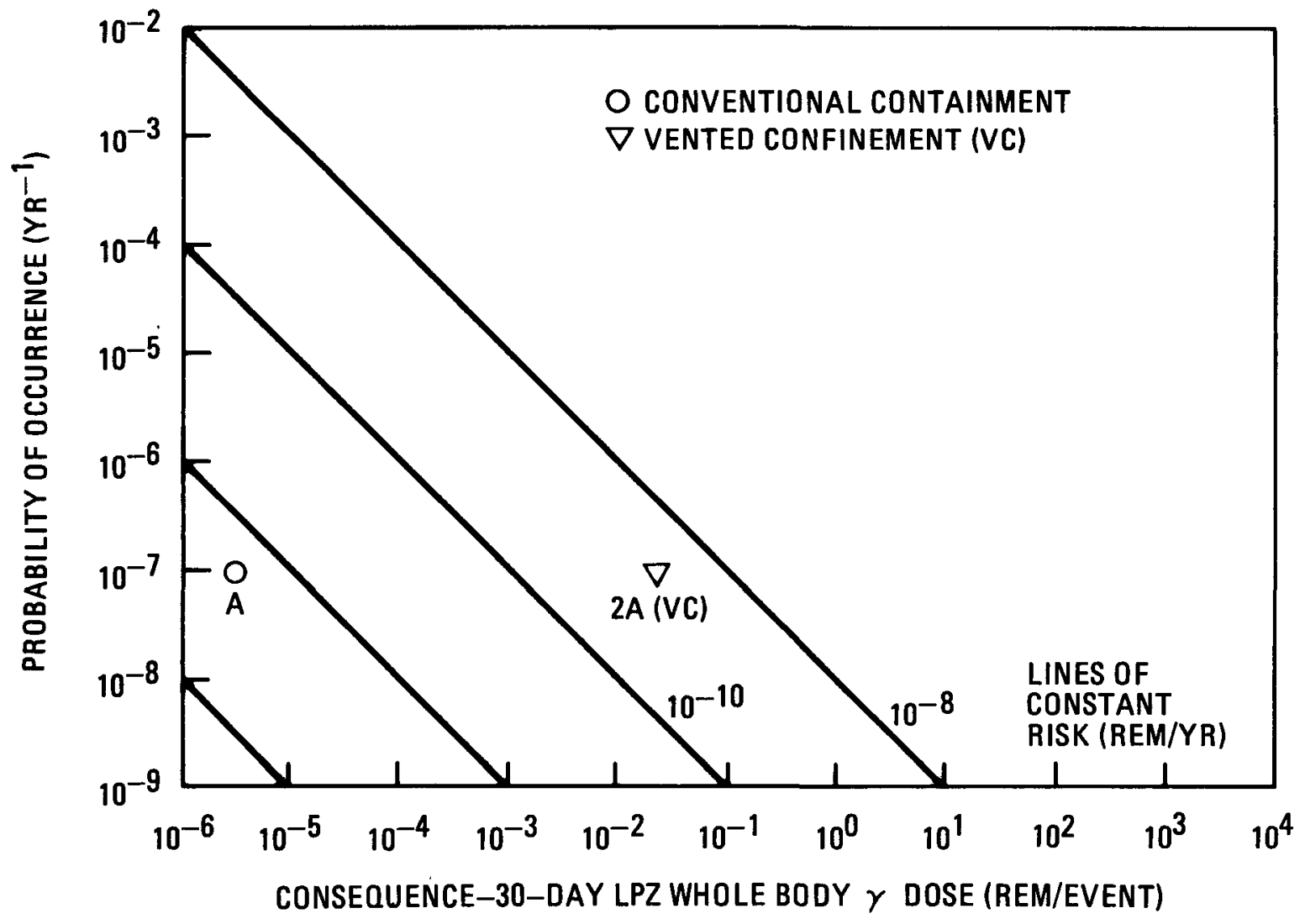

Fig. 5-5. Risk plot for rapid PCRV depressurization 
containment (probabilities from Volume III and consequences from Volume VI). This comparison indicates that the maximum risk shifts from about $10^{-13} \mathrm{rem} / \mathrm{yr}$ with conventional contalnment to $2.3 \times 10^{-9} \mathrm{rem} / \mathrm{yr}$ with $\mathrm{VC}$.

5.1.1.3. Slow Depressurization of Primary Coolant System. The event tree of Fig. 4-2 in Volume III of the AIPA Status Report was modified as shown in Fig. 5-6 to reflect representative event sequences leading to release from a slow depressurization in the VC design. The class of initiating events considered is represented by breaks in lines with about $1 \mathrm{sq}$ in. cross-sectional area, which are connected to the primary coolant system. The consequences were calculated for sequences $3 A(V C)$ and $3 C(V C)$ using the TDAC program assuming essentially instantaneous release from confinement and $X / Q=8 \times 10^{-6} \mathrm{sec} / \mathrm{m}^{3}$. The release of activity from the PCRV was assumed to be complete after $2 \mathrm{hr}$. Contributions for liftoff of plateout and dust appropriate for the slow depressurization event were taken from Tables 5-13 and 5-14 of AIPA Status Report Volume VI. Noble gases from decay of remaining plateout were added to the circulating activity. The consequences are summarized in Table 5-2. The risk from this event with VC is compared in Fig. 5-7 with that of conventional containment as derived previously in Volume III and updated for consequence modeling in Volume VI of the AIPA Status Report.

As noted in Table 5-2, the differences in the respective 30 -day whole body gamma and thyroid doses for rapid and slow depressurization events are small. Since the likelihood of a small line break is much greater than a failure of a PCRV penetration closure, the overall risk from the slow event at $5.1 \times 10^{-7} \mathrm{rem} / \mathrm{yr}$ (whole body gamma) is greater than that of rapid depressurization at $2.3 \times 10^{-9} \mathrm{rem} / \mathrm{yr}$. This may be seen by comparing points $2 A(V C)$ and $3 A(V C)$ on Figs. 5-5 and 5-7, respectively. Sequences other than $3 A(V C)$ and $3 C(V C)$ shown in Fig. 5-6 are seen to have probabilities less than $10^{-9} / \mathrm{yr}$ and are not developed in this study.

5.1.1.4. Spurious PCRV Pressure Relief Train Opening. Another possible cause of PCRV depressurization is spurious opening of the PCRV pressure 


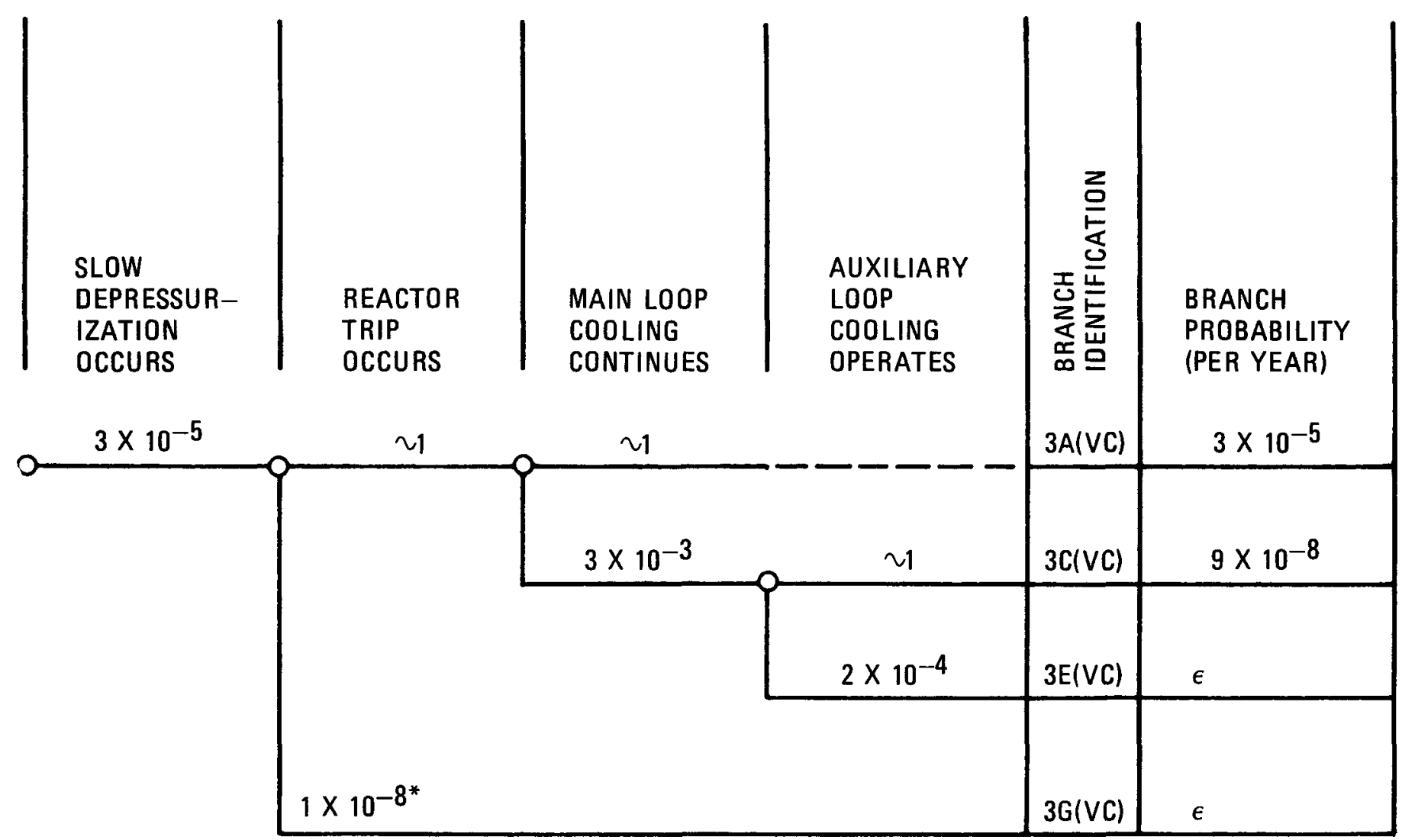

${ }^{*}$ SEQUENCES BEYOND FAILURE TO TRIP REACTOR ARE NOT DEVELOPED

Fig. 5-6. Event tree for slow PCRV depressurization with vented confinement 


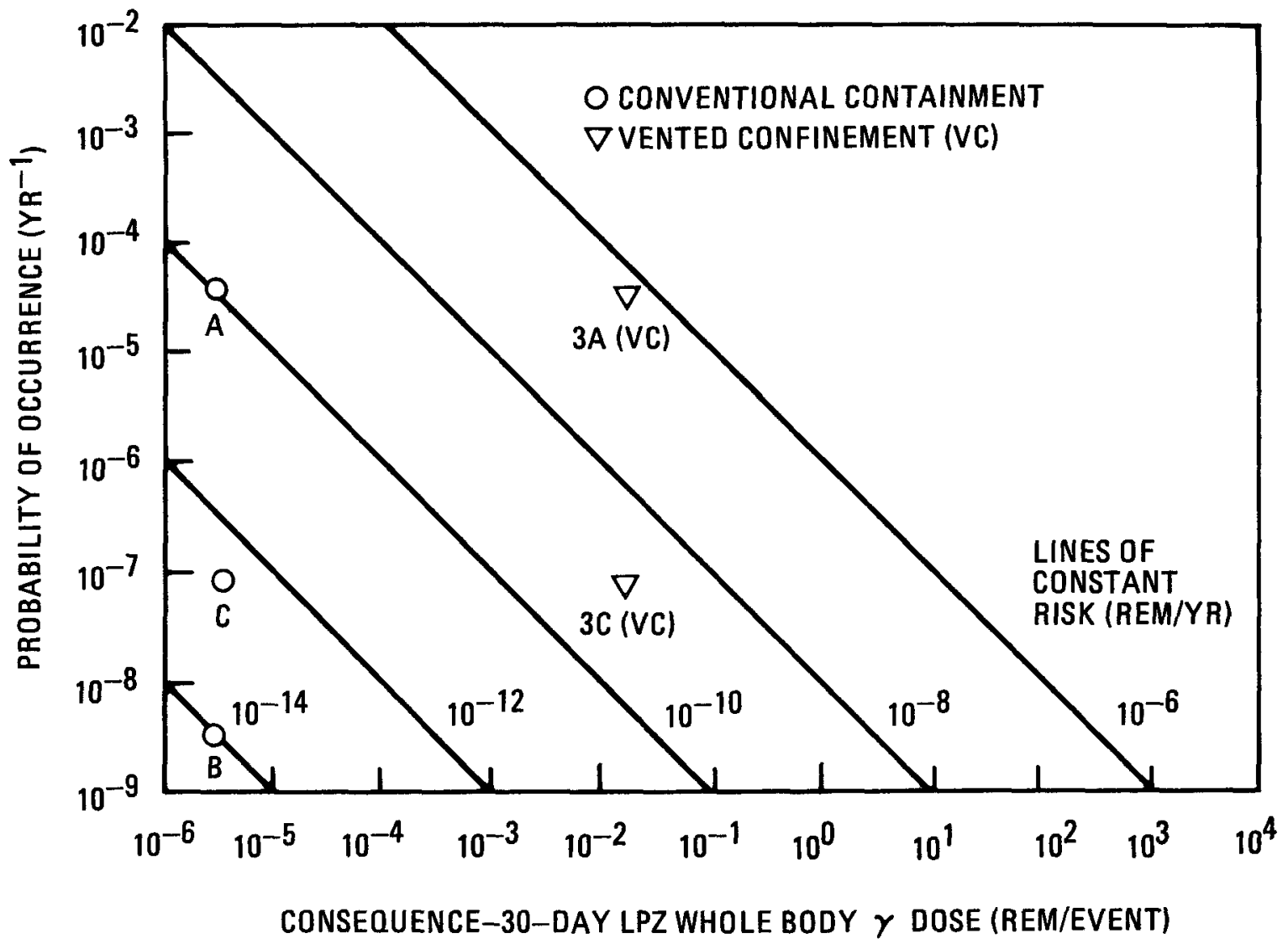

Fig. 5-7. Risk plot for slow PCRV depressurization 
relief train. In the vented confinement configuration, this event could lead to a nearly direct release of fission products to the environment. Such a depressurization would require a fallure of two diverse barriers: a relief valve and a rupture disk. If both failed to maintain integrity in the same time frame, a depressurfzation would be initiated. If the event were not due to overpressurization relief such as that which may arise following a steam generator tube leak, the relief valve would most likely remain open. However, the operator can mitigate the depressurization by closing the relief train block valve. The event tree shown in Fig. 5-8 for this event was constructed by reference to that for the rapid depressurization presented in the AIPA Status Report, Volume III (p. 4-24), taking into account the containment design change and a recent reexamination of the likelihood of the initiating event discussed below.

The chance of a common failure at normal pressure of both the relief valve and the rupture disk is minimized by the rupture disk arrangement, diverse operating mechanioms, and independent calibration. In addition, alarm systems warn the operator if pressure varies from the setpoint in the chamber between the valve and rupture disk. Thus, the operator would be alerted to relief train leak modes at the onset of the first failure and could rapidly initiate block valve operation. Therefore, the likelihood of double failures in the relief train is dominated by situations in which the reactor is maintained at power after a failure of one of the diverse relief train mechanisms has been discovered.

During the shutdown period prior to repair of the failed mechanism, the relief train affords the highest risk for initiation of a PCRV depressurization. Assuming that approximately $100 \mathrm{hr}$ would elapse between the first failure and shutdown, the likelihood of spuriously initiating such a depressurization of $20 \mathrm{sq}$ in. effective area has been calculated to be $1 \mathrm{x}$ $10^{-4} \mathrm{yr}^{-1}$. (Spurious relief valve operation does not consider response to actual overpressure relief initiated by other events.) Because of the prewarning to the operator, the probability of operator success in blocking the blowdown path within 1 min after failure of the second barrier was 


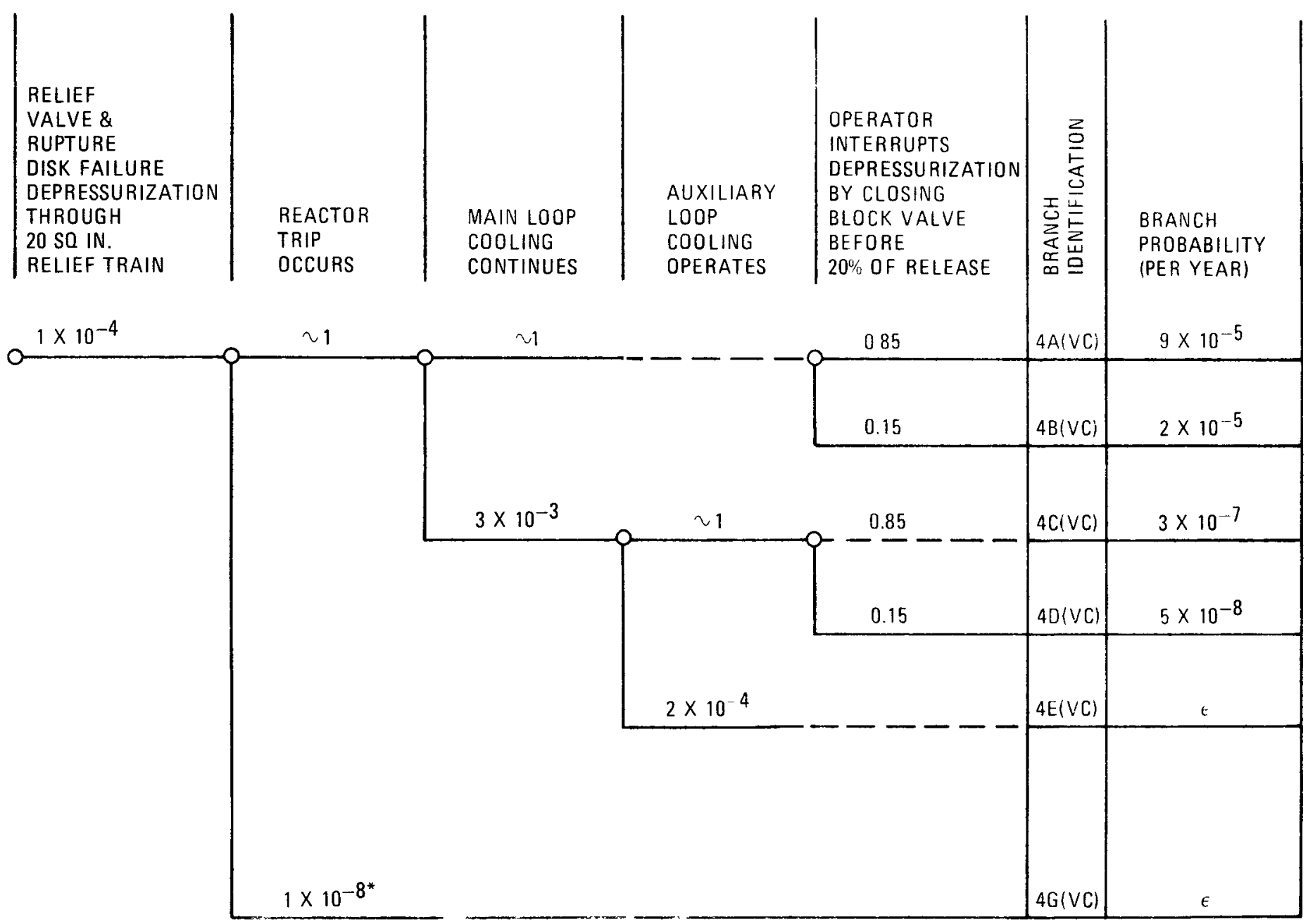

"SEQUENCES BEYOND FAILURE TO TRIP REACTOR ARE NOT DEVELOPED

Fig. 5-8. Event tree for relief train spurious depressurization of PCRV with vented confinement 
estimated to be 0.35 assuming a mean time of operator response of approximately 50 sec. This estimate is based on the reactor operator model described in Section 4.4 of Volume II of the AIPA Status Report. The probability of correct operator response is less in the event that a relief train fails abruptly. However, the likelihood of such a failure was calculated in the preliminary AIPA analysis to be more than an order of magnitude less than that of the sequential failure considered here.

The consequences corresponding to sequences shown in Fig. 5-8 were evaluated. For Branches $4 B(V C)$ and $4 D(V C)$, it was assumed that total depressurization occurred through the 20-sq-in. opening. Analysis of the blowdown dynamics indicated that the activity released is equivalent to that of the rapid (100-sq-in.) depressurization. Therefore, the doses reported above for Branch $2 \mathrm{~A}(\mathrm{VC})$ were employed for Branches $4 \mathrm{~B}(\mathrm{VC})$ and $4 D(V C)$.

For $B$ ranches $4 A(V C)$ and $4 C(V C)$, credit is taken for operator action to close the block valve in the spuriously open relief train, which would result in the release of only about $20 \%$ of the primary coolant during the early depressurization phase. Hence, the corresponding doses were obtained by assuming $20 \%$ of the gasborne doses and $20 \%$ of the dust/liftoff doses but disregarding any contribution to the circulating gas activity due to decay of remaining plateout. The consequences of the low probability Branch $4 \mathrm{E}(\mathrm{VC})$ would be equivalent to those of LOSP $1 \mathrm{BD}(\mathrm{VC})$.

The consequences for the relief valve depressurization event are summarized in Table 5-2 with the associated uncertainty ranges. Figure 5-9 is a risk plot for the representative sequences for this event with the HTGRVC. Previous AIPA studies did not develop this event to a comparable degree and therefore do not afford a basis for direct comparison in Fig. 59. However, comparison between Figs. 5-9 and 5-7 shows that the maximum risk of spurious relief train depressurization at $4.6 \times 10^{-7} \mathrm{rem} / \mathrm{yr}$ is comparable to that of slow depressurization at $5.1 \times 10^{-7} \mathrm{rem} / \mathrm{yr}$. 


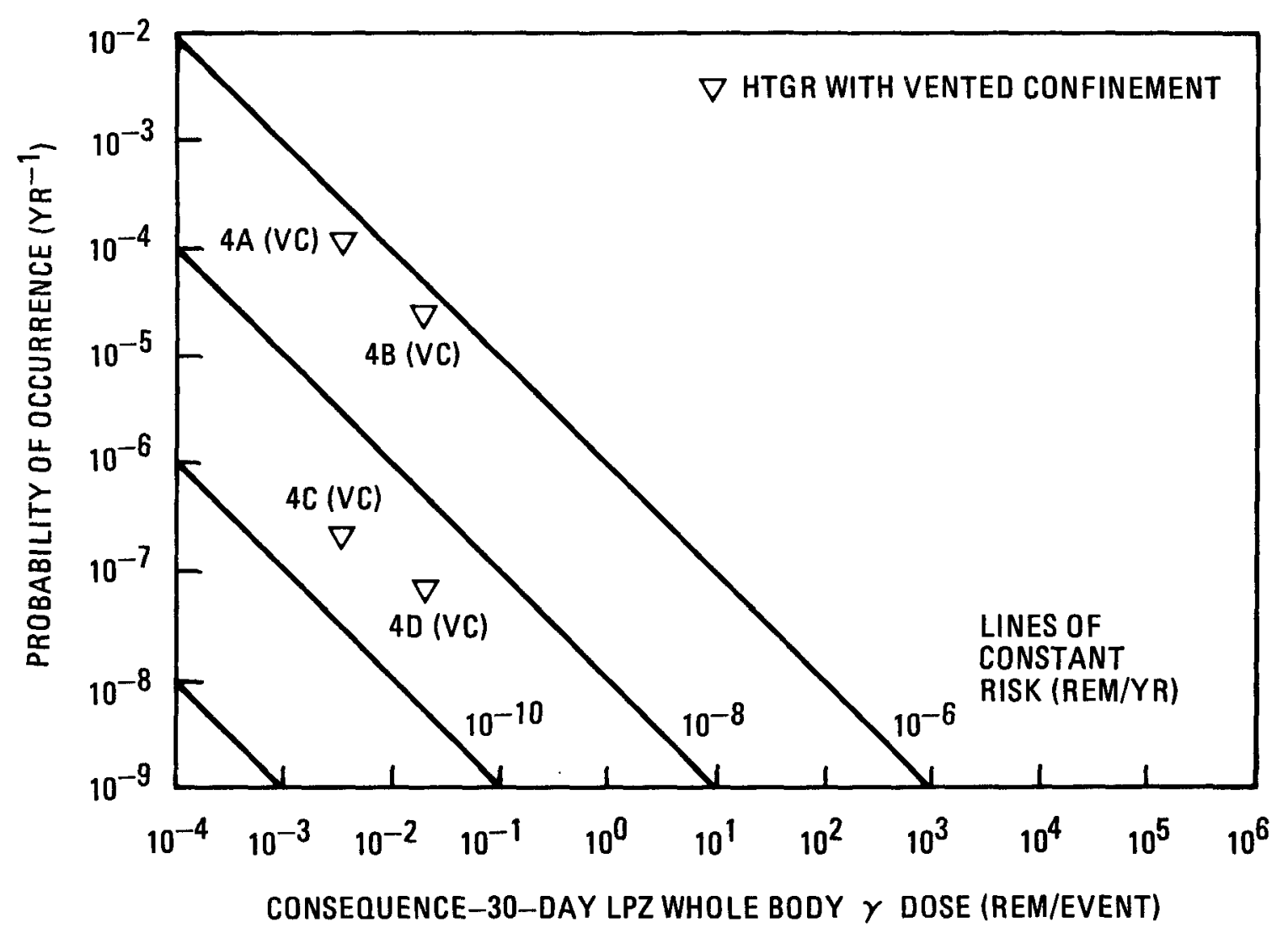

Fig. 5-9. Risk plot for relief train spurious depressurization of PCRV 
5.1.1.5. Steam/Water Ingress. The event tree shown in Fig. 5-10 for the VC was derived from the steam/water ingress event tree for conventional containment similar to that found in Volume VI of the AIPA study (p. 5-47). The VC risk assessment was derived as previously described by associating the appropriate consequences with the probabilities of event sequences which lead to fission product release from the PCRV. Whereas consideration was given to local burning inside the containment in the previous AIPA analysis described in Volume VI for sequences which involved dumping of a nonleaking steam generator as a result of ineffective or incorrect plant protection system response, the burning probability approaches zero for the VC design. In principle, the affected branch probabilities had to be corrected for the burning probability. However, none of the branches corrected for burning were sufficiently probable (i.e., greater than $10^{-9} / \mathrm{yr}$ ) to be considered further. Overall, only two steam/water accident sequences as summarized in Table 5-2 were retained as significant contributors to the risk. The consequences for the steam/water ingress sequences with vented confinement, as summarized, were evaluated as follows.

Branch $5 A E(V C)$ yields the worst consequences since this sequence involves complete PCRV blowdown and fuel hydrolysis while the relief valve and relief train block valves remain open for the duration of the accident. The consequences associated with Branch $5 \mathrm{AE}(\mathrm{VC})$ are employed as a basis for the other moisture ingress sequences. The release was assumed to consist of (1) $100 \%$ of the median gasborne activity (as for the rapid depressurization case), (2) $100 \%$ of dust/liftoff equivalent to that of the slow depressurization since it is primarily dust rather than liftoff, (3) noble gases from plateout decay, and (4) $100 \%$ fuel hydrolysis. The activity available for release from the latter was based on a failed fuel fraction of $1.43 \mathrm{x}$ $10^{-3}$ (Table 5-4, Volume VI) and the median fuel body activity (Table 4-5, Volume V) for 3944 fuel blocks. An average decay time of $1 \mathrm{hr}$ was assumed for the noble gas fuel activity since hydrolysis is complete in approximately $2 \mathrm{hr}$. It is found that the hydrolysis contributes the major share of the whole body gamma dose. Since the probability of Branch 5AE(VC) is less than $10^{-9} \mathrm{yr}^{-1}$, the risk associated with this branch was not developed further in this study. 


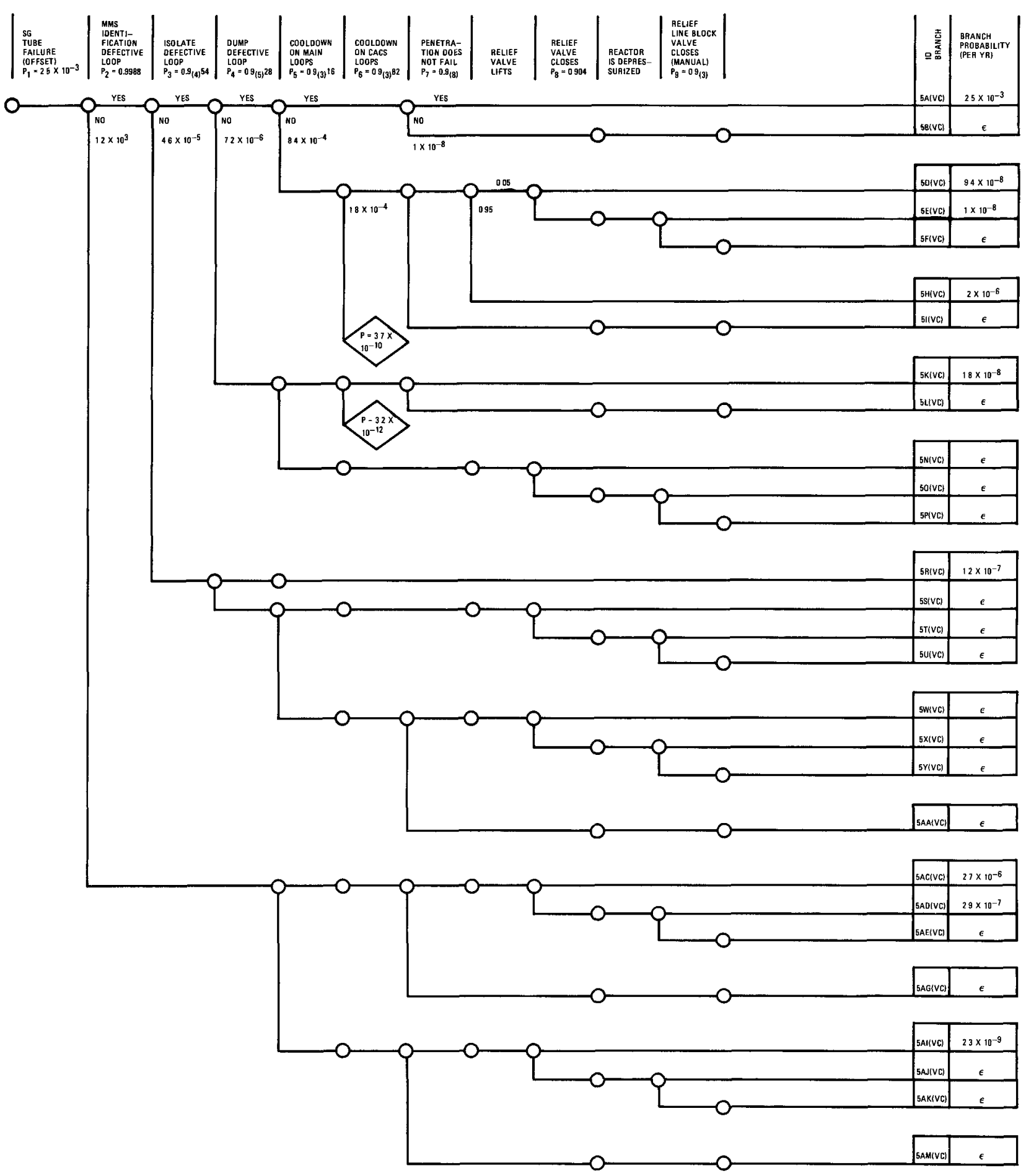

Fig. 5-10. Event logic tree for steam ingress 
In Branch $5 A D(V C)$, the block valve is manually closed within 30 min, which yields complete blowdown of the PCRV with release of $100 \%$ gasborne and dustborne activity but only $25 \%$ completion of fuel hydrolysis and negligible contribution by noble gas from decay of plateout. The fuel hydrolysis source was credited with 30 min decay.

In Branch $5 \mathrm{AC}(\mathrm{VC})$, the relief valve recloses at $10 \mathrm{~min}$ after the event initiation. For the consequence calculation, $18 \%$ of the gasborne activity, $18 \%$ of the dust/liftoff, and $18 \%$ of the noble gases available from fue 1 hydrolysis were assumed to be released to the environment. The latter is quite small since only one-eighth of the hydrolysis reaction is completed during the interval when the PCRV relief train is open.

As for all consequence modeling with the VC, activity released from the PCRV is assumed to be instantly available for dispersion in the environment. The consequences for the steam/water ingress sequences are presented in Table 5-2 with the appropriate uncertainty factors as derived in Appendix A.

Figure 5-11 is a risk plot for these sequences with VC and similar sequences for conventional containment. The maximum risk values at $9.6 \mathrm{x}$ $10^{-8} \mathrm{rem} / \mathrm{yr}$ are seen to be comparable in magnitude to those of the spurious relief train depressurization event at $3.6 \times 10^{-7} \mathrm{rem} / \mathrm{yr}$.

5.1.1.6. Summary of Probabilistic Risk Assessment for HTGR-VC. Table 5-1 summarizes the probability evaluations for the prominent initiating events and event sequences for the HTGR with vented confinement. The consequences of these sequences in terms of the 30-day whole body gama dose and inhalation thyroid dose at the 2500-m LPZ are presented in Table 5-2. From these data, the probability-consequence (P-C) summary risk plot of Fig. 5-12 was constructed. This plot shows the relative importance of the various accident sequences. Several sequences yield comparable risk at about $10^{-6}$ $\mathrm{rem} / \mathrm{yr}$. In the low consequence range, the dominant sequences appear to be those initiated by slow and spurious relief valve depressurization events. 


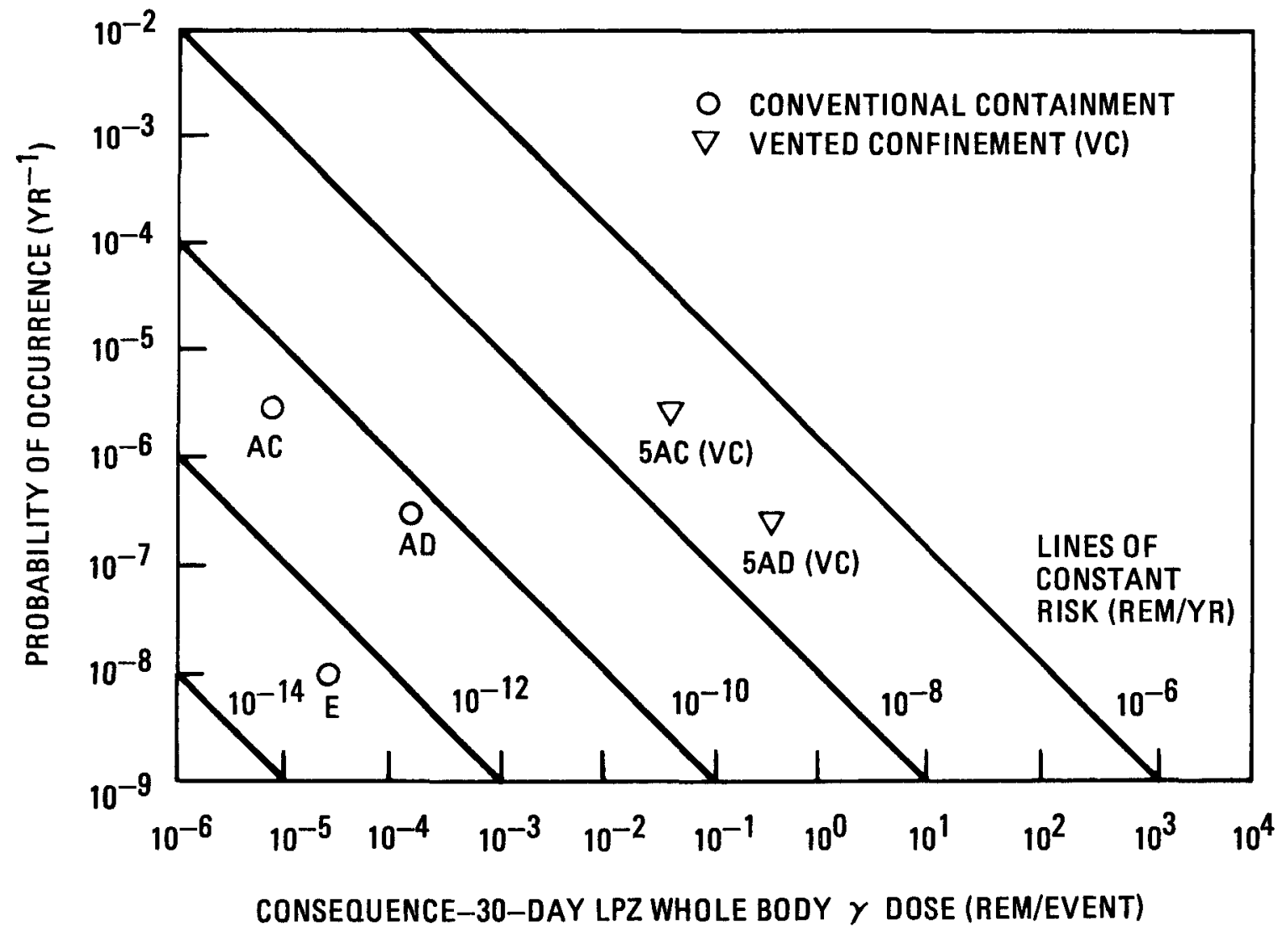

Fig. 5-11. Risk plot for steam ingress 


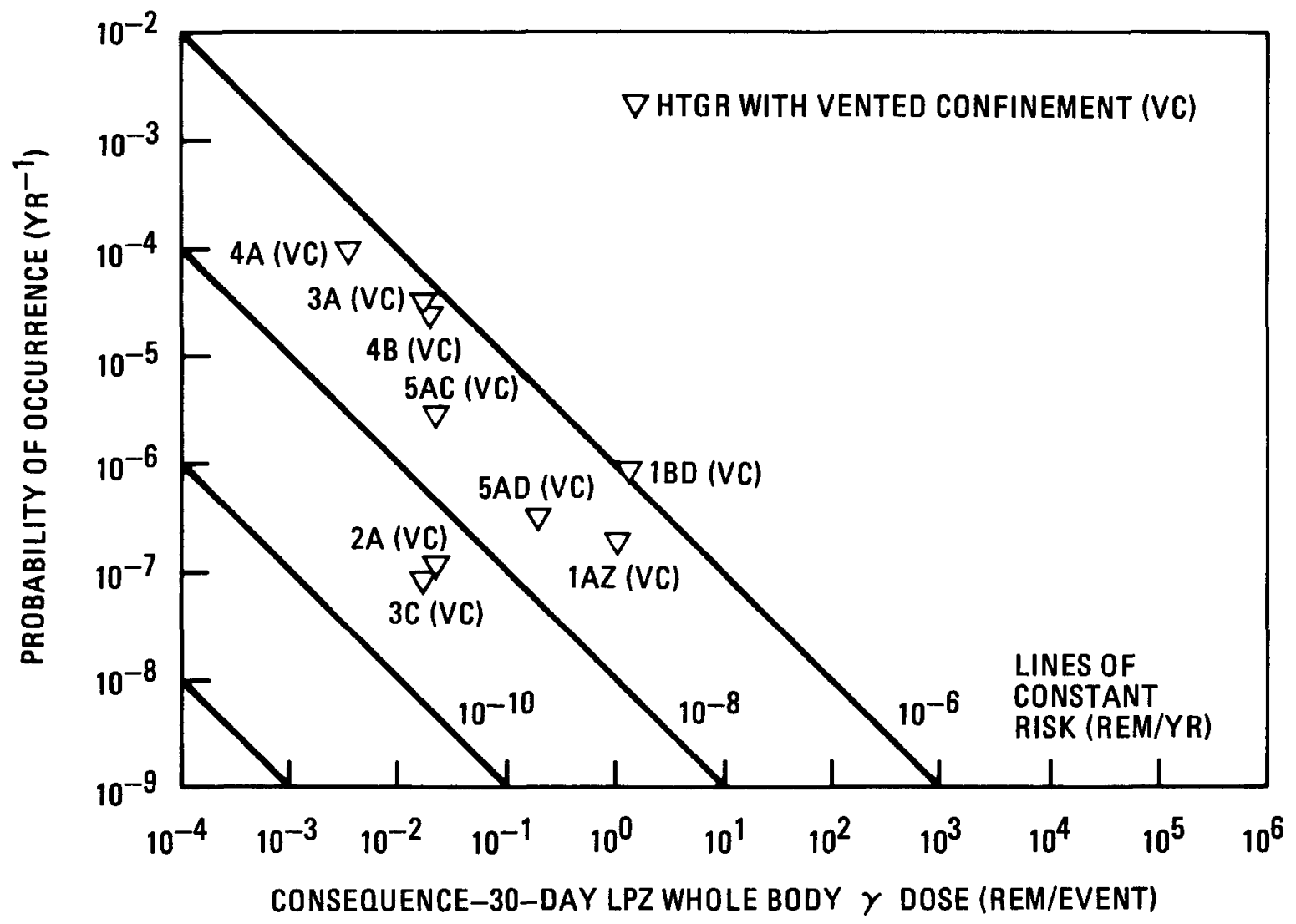

Fig. 5-12. Summary risk plot of dominant sequences for HTGR with vented 
This represents a change from the conventional containment case, which was dominated in the low consequence range by the reheater leak event. A reheater leak provides a significant primary coolant leakage path through the condenser to the atmosphere while depressurization releases are held up in containment in the case of a conventional containment. With the vented confinement design, however, both reheater leaks and depressurization events result in essentially direct release to the environment. For the VC, reheater leak sequence contributions to the risk envelope are about two orders of magnitude less than those resulting from the depressurization events. In the high consequence range, the LOSP-initiated core heatup sequence is the dominating risk sequence for the VC design as well as for conventional containment. Hovever, there is more than an order of magnitude difference in the consequences between the two containment designs.

In this section, the comparative risk of VC vis-a-vis conventional containment was evaluated on the basis of whole body gamma dose only. In the overall study, however, both whole body gamma and thyroid inhalation doses were employed in risk comparisons on the basis that these dominate other exposures with respect to health effects and serve to illustrate risk trends. Doses for the representative sequences are summarized in Table 5-2. From the product $P \times C$ for the various sequences, it may be seen that Branches $3 A(V C), 4 A(V C)$, and $4 B(V C)$ yield the highest thyroid risk at about $2 \times 10^{-5}$ rem/yr. However, the core heatup Branch $1 B D(V C)$ still dominates the high consequence risk at about $10^{-5} \mathrm{rem} / \mathrm{yr}$. Even though additional organ doses will be calculated in future, more detailed design analyses for vented confinement, the trends reported here are expected to continue.

In the remaining evaluations in this section, accident sequences that do not significantly affect the risk envelope curves are not considered independently. For example, the rapid depressurization sequences are well within the risk envelope and appear to be insignificant compared to spurious relief train depressurization sequences. In the evaluation of the summary cumulative distribution curves in Section 5.3, the risk from the rapid depressurization is shown to afford an indiscernible contribution. 
Other event risks, such as those arising from reheater tube leaks, are also insignificant compared to the depressurization events in the vented confinement design, also making an insignificant contribution to the overall risk envelope. Therefore, the comparisons in this section should be valid in principle for the risks from all accident-initiated events.

\subsection{PROBABILISTIC RISK ASSESSIENT OF A PIR WITH CONVENTIONAL CONTAINMENT}

As indicated above, the radiological risk associated with the PWR evaluated in the RSS was selected as a basis for comparison with the HTGRVC. Since risk data in a commensurate format were not directly available from the RSS, it was necessary to construct a compatible assessment of the PWR from RSS data. Although sequence probabilities were available from the RSS, dose consequences at $2500 \mathrm{~m}$ or any other distance were not. Therefore, it was necessary to calculate the required doses with the GA consequence code TDAC using source term data from the RSS. The selection of contributing PWR accident sequences and consequence modeling are discussed below.

\subsubsection{PWR Accident Sequence Selection}

The important PWR accident sequences can be identified from Table V3-14 of WASH-1400 by consideration of the probability of the various sequences. This table is reproduced here in part as Table 5-3 and modified to indicate (1) the most likely sequence for each accident initiator in each release category, and (2) the highest probability sequence for each of the initiators [1arge LOCA-A, small LOCA-S ${ }^{1}$, small LOCA-S $^{2}$, and transient event (loss of offsite power)]. The literal designations for the sequences as defined in Table 5-4 refer to various initiating events, failures of standby engineered safety systems, and containment failure modes. Detailed descriptions of these events can be found in WASH-1400, Appendices I and V.

The important sequences thus designated in Table 5-3 were evaluated in the same style employed for the HTGR-VC: consequences were calculated, 
TABLE 5-3

PWR DOMINANT ACCIDENT SEQUENCES VERSUS RELEASE CATEGORIES

(FROM WASH 1400, TABLE V 3-14)

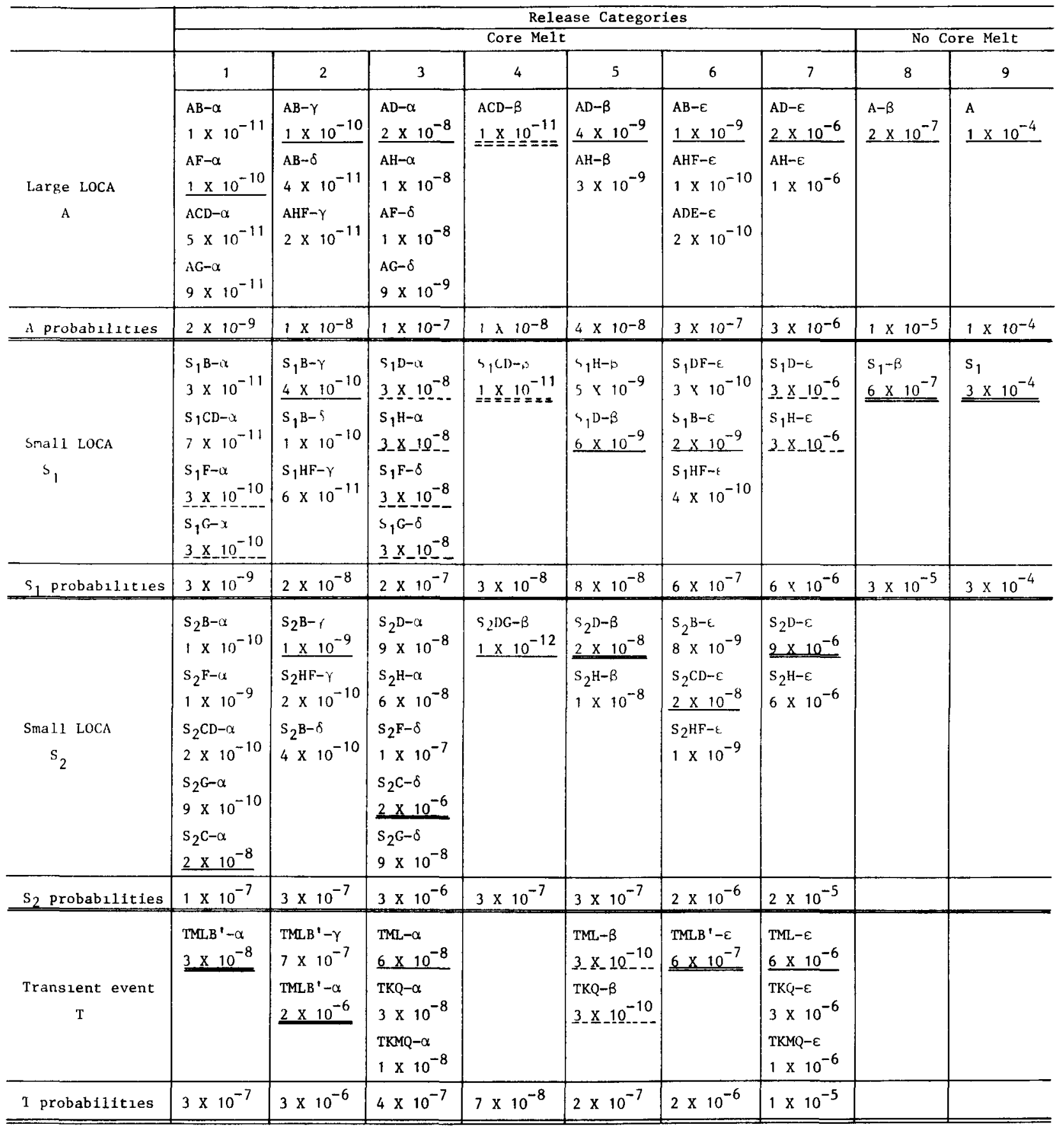

Key._._ Single underline is highest probability event sequence for each intiating event in a release category.

= Double underline is highest probability event sequence for entire release category.

-.--- Dotted lines mean two sequences with equivalent likelihood.

NOTE: Only sequences with probabllity $>10^{-9} \mathrm{yr}^{-1}$ are considered in the present study. 
TABLE $5-4$

KEY TO PWR ACCIDENT SEQUENCE SYMBOLS (FROM WASH 1400, TABLE V 3-15)

Initiating Event Descriptors

A Intermediate to large LOCA.

$B^{\prime} \quad$ Failure to recover either onsite or offsite electric power within about 1 to $3 \mathrm{hr}$ following an initiating transient which is a loss of offsite ac power

$\mathrm{S}_{1}$ A small LOCA with an equivalent diameter of about 2 to 6 in.

$\mathrm{S}_{2} \quad$ A smal1 LOCA with an equivalent diameter of about $1 / 2$ to 2 in.

T Transient event.

$\mathrm{V} \quad$ LPIS check valve failure

$\mathrm{R}$ Massive rupture of the reactor vesse1.

Engineered Safety Systems Failures

B Failure of electric power to ESFs.

C Failure of the containment spray injection system.

D Failure of the emergency core cooling injection system.

F Failure of the containment spray recirculation system.

G Failure of the containment heat removal system.

$\mathrm{H} \quad$ Failure of the emergency core cooling recirculation system.

$\mathrm{K}$ Failure of the reactor protection system.

L Failure of the secondary system steam relief valves and the auxiliary feedwater system.

M Failure of the secondary system steam relief valves and the power conversion system.

Q Failure of the primary system safety relief valves to reclose after opening.

Containment Failure Modes

$\alpha \quad$ Containment rupture due to a reactor vessel steam explosion.

B Containment failure resulting from inadequate isolation of containment openings and penetrations.

$\gamma$ Containment failure due to hydrogen burning.

$\delta \quad$ Containment failure due to overpressure.

$\varepsilon \quad$ Containment vessel melt-through. 
risk plots of probability times consequence were constructed, and cumulative distribution curves were derived taking into account an assumed consequence uncertainty factor.

\subsubsection{Consequence Modeling for PIRs}

The release category designations in the RSS are defined by the fraction of isotopic core inventory released, time of release, and duration of release as shown in Table V2-1 of Ref. 5-1, which is shown here in modified form as Table 5-5. These data and appropriate PIJR fission product inventories were input to the TDAC dose model along with the atmospheric dispersion parameters, $X / Q$, appropriate for each release category in order to make equivalent comparisons with the HTGR. The median $X / Q$ values for the PWR categories, calculated as described in Appendix B, are less than the median $X / Q$ for the HTGR releases because of considerations of plume rise and plume meander in the PWR sequences. This difference gives a slight advantage to the PWR at the LPZ boundary. The median doses corresponding to the PWR release caregories as calculated with the TDAC program are summarized in Table 5-6. These doses are associated with corresponding accident sequence probabilities in subsequent sections to quantify accident risk for the PWR.

To maintain equivalent bases for risk comparison between the HTGR-VC and PWR, the same weather uncertainty factor of 5 (as described in Appendix A) was employed for both reactor types. For the PWR, the total consequence uncertainty was equated to a single cause: weather. Although additional uncertainty factors should be employed with the PWR consequences, it was felt that any factor derived by GA would be open to criticism. Therefore, in cumulative risk curve derivations in this study, the PWR is afforded an advantage in total uncertainty factor compared to the HTGR-VC. The following sections discuss the median value probabilistic risk assessment for the PWR. 
TABLE 5-5

SUMMARY OF INPUT DATA TO PWR CONSEQLENCE ANALYSIS

\begin{tabular}{|c|c|c|c|c|c|c|c|c|c|c|c|c|c|}
\hline \multirow[b]{2}{*}{$\begin{array}{l}\text { Release } \\
\text { Category }\end{array}$} & \multirow{2}{*}{$\begin{array}{l}\text { Time of } \\
\text { Release } \\
\text { (hr) }\end{array}$} & \multirow{2}{*}{$\begin{array}{c}\text { Duration } \\
\text { of Release } \\
(\mathrm{hr})\end{array}$} & \multirow{2}{*}{$\begin{array}{c}\text { Elevation } \\
\text { of Release } \\
\text { (meters) }\end{array}$} & \multirow{2}{*}{$\begin{array}{c}\text { Energy } \\
\text { Release } \\
\left(10^{6} \mathrm{Btu} / \mathrm{hr}\right)\end{array}$} & \multirow{2}{*}{$\begin{array}{c}\text { Representative } \\
\text { Atm. Diffusion } \\
\text { Factor } \\
\text { (sec/in?) (a) }\end{array}$} & \multicolumn{8}{|c|}{ Fraction of Core Inventory Released } \\
\hline & & & & & & $\mathrm{Xe}-\mathrm{Kr}$ & $\begin{array}{c}\text { Organic } \\
\text { I }\end{array}$ & $\mathrm{I}$ & $\mathrm{Cs}-\mathrm{Rb}$ & Te-Sb & $\mathrm{Ba}-\mathrm{Sr}$ & $\mathrm{Ru}^{(\mathrm{b})}$ & $\mathrm{La}^{(\mathrm{c})}$ \\
\hline PWR 1a & 2.5 & 0.5 & 25 & 20 & $3 \times 10^{-6}$ & 0.9 & $6 \times 10^{-3}$ & 0.7 & 0.4 & 0.4 & 0.05 & 0.4 & $3 \times 10^{-3}$ \\
\hline PWR 1b & 2.5 & 0.5 & 25 & 520 & $1 \times 10^{-6}$ & 0.9 & $6 \times 10^{-3}$ & 0.7 & 0.4 & 0.4 & 0.05 & 0.4 & $3 \times 10^{-3}$ \\
\hline PWR 2 & 2.5 & 0.5 & 0 & 170 & $1 \times 10^{-6}$ & 0.9 & $7 \times 10^{-3}$ & 0.7 & 0.5 & 0.3 & 0.06 & 0.02 & $4 \times 10^{-3}$ \\
\hline PWR 3 & 5.0 & 1.5 & 0 & 6 & $3 \times 10^{-6}$ & 0.8 & $6 \times 10^{-3}$ & 0.2 & 0.2 & 0.3 & 0.02 & 0.03 & $3 \times 10^{-3}$ \\
\hline PWR 4 & 2.0 & 3.0 & 0 & 1 & $3 \times 10^{-6}$ & 0.6 & $2 \times 10^{-3}$ & 0.09 & 0.04 & 0.03 & $5 \times 10^{-3}$ & $3 \times 10^{-3}$ & $4 \times 10^{-4}$ \\
\hline PWR 5 & 2.0 & 4.0 & 0 & 0.3 & $3 \times 10^{-6}$ & 0.3 & $2 \times 10^{-3}$ & 0.03 & $9 \times 10^{-3}$ & $5 \times 10^{-3}$ & $1 \times 10^{-3}$ & $6 \times 10^{-4}$ & $7 \times 10^{-5}$ \\
\hline PWR 6 & 12.0 & 10.0 & 0 & $\mathrm{~N} / \mathrm{A}$ & $2 \times 10^{-6}$ & 0.3 & $2 \times 10^{-3}$ & $8 \times 10^{-4}$ & $8 \times 10^{-4}$ & $1 \times 10^{-3}$ & $9 \times 10^{-5}$ & $7 \times 10^{-5}$ & $1 \times 10^{-5}$ \\
\hline PWR 7 & 10.0 & 10.0 & 0 & $\mathrm{~N} / \mathrm{A}$ & $2 \times 10^{-6}$ & $6 \times 10^{-3}$ & $2 \times 10^{-5}$ & $2 \times 10^{-5}$ & $1 \times 10^{-5}$ & $2 \times 10^{-5}$ & $1 \times 10^{-6}$ & $1 \times 10^{-6}$ & $2 \times 10^{-7}$ \\
\hline PWR 8 & 0.5 & 0.5 & 0 & $\mathrm{~N} / \mathrm{A}$ & $7 \times 10^{-6}$ & $2 \times 10^{-3}$ & $5 \times 10^{-6}$ & $1 \times 10^{-4}$ & $5 \times 10^{-4}$ & $1 \times 10^{-6}$ & $1 \times 10^{-8}$ & 0 & 0 \\
\hline PWR 9 & 0.5 & 0.5 & 0 & $\mathrm{~N} / \mathrm{A}$ & $7 \times 10^{-6}$ & $3 \times 10^{-6}$ & $7 \times 10^{-9}$ & $1 \times 10^{-7}$ & $6 \times 10^{-7}$ & $1 \times 10^{-9}$ & $1 \times 10^{-11}$ & 0 & 0 \\
\hline BWR 1 & 2.0 & 0.5 & 25 & 130 & $1 \times 10^{-6}$ & 1.0 & $7 \times 10^{-3}$ & 0.40 & 0.40 & 0.70 & 0.05 & 0.5 & $5 \times 10^{-3}$ \\
\hline BWR 2 & 30.0 & 3.0 & 0 & 30 & $1 \times 10^{-6}$ & 1.0 & $7 \times 10^{-3}$ & 0.90 & 0.50 & 0.30 & 0.10 & 0.03 & $4 \times 10^{-3}$ \\
\hline BWR 3 & 30.0 & 3.0 & 25 & 20 & $2 \times 10^{-6}$ & 1.0 & $7 \times 10^{-3}$ & 0.10 & 0.10 & 0.30 & 0.01 & 0.02 & $4 \times 10^{-3}$ \\
\hline BWR 4 & 5.0 & 2.0 & 25 & $\mathrm{~N} / \mathrm{A}$ & $4 \times 10^{-6}$ & 0.6 & $7 \times 10^{-4}$ & $8 \times 10^{-4}$ & $5 \times 10^{-3}$ & $4 \times 10^{-3}$ & $6 \times 10^{-4}$ & $6 \times 10^{-4}$ & $1 \times 10^{-4}$ \\
\hline BWR 5 & 3.5 & 5.0 & 150 & $\mathrm{~N} / \mathrm{A}$ & $2 \times 10^{-6}$ & $5 \times 10^{-4}$ & $2 \times 10^{-9}$ & $6 \times 10^{-11}$ & $4 \times 10^{-9}$ & $8 \times 10^{-12}$ & $8 \times 10^{-14}$ & 0 & 0 \\
\hline
\end{tabular}

(a) See Appendix B, "Atmospheric Dispersion Assumptions and Parameter Selections for PWR Consequence Analysis."

(b) Includes $\mathrm{Ru}, \mathrm{Rh}$, Co, Mo, Tc.

(c) Includes $\mathrm{V}, \mathrm{La}, \mathrm{Zr}$, No, Ce, Pr, Nd, Np, Pu, Am, Cm. 
TABLE 5-6

MEDIAN 30-DAY INTEGRATED DOSE AT $2500 \mathrm{M}$

FOR PWR RELEASE CATEGORIES(a)

\begin{tabular}{c|c|c}
\hline $\begin{array}{l}\text { Release } \\
\text { Category }\end{array}$ & $\begin{array}{c}\text { Externa1 W.B. } \\
\text { (rem) }\end{array}$ & $\begin{array}{c}\text { Inhalation Thyroid } \\
\text { (rem) }\end{array}$ \\
\hline PWR-1a & $4.5+02$ & $9.9+04$ \\
PWR-1b & $1.5+02$ & $3.3+04$ \\
2 & $1.3+02$ & $3.3+04$ \\
3 & $1.7+02$ & $2.8+04$ \\
4 & $1.0+02$ & $1.3+04$ \\
5 & $4.2+01$ & $4.3+03$ \\
6 & $4.0+00$ & $6.6+01$ \\
7 & $9.9-02$ & $1.7+00$ \\
8 & $7.9-01$ & $3.5+01$ \\
9 & $1.1-03$ & $3.5-02$ \\
\hline
\end{tabular}

(a) See Appendix B, "Atmospheric Dispersion Assumptions and Parameter Selections for PWR Consequence Analysis." Values reported are for external dose and internal dose commitment from the plume exposure pathway. 


\subsubsection{Loss of Offsite Power (PWR)}

From Table 5-3, it can be seen that three transient sequences initiated by loss of offsite power (LOSP) contribute to the risk envelope for PWRs. These are designated $\operatorname{ThILB}-\alpha,-\delta$, and $-\varepsilon$. By reference to the event tree for this initiating fault in Fig. I4-11 of WASH-1400, it may be seen that this sequence is similar to LOSP Branch BD for the HTGR (see Volume IV of Ref. 5-2). The dominant PWR risk points from this initiator all arise from the same reactor accident sequence, TMB', with different containment failure modes: $\alpha$ - containment rupture due to steam explosion, $\delta$ - failure due to overpressurization, or $\varepsilon$ - containment melt-through. Detalls of these containment failure modes are provided in WASH-1400, Appendices I and $V$.

Using the probabilities from Table 5-3 and the dose values from Table 5-6 (also summarized in Table 5-7), the risk points for the whole body gamma dose associated with PWR-LOSP sequences are plotted in Fig. 5-13. For comparison, the figure also shows the LOSP risk points for the HTGR-VC. In this style of comparison where risk is the product of probability and consequence, the PWR risk is dominated by the point TMLB'- $\delta$ and exceeds that of the HTGR-VC sequences $1 \mathrm{BD}(\mathrm{VC})$ and $1 \mathrm{AZ}(\mathrm{VC})$. In a later section, cumulative distributions are employed to compare the risk between PWR and HTGR LOSP and other accident sequences.

\subsubsection{Large Loss-of-Coolant Accident (LOCA)}

The probabilities of the dominant large LOCA sequences from Table 5-7 were plotted against the corresponding consequences as shown in Fig. 5-14.

Sequence A in Fig. 5-14 represents the large pipe break in the PWR, followed by the successful response of engineered safety features (ESF), terminating in the release of primary coolant to the containment with a resulting small release (Category 9) of radioactivity to the environment. The probability of this event is estimated at $10^{-4}$ events per year. 
TABLE 5-7

SUMMARY: RISK FOR PWR ACCIDENT SEQUENCES

\begin{tabular}{|c|c|c|c|c|}
\hline \multirow[b]{2}{*}{$\begin{array}{l}\text { Initiating } \\
\text { Event }\end{array}$} & \multirow[b]{2}{*}{$\begin{array}{c}\text { Accident Sequence } \\
\text { Designator }\end{array}$} & \multirow[b]{2}{*}{$\begin{array}{l}\text { Probability } \\
\left(\mathrm{yr}^{-1}\right)\end{array}$} & \multicolumn{2}{|c|}{$\begin{array}{l}\text { Median 30-Day Dose } \\
\text { at } 2500 \mathrm{~m} \text { (rem) }\end{array}$} \\
\hline & & & $\begin{array}{l}\text { Whole Body } \\
\text { Gamma }\end{array}$ & $\begin{array}{c}\text { Inhalation } \\
\text { Thyroid }\end{array}$ \\
\hline $\begin{array}{l}\text { Loss of off- } \\
\text { site power } \\
\text { for greater } \\
\text { than } 30 \text { min } \\
\text { T__B' }\end{array}$ & $\begin{array}{l}\text { TMLB }-\alpha \\
\text { TMLB }-\delta \\
\text { TMLB }-\varepsilon\end{array}$ & $\begin{array}{lll}3 & \times 10^{-8} \\
2 & \times & 10^{-6} \\
6 & \times & 10^{-7}\end{array}$ & $\begin{array}{l}1.5 \times 10^{2} \\
1.3 \times 10^{2} \\
4.0 \times 10^{0}\end{array}$ & $\begin{array}{l}3.3 \times 10^{4} \\
3.3 \times 10^{4} \\
6.6 \times 10^{1}\end{array}$ \\
\hline $\begin{array}{l}\text { Large } \\
\text { LOCA, } \\
\text { A }\end{array}$ & $\begin{array}{l}\mathrm{AD}-\alpha \\
\mathrm{AD}-\varepsilon \\
\mathrm{A}\end{array}$ & $\begin{array}{lll}2 & \times & 10^{-8} \\
2 & \times & 10^{-6} \\
1 & \times & 10^{-4} \\
\end{array}$ & $\begin{array}{l}1.7 \times 10^{2} \\
9.9 \times 10^{-2} \\
1.1 \times 10^{-3}\end{array}$ & $\begin{array}{l}2.8 \times 10^{4} \\
1.7 \times 10^{0} \\
3.5 \times 10^{-2}\end{array}$ \\
\hline $\begin{array}{l}\text { Sma11 } \\
\text { LOCA, } \\
2 \text { in. - } \\
6 \text { in. } \\
\text { diameter, } \\
\mathrm{S}_{1} \text {.. }\end{array}$ & $\left.\begin{array}{l}S_{1} D-\alpha, S_{1} H-\alpha, \\
S_{1} F-\delta, s_{1} G-\delta \\
s_{1} D-\varepsilon, s_{1} H-\varepsilon\end{array}\right\}$ & $\begin{array}{l}\left(3 \times 10^{-8} \text { each }\right) \\
1.2 \times 10^{-7} \text { total } \\
\left(3.10^{-6} \text { each }\right) \\
6 \times 10^{-6} \text { total } \\
6 \times 10^{-7} \\
3 \times 10^{-4}\end{array}$ & $\begin{array}{l}1.7 \times 10^{2} \\
9.9 \times 10^{-2} \\
7.9 \times 10^{-1} \\
1.0 \times 10^{-3}\end{array}$ & $\begin{array}{l}2.8 \times 10^{4} \\
1.7 \times 10^{0} \\
3.3 \times 10^{1} \\
3.5 \times 10^{-2}\end{array}$ \\
\hline $\begin{array}{l}\text { Sma11 } \\
\text { LOCA, } \\
1 / 2 \text { in. - } \\
2 \text { in. } \\
\text { diameter, } \\
\mathrm{S}_{2}-\end{array}$ & $\begin{array}{l}S_{2} C-\alpha \\
S_{2} B-\gamma \\
S_{2} C-\delta \\
S_{2} D-\beta \\
S_{2} D-\varepsilon\end{array}$ & $\begin{array}{lll}2 & \times & 10^{-8} \\
1 & \times & 10^{-9} \\
2 & \times & 10^{-6} \\
2 & \times & 10^{-8} \\
9 & \times & 10^{-6}\end{array}$ & $\begin{array}{l}1.5 \times 10^{2} \\
1.3 \times 10^{2} \\
1.7 \times 10^{2} \\
4.2 \times 10^{1} \\
9.9 \times 10^{-2}\end{array}$ & $\begin{array}{l}3.3 \times 10^{4} \\
3.3 \times 10^{4} \\
2.8 \times 10^{4} \\
4.3 \times 10^{3} \\
1.7 \times 10^{3}\end{array}$ \\
\hline
\end{tabular}




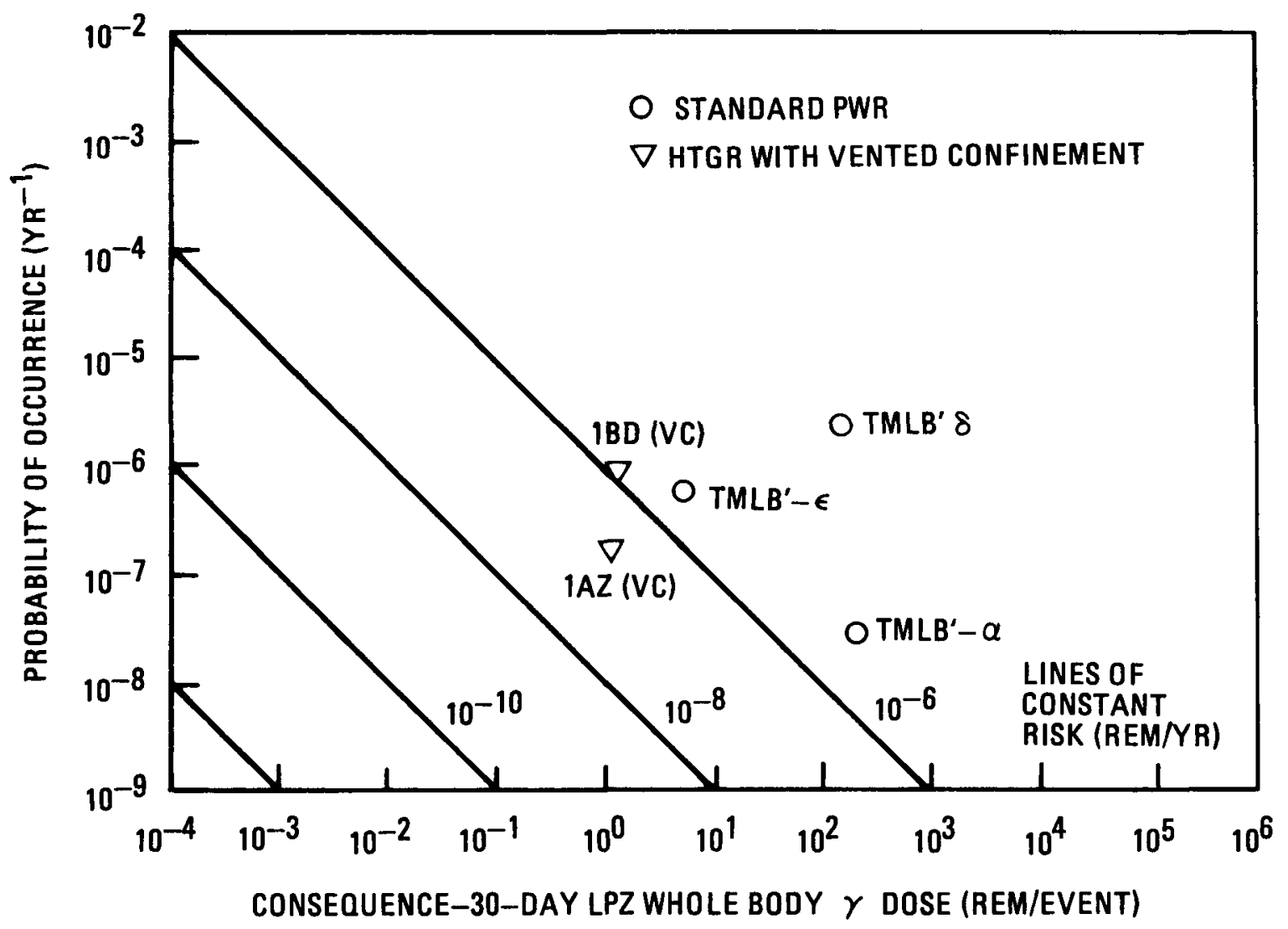

Fig. 5-13. Risk plot for loss of offsite power for PWR 


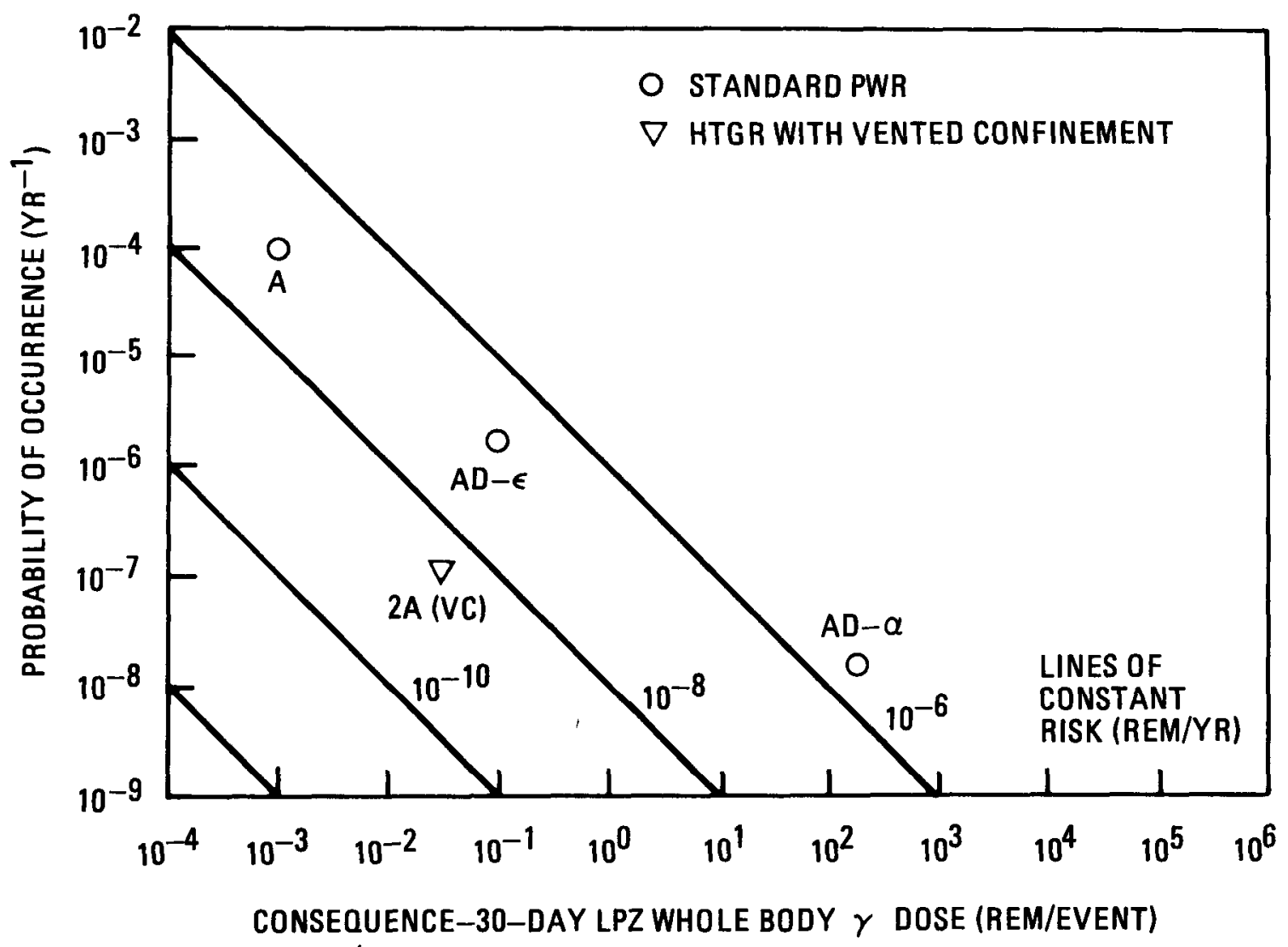

Fig. 5-14. Risk plot for large LOCA event for PWR 
Sequence $A D-E$ represents a large pipe break, followed by failure of the emergency core cooling system, leading to core melt through the containment floor. The severity of this event is diminished by the preservation of the integrity of the containment dome and attenuation of the fission products in the soil. Additional details can be found in the RSS.

As explained in the RSS, some of the failures of the emergency core cooling system which lead to the core melt may result in the destruction of the LWR containment from steam explosions, hydrogen burning, overpressurization, or melt-through. These events are represented by sequences AD- $\alpha$ (large LOCA, failure of emergency core cooling injections system, reactor vessel steam explosions), $\mathrm{AB}-\gamma$ (large LOCA, failure of electric power to ESFs, hydrogen burning in the containment), and AF- $\alpha$ (large LOCA, failure of spray recirculation system, reactor vessel steam explosions). These sequences represent a potential for large dose but the probability of their occurrence is small, i.e., of the order of $10^{-8}$ to $10^{-10}$ events per reactor year. Since this report includes only sequences with probability greater than $10^{-9} \mathrm{yr}^{-1}, A B-\gamma$ does not appear in Fig. 5-14.

By comparison with the point $2 \mathrm{~A}(\mathrm{VC})$, also shown in Fig. 5-14, it appears that the median value risk associated with whole body gamma doses of PWR major pipe ruptures exceeds that of the HTGR with vented confinement. These events are compared further with respect to cumulative distributions for both whole body gamma and inhalation thyroid doses in a later section.

5.2.5. Small LOCA $S_{1}$ (2- to 6-in.-Diameter Break)

As noted in Table 5-3, the RSS presents two categories of small LOCA in the list of dominant sequences. Category $S_{1}$ includes breaks in the range of 2 to 6 in. diameter. This initiating event category can lead to core melt sequence. The probabilities for $S_{1}$ sequences from $T a b l e ~ 5-7$ were plotted against the corresponding whole body gamma doses as shown in Fig. 5-15. For comparison, the risk points for HTGR-VC spurious relief valve 


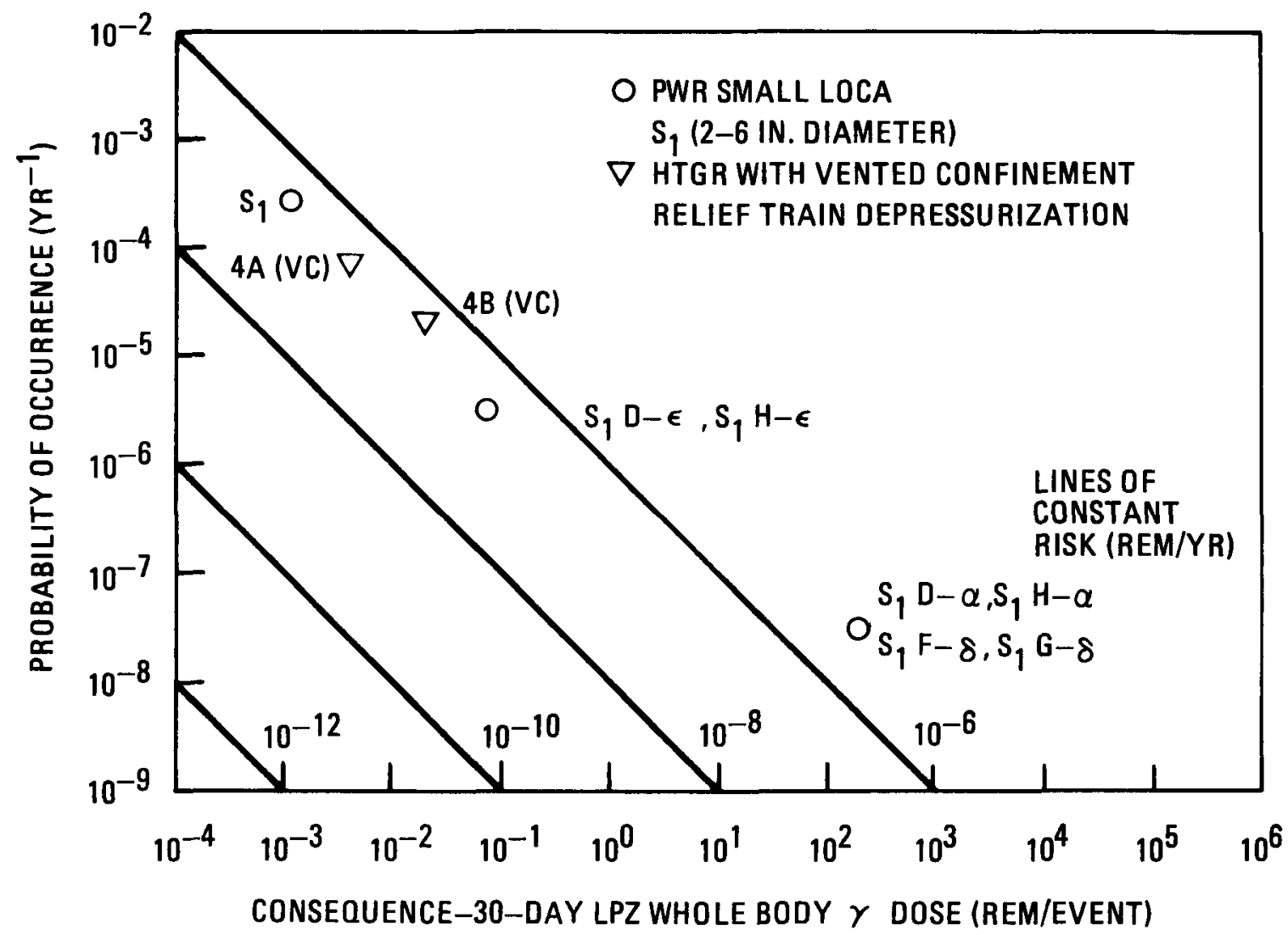

Fig. 5-15. Risk plot for PWR $\mathrm{S}_{1}$ LOCA event (2 in. -6 in. diameter) 
depressurization sequences are shown in Fig. 5-15. The latter results in a depressurization area of about $20 \mathrm{sq}$ in., which is in the same area range as the PWR events LOCA $S_{1}$. As detailed in the RSS, the dominant PWR sequences result from failure of the engineered safety features and subsequent failure of the conventional containment.

As seen in Fig. 5-15, the respective envelopes of median value risk for small to intermediate breaks in the primary coolant system for the HTGR-VC and PWR appear to be similar in the low consequence range. In the higher consequence range, the HTGR appears to afford a lower risk since the high consequence HTGR-VC core heatup sequence $4 \mathrm{E}$ (VC) has a probability of less than $10^{-9} \mathrm{yr}^{-1}$. Further risk comparisons for these events are described in Section 5.3.

\subsubsection{Small LOCA S 2 (1/2- to 2-in.-Diameter Break)}

The final category of dominant sequences in the RSS is the sma11 LOCA $\mathrm{S}_{2}$. The plot of probability versus whole body gamma dose from Table 5-7 results is shown in Fig. 5-16. The highest risk sequence is seen to be $\mathrm{S}_{2} \mathrm{C}-\delta$, which results when failure of the containment spray follows the small LOCA. The containment failure is consequential to this loss of containment cooling.

For comparison, the median point risks for slow depressurization sequences for the HTGR-VC (break areas of up to $1 \mathrm{sq}$ in.) are also shown in Fig. 5-16. This comparison indicates that the representative PWR and HTGRVC risk envelopes for small breaks in the primary coolant system are comparable in the low consequence range. In the high consequence range, no HTGR-VC sequence has a high enough probability to appear in the figure. Further comparisons for these events are provided in Section 5.3 in terms of cumulative distribution for whole body gamma and inhalation thyroid doses. 


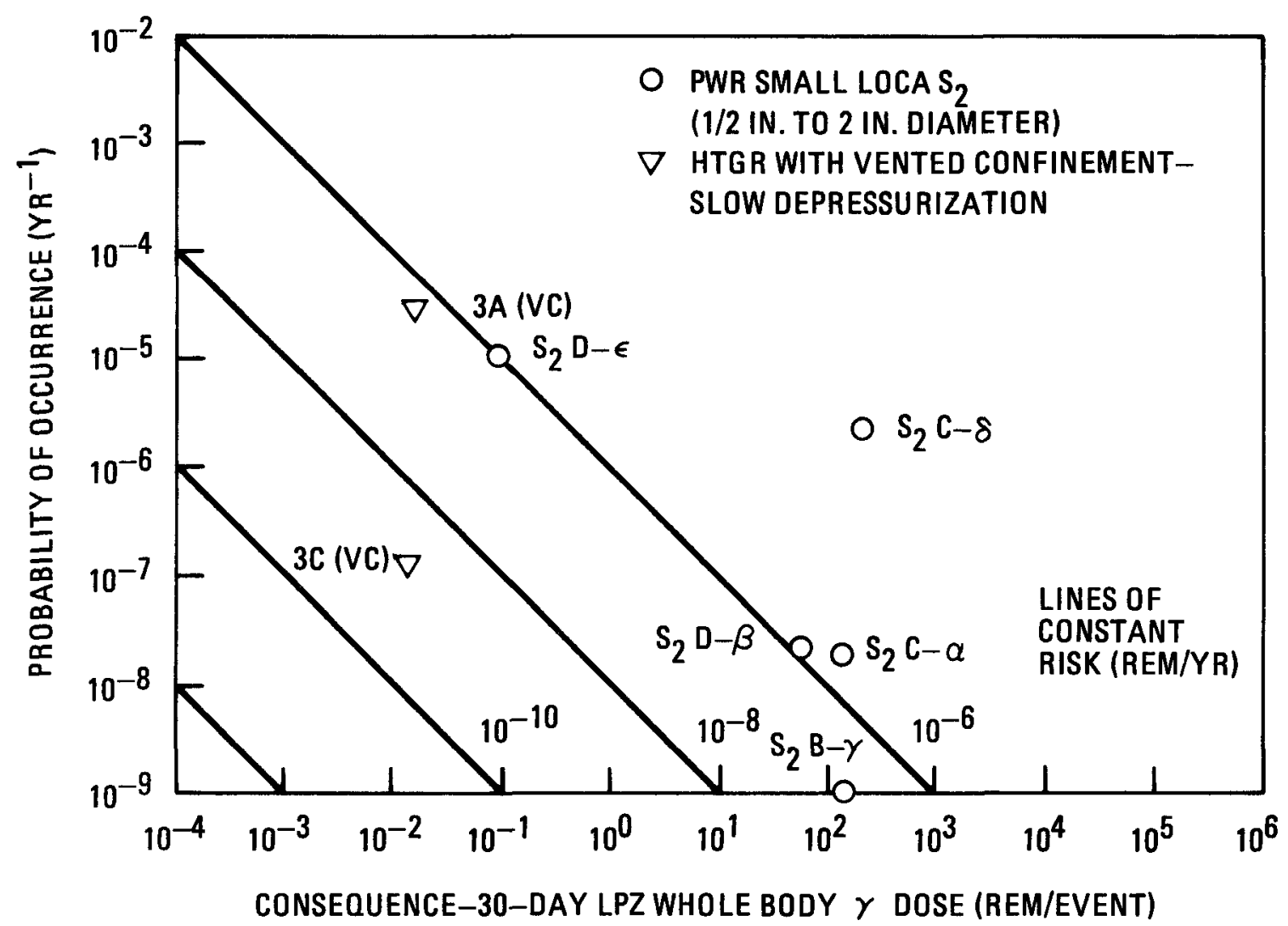

Fig. 5-16. Risk plot for PWR $S_{2}$ LOCA event $(1 / 2$ in. -2 in. diameter $)$ 
5.3. COMPARISON OF RISKS FOR HTGR-VC AND PWR WITH CONVENTIONAL CONTAINMENT

As previously stated, an objective of Section 5 is to evaluate the acceptability of the HTGR-VC. In the absence of an absolute standard of acceptable risk for probabilistic evaluation, acceptability of the risk is to be inferred by comparison with risk associated with a representative PWR as evaluated in the RSS. The previous section provided some comparison in presenting the whole body gamma dose median point value risk for the individual initiating events which comprise the dominant risk sequences for the PWR. In this section, a more comprehensive risk comparison is made, which includes ( 1 ) overall median point value risk $(\mathrm{P}-\mathrm{C})$ plots for dominant sequences previously developed based on whole body gamma dose only, and (2) complementary cumulative risk curves for both whole body gamma and inhalation thyroid doses. The latter take into account the uncertainties associated with the consequence evaluation as discussed in Appendix A. The cumulative curves were derived individually for each event sequence using the LATCHE code (see Volume VIII of Ref. 5-2) and then summing graphically to produce the desired summary envelopes.

\subsubsection{Median Value Risk Envelope Comparison}

The highest values of the median risk from whole body gamma dose are plotted in Fig. 5-17 for the sequence described in Sections 5.1 and 5.2. These points establish an overall median value risk envelope for the respective HTGR-VC and PWR plant designs. The results displayed in Fig. 5-17, which are based on detailed consideration of many initiating events and accident sequences for both plants, confirm that the preliminary comparison that provided motivation for this study is valid and that the risk associated with the HTGR-VC is within the risk envelope of a PWR with conventional containment. This is especially noticeable in the high consequence range where core heatup sequences in the HTGR are less consequential than core melt sequences in the PWR. In the low consequence ranges, which may in fact be dominated by "routine" releases not considered in this accident risk comparison, the accident-initiated risk envelopes for the respective reactor types are nearly equivalent. 
HIGH RISK ACCIDENT INITIATORS

$\begin{aligned} & \text { PWR } S_{1}- \\ & S_{2}- \text { LOCA }(2-6 \text { IN. DIAMETER) } \\ & \text { T--B' }- \text { LOSP } \\ & A- \text { LOCA INTERMEDIATE TO LARGE } \\ & \text { HTGR (VC) } 1-2 \text { IN. DIAMETER) } \\ & 3-\text { LOSP } \\ & 4-\text { SLOW DEPRESSURIZATION } \\ & 4 \text { RELIEF TRAIN DEPRESSURIZATION }\end{aligned}$

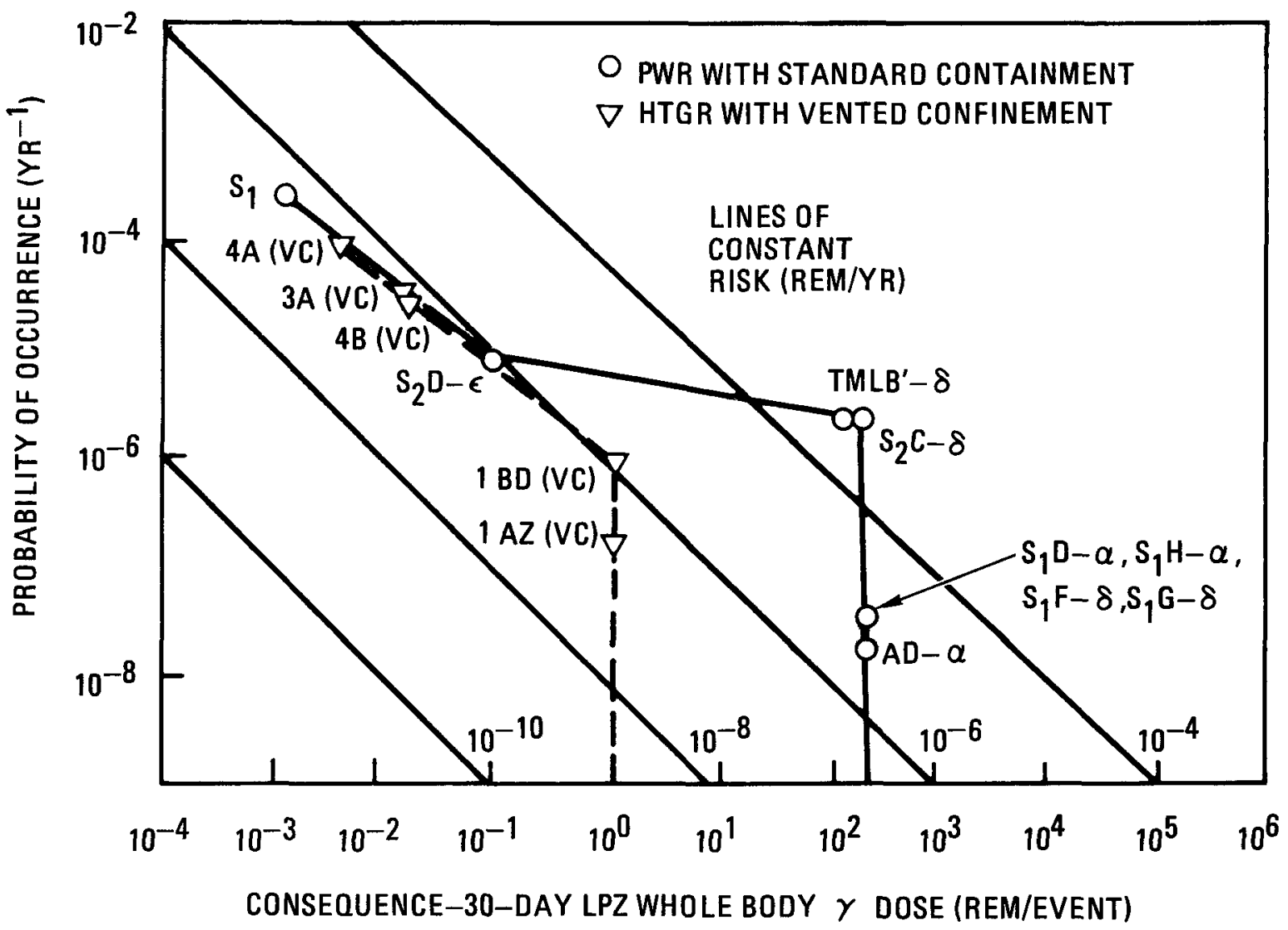

Fig. 5-17. Risk summary comparison of dominant sequences for PWR and HTGR with vented confinement 
Because of the dominance of just a few of the accident sequences, it is shown that the preliminary comparison, based solely on the highest risk core heatup sequence, provided a reasonably good picture of the impact of containment changes even before this more detailed study was undertaken. This suggests that in some cases, probabilistic risk assessments can be useful in scoping analysis to identify areas of concern prior to detailed analysis.

\subsubsection{Complementary Cumulative Distribution Curve Comparisons}

Previous sections dealt with the median, or most likely, probability and consequence associated with each accident sequence. When the uncertainties in consequences are considered, however, the major contributors to the risk envelope could change somewhat from the median value analysis already discussed. Variations about the median dose can arise in any of the sequences, because of the possible range of values for each variable affecting the dose, and their potential range of combinations. Examples causing such variations are: differences in weather prevailing at the time of the event, variability in the fission product content of the release, deviation in the timing and response of the engineered safety features, variability in fission product deposition in the PCRV or containment, etc., as described in Appendix A. Each of these variables is assessed statistically and combined to determine the overall uncertainty factor associated with a given dose calculation.

A risk envelope based on the variable uncertainty can be derived for each initiating event by combining statistically the probabilistic consequences of all the sequences arising from such an event. In principle, this envelope encompasses probabilistically the entire outcome range for a given event. The high consequence range probabilities are based on the most adverse combination of variables affecting the dose. The low consequence range probability then includes all consequence combinations. This type of probability-consequence plot is called a complementary cumulative 
distribution curve. The cumulative curves present the probability that a given dose level is exceeded due to a particular initiating event or combinations of selected initiating events.

Cumulative distribution curves for individual event sequences were generated for both the HTGR-VC and PIVR with the LATCHE code using the probabilities, consequences, and uncertainty data previously presented in Tables 5-1, 5-2, and 5-7 and in Appendix A. Summary cumulative curves for a given initiating event or for combinations of events were obtained by graphically summing over the cumulative curves for the correct mix of sequences. In practical applications of these concepts only the high probability events contribute significantly. Once the dominant sequences for each reactor type are included in an overall cumulative risk curve, less significant sequences have no practical influence on the magnitude of the curve.

In this study, the major consequence contributors to health effects, whole body gamma dose and inhalation thyroid dose, were calculated for a receptor at the $2500 \mathrm{~m}$ low population zone boundary integrated over the 30day period following an initiating event. The 30-day dose evaluations provide an appropriate comparison with respect to time for a variety of accidents because the time is long enough for the integrated dose level to reach an asymptotic value for accident sequences of both reactor types. While it is believed that consideration of only these consequences provides a meaningful risk comparison, the different isotopic mix in the HTGR compared to a PWR could result in dose to other organs being more limiting. Detailed evaluations of the HTGR-VC should consider doses to lungs, bones, etc., in addition to the thyroid and whole body gamma.

\subsubsection{Comparison of Accident Summary Curves. Cumulative distribution} curves for all HTGR-VC and PWR sequences having a probability greater than $10^{-9} \mathrm{yr}^{-1}$ were summed for respective whole body gamma and inhalation thyroid doses. The results are shown in Fig. 5-18 and represent bounding risk envelopes for the spectrum of accident sequences for the respective reactor types. 


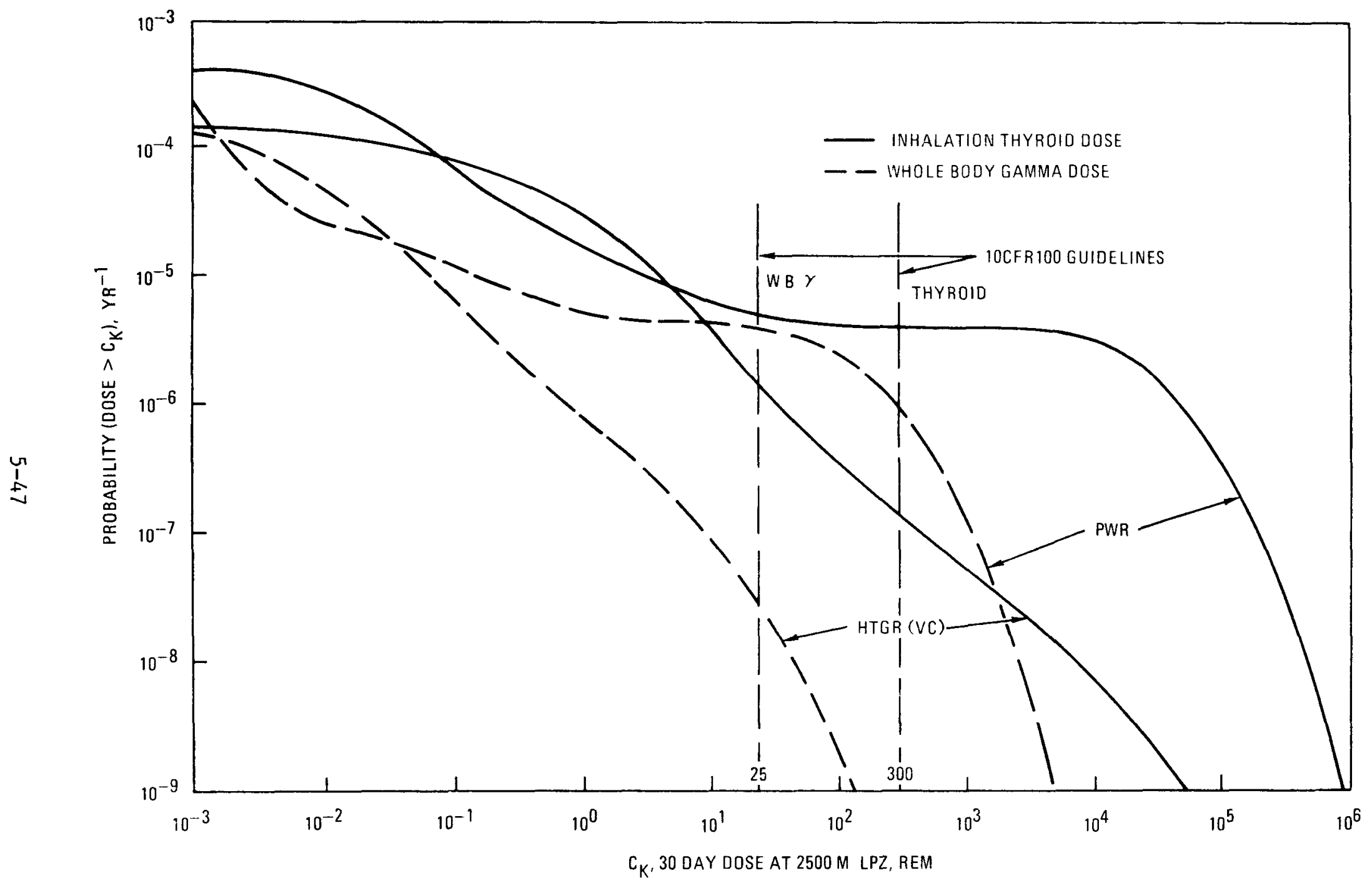

Fig. 5-18. Summary cumulative risk comparison between HTGR-VC and PWR with conventional containment 
From Fig. 5-18, it appears that the HTGR-VC poses a lower risk than the PWR evaluated in the RSS over most of the range of consequences. In the high consequence range, the HTGR-VC has a decided advantage, reflecting the relative effects of core heatup for the HTGR as opposed to core meltdown sequences for the PWR. In the intermediate dose range, both systems display comparable risk with a slight advantage going to the PWR in this range, the magnitude being similar to the variations between the PWR and $B W R$ as presented in the RSS. In the low consequence range where the accident-initiated releases become less than routine emissions and background levels, the comparison becomes academic.

From the overall comparison provided by Fig. 5-18, it is concluded that the risk afforded by the HTGR-VC would appear to be acceptable and that the vented confinement is a viable design option for the HTGR.

For reference, the respective whole body and thyroid dose guidelines for reactor siting are shown in Fig. 5-18 and other cumulative distribution curves described below. These guidelines from 10CFR100 (Ref. 5-5) are used in licensing procedures to establish the outer boundary of the lowpopulation zone (LPZ). Showing the guideline values is intended to add perspective only to the evaluation presented here since the 10CFR100 guidelines are employed to evaluate conservative deterministic dose assessments. Such licensing assessments assume conservative fission product inventories, conservative containment leak rates, adverse weather, etc. Therefore, a direct comparison of the siting guidelines with PRA results, which are based on best-estimate parameters with some allowance for uncertainties, may be inappropriate. However, regulatory guidelines that are more appropriate for PRA comparison have not been established. Nevertheless, it is noted from Fig. 5-18 that the probability of exceeding the whole body dose siting guideline is less than $10^{-7} \mathrm{yr}^{-1}$ for the HTGR-VC and less than $10^{-5} \mathrm{yr}^{-1}$ for the PWR. Similarly, the probability of exceeding the thyroid dose guideline is about $10^{-7} \mathrm{yr}^{-1}$ for the HTGR-VC and less than $10^{-5} \mathrm{yr}^{-1}$ for the PWR. The PWR probabilities appear to be in general agreement with similar evaluations performed by others (Ref. 5-6). 
This comparison of nverall risk on the basis of cumulative distributions forms the basis for the main conclusions of the present study. In the following, cumulative distribution curves for the important contributing classes of accidents of the two reactor systems are compared to provide better understanding of the differences in safety characteristics for the two systems.

5.3.2.2. Loss of Offsite Power (LOSP). Both the HTGR-VC and the PWR are subject to high potential for core damage sequences initiated by loss of offsite porfer (LOSP). The respective cumulative distributions for LOSP were generated for each of the important sequences presented in Tables 5-1, 5-2, and 5-7 and then summed to form Fig. 5-19. From this figure, it appears that the HTGR-VC demonstrates a lower risk for LOSP events over the entire range of consequences. The following description of the respective LOSP sequences provides some insight into the advantage displayed by the HTGR-VC.

1. Many of the core melt sequences in the PWR also have a high probability of containment failure; thus, the presence of the failed containment does little to mitigate the event consequence. Since the containment failure probability is greatest at the time of a core melt, the containment does not always exhibit a leak rate equivalent to that assumed for licensing calculations. This results in a plateau at $2 \times 10^{-6} \mathrm{yr}^{-1}$ in the PWR curve, which corresponds to the probability of core melt.

2. For the HTGR unrestricted core heatup, which is the event most comparable to PWR core melt, the release of fission products from the fuel is significantly delayed by the large thermal capacity of the core, which delays fuel failure from excessive temperatures, thus allowing fission product decay prior to release.

3. Unlike PWRs, where the core melt is accompanied by steam and water reactions supplying energetic processes for fission product 


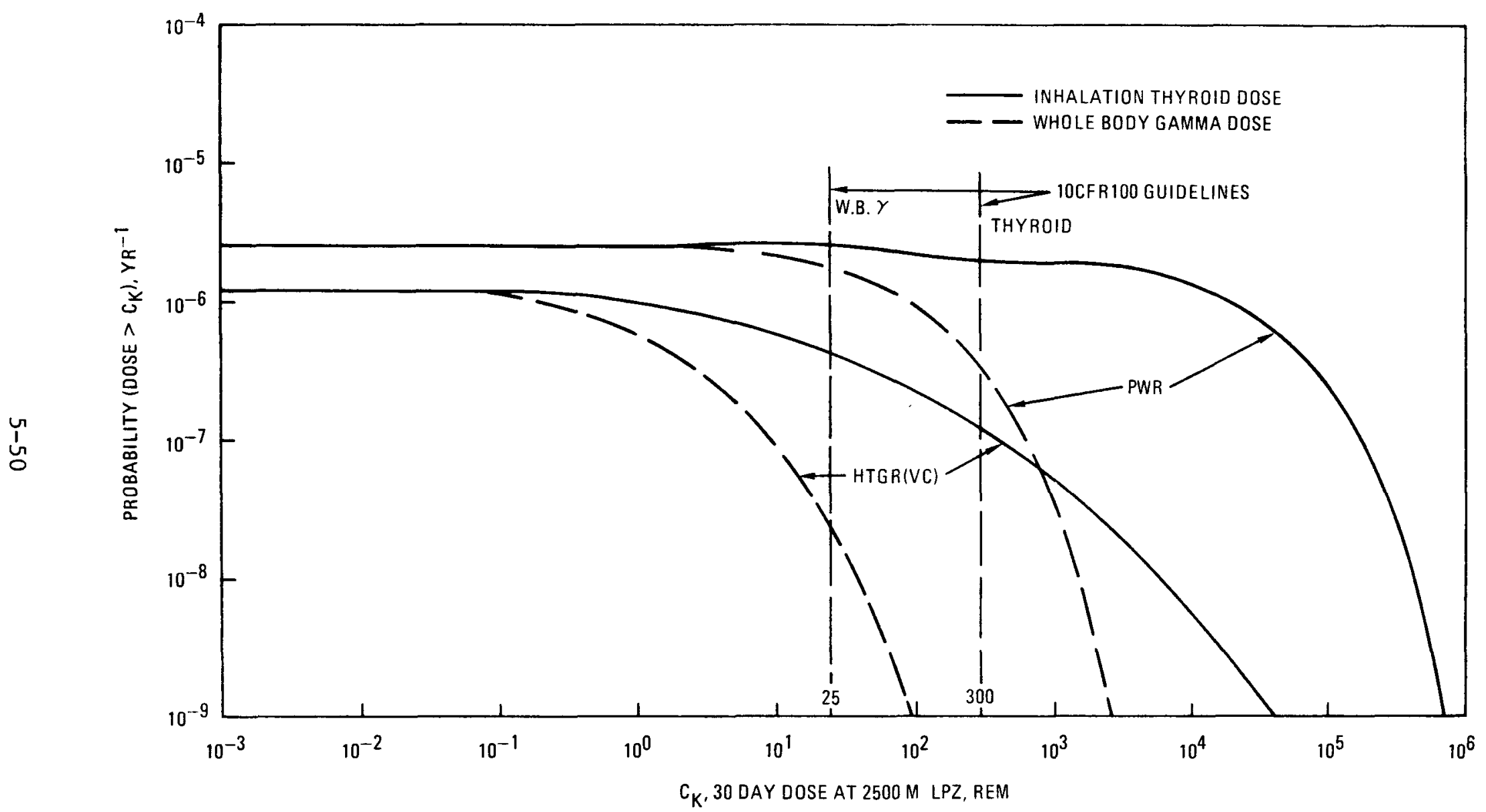

Fig. 5-19, Loss of offsite power transients: cumulative risk comparison between HTGR-VC and PWR with conventional containment. 
dispersion, the HTGR core heatup is a relatively quiescent process in which the release of primary coolant from the PCRV occurs at a finite rate. Th1s process allows a large degree of plateout of radionuclides in the $\mathrm{PCRV}$, further reducing the magnitude of release.

For more discussion of the phenomena associated with the respective PWR and HTGR accident sequences, the reader is referred to WASH-1400 (Ref. 5-1) and the AIPA Status Report (Ref. 5-2), respectively.

In addition to being inftiated by LOSP, core heatup sequences can also result from reactor depressurization events. These events result in the high consequence parts of the cumulative distribution curves for such events as discussed below.

5.3.2.3. Primary Coolant System Depressurization Events. The respective cumulative distribution curves were generated for each reactor type for all depressurization sequences listed in Tables 5-1,5-2, and 5-7 and then summed to form Fig. 5-20. These curves are of comparative interest because they represent the cumulative risk from the entire range of typical lossof-coolant events in the PIJR and depressurization events in the HTGR-VC.

For the PWR, the events include the entire range from small pipe breaks of $1 / 2 \mathrm{sq} \mathrm{in}$. up to the large LOCA. It is found that the $\mathrm{S}_{1}$ and $\mathrm{S}_{2}$ small LOCAs dominate the cumulative risk curve for the PWR. This indicates that the attention devoted to the design basis event (large LOCA) and provision for engineered safety features to mitigate some potentially high risk sequences have been successful. In fact, the contribution of the large LOCA to the overal1 LOCA cumulative risk curves is insignificant.

For the HTGR-VC, the initiating events include the range of depressurization area from 1 to $100 \mathrm{sq}$ in. Such failures result in a loss of primary coolant to the confinement building. For the purpose of this study, the confinement release rate to the atmosphere was assumed to be essentially instantaneous, thus reducing the chance for decay or plateout in the 


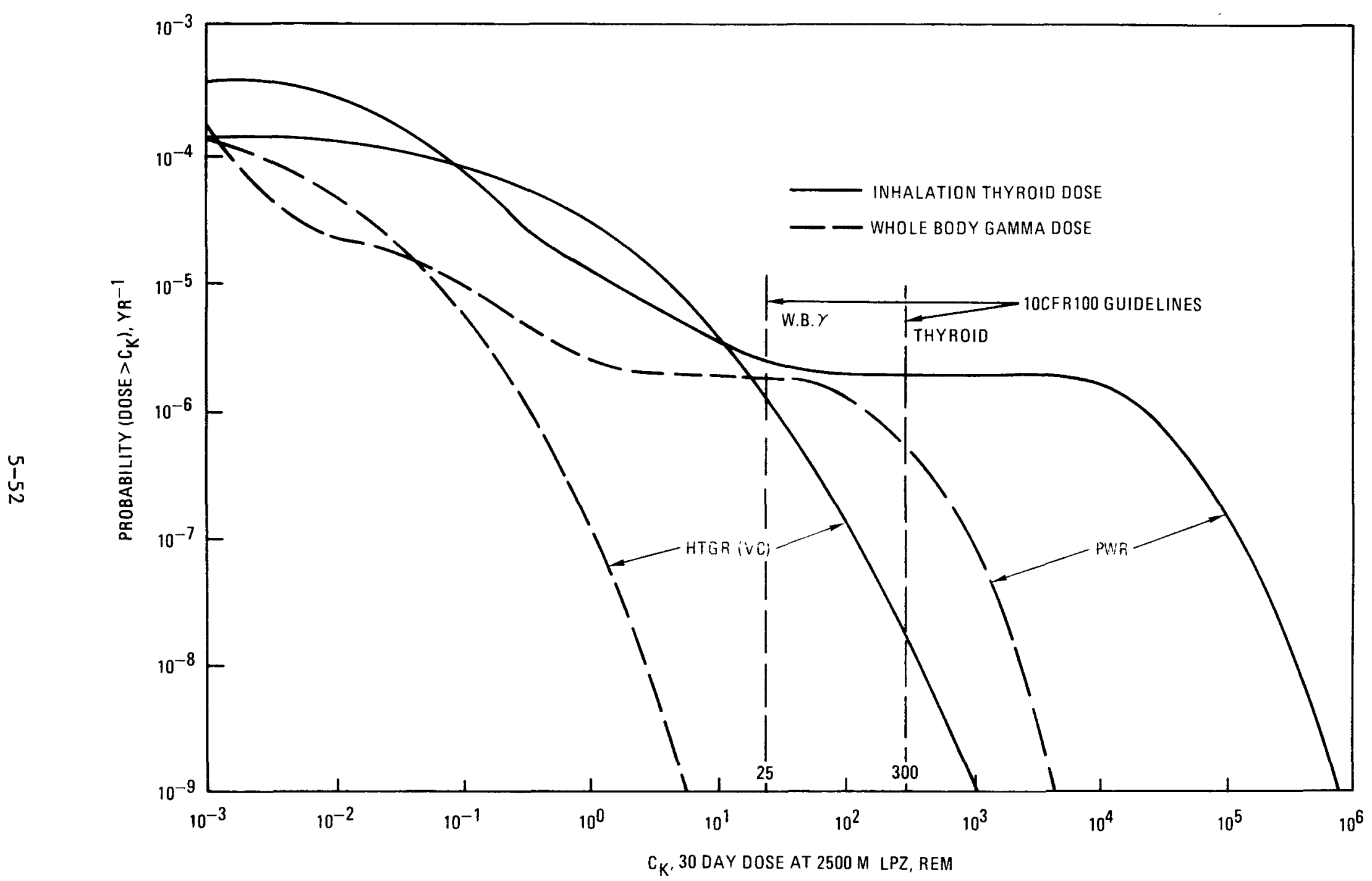

Fig. 5-20. Spectrum of primary coolant system depressurization events: cumulative risk comparison between HTGR-VC and PWR with conventional containment 
confinement building. The model, therefore, is somewhat conservative in the calculation of primary coolant activity release. This assumption is consistent with the initial objective of providing minimal confinement outside the PCRV. It is of interest to note that the risk from the design basis event in the HTGR-VC, as in the PWR, is also insignificant with respect to the risk from the other depressurization events.

From Fig. 5-20, it is observed that in the high consequence range which results from depressurization-initiated core heatup sequences, the HTGR-VC demonstrates lower risk than the PWR for reasons discussed in Section 5.3.2.2. In the intermediate thyroid dose range and low whole body gamma dose range, the HTGR-VC and PWR risk curves are comparable. It should be noted that for the HTGR-VC, the high consequence contribution of the depressurization events to the overall cumulative distribution curves is comparable to that from LOSP sequences.

5.3.2.4. Design Basis Events. Cumulative distribution curves were generated for the PWR AND HTGR-VC design basis events: large LOCA and 100-sqin. rapid depressurization, respectively. The risks associated with these events are compared on a probabilistic basis because of the interest in these events from a licensing viewpoint. From the results shown in Fig. 5-21, it may be observed by comparison with Figs. 5-19 and 5-20 that the cumulative risk from design basis events in both plant designs is much less than that from other representative sequences. For the HTGR-VC, the design basis event is insignificant with respect to other depressurization events.

The PWR risk curves in Fig. 5-21 represent in principle the limit of the 30-day dose at the LPZ which may result from any combination of events following the occurrence of LOCA. At the low consequence end of the scale are the events initiated by a large pipe failure that are terminated successfully by the ESFs. They result in the release of primary coolant to the containment and a small consequence. However, the probability that this low dose is exceeded is approximately $10^{-4}$. Much more severe consequences can result if the ESFs fail, leading to the possibility of core 


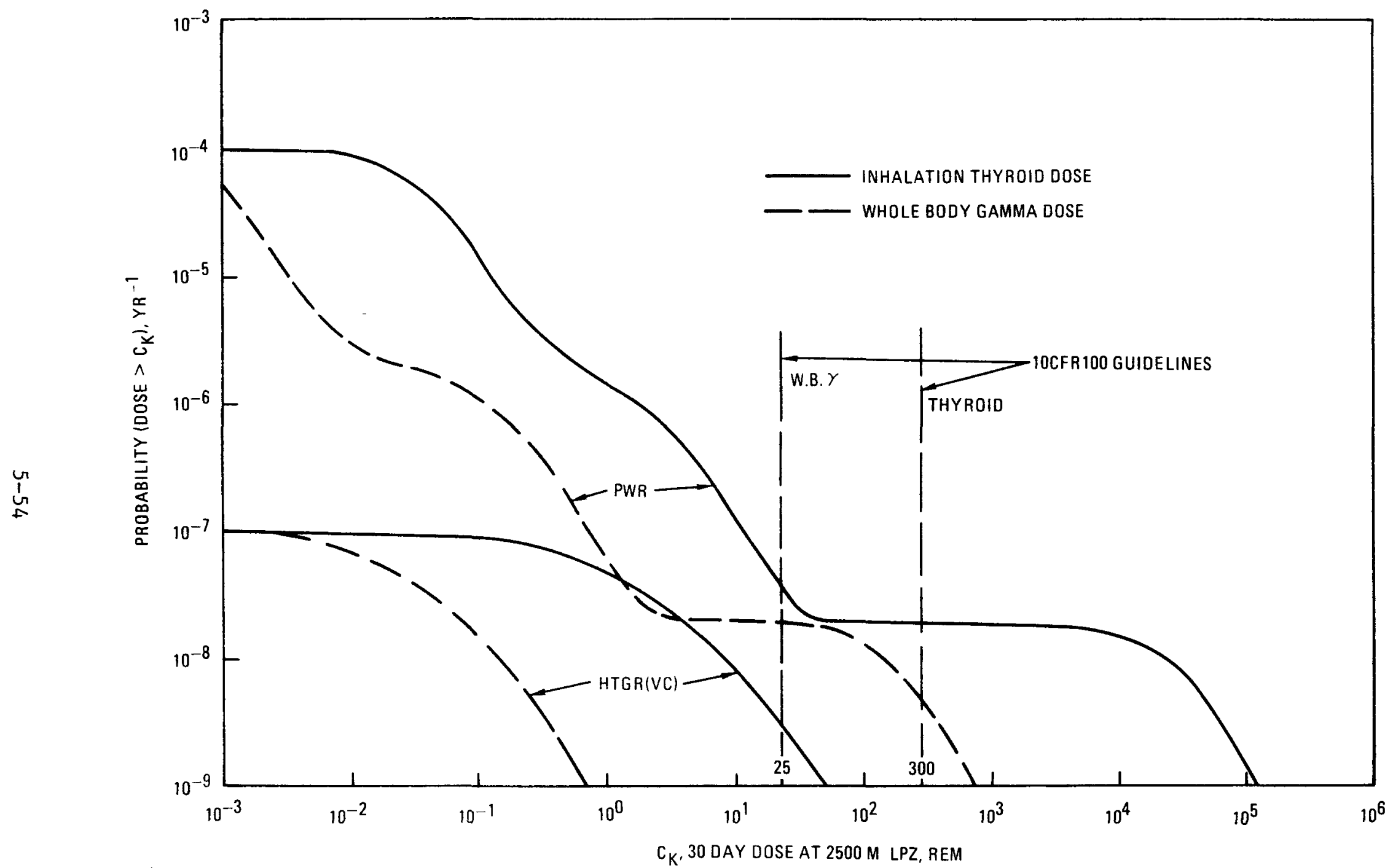

Fig. 5-21. Design basis events: cumulative risk comparison between HTGR-VC and PWR with conventional containment 
melt and containment failure. In combination with unfavorable weather, these can exceed even the PWR Release Category 1 (Ref. 5-2) consequences, although at a very low probability.

The HTGR-VC curves in Fig. 5-21 show similar data for rapid depressurization. A very low consequence $\left(\sim 10^{-2}\right.$ rem) would result from this accident if it occurred with low activity level in the primary coolant and was terminated by the successful reactor shutdown and core cooldown. However, a failure of the CACS to provide forced core cooling would initiate an unrestricted core heatup. If subsequent forced circulation was not restored within 2 to $3 \mathrm{hr}$, fission product release from the fuel and transport to the environment could result in an increase in the level of consequences. The probability of this sequence initiated by a depressurization event is very remote and less than the $10^{-9} \mathrm{yr}^{-1}$ threshold imposed in this study.

\subsection{SUROARY OF PROBABILISTIC RISK ASSESSIENT}

The objective of probabilistic risk assessment is not only to improve the appreciation of the various facets of reactor safety, but also to attempt to quantify a lack of precise knowledge of parameters and sequences affecting risk. Hence, the use of uncertainty ranges in the cumulative distribution curve tends to quantify probabilistically this lack of precise understanding. The results presented in the previous sections show how this methodology can be applied to a practical comparative problem. As a result of these comparisons, the reactor design concepts can be reviewed with respect to their safety implications in a quantitative manner rather than by qualitative judgments. In this regard, the present study affords the following observations:

1. The radiological risk from an HTGR with vented confinement appears to be less than that from a representative PWR with conventional containment for high consequence events and comparable for lower consequences. Similar risk comparisons appear 
to hold for efther whole body gama or Inhalation thyroid doses and in both risk evaluation formats: median point value plots $(P \times C)$ or cumulative distribution curves.

2. Because of the similarity in risk for the PWR and BWR shown in WASH-1400, Volume VI, it is inferred that observation 1 would hold, by and large, for a comparison between the HTGR-VC and a BWR.

3. The advantage of an HTGR-VC system in the high consequence range, which is dominated by core heatup or core melt sequences for the respective reactors, may be explained mechanistically by the inherent safety features of the HTGR. These include (a) various aspects of the core design including the high core heat capacity, low power density, fuel element design, and the use of ceramic materials which maintain their integrity at high temperatures; (b) the low stored energy and inert properties of the helium coolant; and (c) to a lesser extent the PCRV. In the core heatup sequences, these inherent features provide for a time-delayed release of fission products from the core and a rather quiescent release of coolant from the PCRV, allowing additional holdup and plateout of fission products in the PCRV.

4. The highest risk event determined by probabilistic evaluation with best-estimate parameters for both HTGR-VC and PWR appear to be associated with sequences initiated by loss of offsite power and subsequent uncooled core heatups. Since the risk comparisons indicate that the risk from design basis accidents for both reactor types is insignificant compared to the risk from other events, it appears that real safety issues in terms of risk to the public could be more uniformly addressed through the use of probabilistic risk assessment in licensing. 
Assuming, therefore, that the risk envelopes for LWRs as evaluated in the RSS (Ref. 5-1) can serve as a reference level of acceptable risk, it appears from the probabilistic risk assessment presented here that the use of a vented confinement building is a viable design option for an HTGR plant.

REFERENCES

5-1. "The Reactor Safety Study -- An Assessment of Accident Risks in U.S. Commercial Nuclear Plants," USAEC Report WASH-1400, October 1975.

5-2. "HTGR Accident Initiation and Progression Analysis Status Report," ERDA Report GA-A13617, v. I-VII, General Atomic Company, October 1975 to February 1976.

5-3. Letter from R. P. Denise, Assistant Director for Special Projects, USNRC, to L. W. Caffey, Director, Clinch River Breeder Reactor Project office, May 6, 1976.

5-4. "Fulfillment of Milestone (a) Under Subtask G - Balanced Safety/ Economic Studies. Contract E(04-3)-167, Project Agreement 51, SU018," V. Joksimovic of General Atomic, letter to W. L. Walker, U. S. Energy Research and Development Administration, December 18, 1975 .

5-5. "Reactor Site Criteria," Code of Federal Regulations, Title 10, Part 100.

5-6. For example: Statement to California State Energy Resources Conservation and Development Commission by Ben C. Rusche, Director of the Office of Nuclear Reactor Regulation, USNRC, at San Diego, August 23, 1976. 
• 


\section{LICENSING CONSIDERATIONS}

In Section 5 of this report, best-estimate-type safety analyses were presented for the limiting case of vented confinement to demonstrate the actual effect that a nonconventional HTGR containment would have on the risk to the public. In this section, traditional licensing issues and deterministic safety analyses for the containment options are addressed to evaluate each option with respect to current licensing rules and regulations.

Section 6.1, "Historical Perspective for HTGR Containment Licensing," establishes the background for the present considerations via discussions of past HTGR containment provisions, the evolution and applicability of the general design criteria $(G D C)$, and the potential impact of probabilistic risk assessment on present licensing issues.

Section 6.2, "Seismic Design Considerations," discusses possible means to meet seismic requirements set forth in NRC regulations.

Section 6.3, "Licensing of Containment Options," addresses specific requirements for licensing of the various containment options within the current practices. Dose calculations for enveloping events are tabulated for each containment option.

Section 6.4, "Summary of Licensing Considerations," specifies the conclusions derived from this portion of the containment options study.

\subsection{HISTORICAL PERSPECTIVE FOR HTGR CONTAINMENT LICENSING}

When considering design features that differ from generally accepted concepts, licensability becomes a concern. For such cases, a study of 
precedents can provide significant insight. The evolution of HTGR containment and the evolution of some significant aspects of the AEC (NRC) licensing procedure have been studied to provide insight into the means and potential problems of licensing of nonconventional containment. The results of these studies are discussed below.

\subsubsection{Evolution of HTGR Containment Provisions}

The present consideration of HTGR containment options has been preceded by four interactions between General Atomic and the AEC or NRC, in which HTGR containment was accepted or proposed. First was the prototype Peach Bottom I plant, which incorporated a steel shell containment. This was followed by the Fort St. Vrain commercial-demonstration plant, which incorporated a reclosable vented confinement-type containment. These two actual plants were followed by the docketed applications for the Summit and Fulton plants, both of which proposed use of conventional containment. Finally, in March of 1975, General Atomic submitted a special licensing report for a 3800-1W (t) HTGR which proposed use of a vented, unlined containment. These containment provisions are sumarized in Table 6-1, which also lists the reasons for selection of the particular containment concept for each iteration. These reasons are discussed in more detail in the following paragraphs.

6.1.1.1. Peach Bottom I. The Peach Bottom HTGR was constructed with a steel shell containment building, for three basic reasons. First, the HTGR was an untested concept; prudent engineering judgment called for a high degree of protection. Secondly, except for the use of helium as the primary coolant, the Peach Bottom HTGR closely resembled a water-cooled reactor, and since LWRs specified leak-tight, steel shell containment at that time, the same was specified for Peach Bottom without regard to unique features of the HTGR. Third, the potential for air-graphite reactions following rupture of an external helium loop led to a requirement for containment inerting; a leak-tight containment was an essential part of the inerting engineered safety feature.

$6-2$ 
TABLE 6-1

EVOLUTION OF HTGR CONTAINMENT PROVISIONS

\begin{tabular}{|c|c|c|}
\hline HTGR Plant & Containment Concept & Reasons for Containment Selection \\
\hline Peach Bottom I & Steel shel1 containment & $\begin{array}{l}\text { 1) HTGR was new concept. } \\
\text { 2) LWR-type steel pressure vessel was } \\
\text { utilized. } \\
\text { 3) Inert containment atmosphere was required. }\end{array}$ \\
\hline Fort St. Vrain & Reclosable vented confinement & $\begin{array}{l}\text { 1) Steel-1ined prestressed concrete reactor } \\
\text { vessel (PCRV) was introduced. } \\
\text { 2) Double closures on PCRV penetrations } \\
\text { were incorporated. } \\
\text { 3) Remote site allowed acceptable doses for } \\
\text { 87-sq-in. design basis depressurization } \\
\text { accident (DBDA). } \\
\text { 4) Processing of siting event fission } \\
\text { products allowed acceptable doses. }\end{array}$ \\
\hline Summit/Fulton & Conventional containment & $\begin{array}{l}\text { 1) This was a licensing/marketing decision } \\
\text { based on: } \\
\text { a) ACRS generic approval was required for } \\
\text { marketing. } \\
\text { b) GA wanted to carry on1y a single design. } \\
\text { c) ACRS was unwilling at that time to } \\
\text { give site-independent approval for } \\
\text { nonconventional containment. }\end{array}$ \\
\hline Proposed $3800 \mathrm{MW}(\mathrm{t})$ & Reclosable vented, unlined containment & $\begin{array}{l}\text { 1) Mechanistic failure as basis for DBDA } \\
\text { was proposed } \\
\text { 2) Direct release of DBDA activity allowed } \\
\text { acceptable doses. } \\
\text { 3) For siting event, reclosing of contain- } \\
\text { ment allowed acceptable doses. }\end{array}$ \\
\hline
\end{tabular}


6.1.1.2. Fort St. Vrain. The Fort St. Vrain HTGR incorporated a major safety improvement over Peach Bottom and LWRs by use of a prestressed concrete reactor vessel (PCRV). This significant advance in reactor safety had earlier been recognized in the United Kingdom and Europe. Approval by the $\mathrm{AEC}$ of a reclosable vented confinement reactor building for Fort St. Vrain represented recognition of the remote site and moderate power level of Fort St. Vrain, and also represented, in part, acknowledgment of the safety significance of a PCRV. A leak-tight containment with containment inerting, as provided for Peach Bottom $I$, was not required for Fort St. Vrain because, for the integral arrangement of a PCRV, the potential for air-graphite reaction is greatly reduced. As an added safety measure, the prototype Fort St. Vrain PCRV incorporated double penetration closures and flow restrictors. In spite of these conservatisms, the AEC required analysis of the hypothetical sudden failure of both closures in any penetration. Acceptable doses for depressurization through an 87-sq-in. blowdown area were demonstrated for the remote Fort St. Vrain site, even without credit for processing by the effluent filtration system.

In addition, at the $\mathrm{AEC}^{\prime} \mathrm{s}$ request, to demonstrate site acceptability in accordance with 10CFR100, a time-delayed release of fission products which incorporated the release fractions of TID-14844 (Ref.6-1) was postulated ( $100 \%$ noble gases, $25 \%$ halogens, $1 \%$ particulates). Because of finite leakage of fission products from the PCRV and the processing of fission products through effluent filters, acceptable doses could be demonstrated. Both Peach Bottom I and Fort St. Vrain represent the regulatory precedents for recognition of time-delayed release of fission products for siting considerations for the HTGR.

6.1.1.3. Summit/Fulton. The next iteration in HTGR containment evolution was the Summit and Fulton applications, which were docketed in August 1973 and November 1973, respectively. However, the decision which resulted in specification of conventional containment for these two applications had been made in 1969. From January to September of 1969, several meetings took place involving GA, the $\mathrm{AEC}$, and the Advisory Committee on Reactor Safeguards (ACRS). Several containment alternatives were discussed, 
including conventional containment, vented containment, and a sealed reactor building with a water-seal vent to an evacuated containment. The intent of GA was to carry a single design that could be marketed throughout the country. To this end, generic approval by the ACRS of the large HTGR concept was being sought. However, the ACRS was reluctant to give siteindependent approval to a nonconventional containment. Thus, to meet the objective of HTGR marketability, GA ultimately agreed to a conventional containment. On September 3, 1969, GA indicated to the ACRS that a bid was being prepared based on a conventional contalnment, and on November 12 , 1969, the ACRS issued a letter that tentatively approved the large HTGR concept with conventional contalnment as described in Ref. 6-2. When the PSARs for Summit and Fulton were submitted, analysis of depressurization of the PCRV limited to 100-sq-in. blowdown area was included as a design basis depressurization accident (DBDA), in accordance with prior AEC concurrence. To demonstrate site acceptability, a source term was identified, consisting of the initial DBDA release plus a time-delayed release of the TID-14844 release fractions (Ref. 6-1). With a conventional containment, the resulting doses for these two events were shown to be small fractions of the 10CFR100 exposure guidelines. Whereas Fort St. Vrain incorporated all TRISO coated fuel particles, for the large HTGR with conventional containment it was possible to allow the use of BISO coated fuel particles (a single pyrolytic carbon ( $\mathrm{PyC}$ ) coating compared to multiple coatings of PyC/silicon carbide/PyC for TRISO particles) and still ensure adequate protection of the public. A tradeoff of one type of effective fission product retention (fuel particle coating) versus another (containment or confinement) was thus in evidence.

6.1.1.4. Proposed 3800-MW( $t$ ) HTGR. The most recent GA/NRC dialogue on HTGR containment took place in 1975 with the submittal by GA of a speclal licensing report (Ref.6-3). A containment which would allow venting of the DBDA activity was proposed on the basis that fallure of an ASME Section III, Class I, PCRV penetration closure would not be a design basis event. The direct release of activity resulting from mechanistic fallures was shown to be acceptable even without benefit of retention by the secondary contalnment. To satisfy 10CFR100.11 requirements for site evaluation, a 
hypothetical, nonmechanistic transfer of an appropriate fraction of fission product inventory to the containment building, which was assumed to leak at a finite rate, was assumed. For the TID-14844 release fractions, it was shown that for certain site conditions site acceptability could be demonstrated.

In its initial response to this report (Ref. 6-4), the NRC agreed that a containment liner was not essential:

"We agree that a containment building liner would not be necessary if it is established that the containment building will perform as designed and that the leak rate will not result in doses exceeding 10CFR Part 100 guidelines for the appropriate spectrum of postulated accidents. For any specific design, however, it would be necessary for us to establish by means of a detailed review that the Part 100 guidelines could be achieved with a satisfactory degree of margin."

While stating that a containment liner was not essential, the NRC responded negatively with respect to venting of the containment on the basis that GDC-16 makes it necessary to contain fission products escaping the primary coolant system boundary by means of "an essentially leak-tight barrier."

\subsubsection{Evolution of the General Design Criteria}

Today, in light of comparison of probabilistic data from the AIPA study (Ref. 6-5) and WASH-1400 (Ref. 6-6), it can be seen that venting of the HTGR containment would not result in public risk beyond presently accepted risks. The introduction to the general design criteria (10CFR50, Appendix A) states that the GDC merely "provide guidance" for other than water-cooled reactors. Thus, it seems that disallowing venting on the basis of GDC-16 is a case of applying LWR-derived rules to the HTGR without due consideration of the unique features of the HTGR. Indeed, several other criteria from the GDC have been shown in the past to be not applicable to the HTGR, and the NRC has agreed to their nonapplicability on the 
basis of unique HTGR features. For example, GDC-33 requires a safetyrelated reactor coolant makeup system, and GDC-38 requires a safety-related containment heat removal system. For the Summit and Fulton HTGR applications, the NRC agreed that these systems were not required.

This precedent regarding GDC-38 offers an interesting parallel. An LWR of a certain power level requires a containment heat removal system of a certain capacity, whereas HTGR containment heat removal requirements are much less demanding for a similar power level. Because of inherent differences between the reactors, the energy potentially releasable to containment is considerably less for the HTGR, and an active containment heat removal system is not required to adequately protect the public. The same is true for fission product release to containment. The amount of fission products potentially releasable to containment is considerably less for the HTGR, and, therefore, a containment system of lesser capability to retain fission products is sufficient to adequately protect the public.

To further define the applicability of the general design criteria to the HTGR, a study of the evolution of the criteria was undertaken. This study was expected to provide insight into the $\mathrm{AEC}$ intent in producing the GDC and GDC-16 in particular.

6.1.2.1. Iterations in GDC Development. The GDC evolved over a 5-1/2-year period from 1965 to 1971, during which three iterations took place. First, on November 22, 1965, proposed "General Design Criteria for Nuclear Power Plant Construction Permits" were informally distributed for comment via an AEC press release (denoted "iteration 1 " in the discussions that follow).

Comments and suggestions on the proposed criteria were received from the ACRS, from members of the industry, and from the public. Subsequently, on July 11, 1967, the Commission published in the Federal Register a notice that an amendment to 10CFR50 was being considered, which would add an Appendix A, "General Design Criteria for Nuclear Power Plant Construction 
Permits" (denoted "iteration 2" in the discussions that follow). By this means, the Commission formally published the GDC and invited interested persons to submit written comments or suggestions on the proposed Appendix A.

Finally, the comments and suggestions received in response to the above notice as well as subsequent developments in the technology and in the licensing process were considered in development of the final criterfa, which were published in the Federal Register on February 20, 1971 (36 F.R., 3255). This final Appendix A (denoted "iteration 3 " in the discussions that follow) became effective 90 days after publication in the Federal Register, and it remains virtually unchanged today.

6.1.2.2. Substantive Changes Taking Place in the Evolution Process. There is evidence of a distinct change in the intended applicability of the General Design Criteria between iteration 2 and iteration 3. For iteration 2 , the introduction states:

"These General Design Criteria are intended to be used as guidance in establishing the principal design criterla for a nuclear power plant." (Emphasis added.)

This was consistent with the introduction to iteration 1 , which stated:

"... they are intended to give interim guidance..."

However, in iteration 3 , the introduction states:

"These General Design Criteria establish minimum requirements for the principal design criteria for water-cooled nuclear power plants ... . The GDC are also considered to be generally applicable to other types of nuclear power units and are intended to provide guidance in establishing the principal design criteria for such other units." (Emphasis added.) 
This change in iteration 3 represents acknowledgment by the NRC (then $A E C)$ that other types of reactors are distinct from LWRs and may have different requirements. For LWRs, the GDC became more binding; 1.e., they became "minimum requirements." However, for other types of reactors, fundamental differences were acknowledged, conflrming that the GDC were "intended to provide guidance." For the HTGR, therefore, "guidance" has been the intent throughout the evolution of the criteria.

Further insight can be gained by examining the context in which the phrase "generally applicable to other types of nuclear power units," quoted above from iteration 3, was first published in iteration 1 . In the introductory paragraphs for iteration 1 it is stated:

"... they (GDC) reflect the predominating experience to date with water reactors, but most of them are generally applicable to other reactors as we11."

"... there may be Instances in which it can be demonstrated that one or more of the criteria need not be fulfilled. It should also be recognized that the application of these criterla to a specific design involves a considerable amount of engineering judgment."

The point to be emphasized here is that engineering judgment was to be relied upon to determine the applicability of the GDC to speciflc non-LWR designs, such as the HTGR. The situation is unchanged today; prudent engineering judgment must be applied to the evidence at hand to determine applicability of the GDC to the HTGR. Rigid adherence to the letter of specific criteria, which automatically equates LWR requirements to requirements for other designs, does not appear to represent prudent engineering judgment, and it seems to be in conflict with the underlying intent of the recurring phrase "generally applicable to other types of nuclear power units."

6.1.2.3. Changes Leading to GDC-16. In iteration 3, GDC-16 states in its final form that "... containment and associated systems shall be 
provided to establish an essentially leak-tight barrier ... ." It is useful to examine the criteria in iterations 1 and 2 which led to GDC-16. Iteration 1 contained no such explicit statement. However, the existence of containment was tacitly implied in Criteria 11,17, 18, and 19, which described properties and characteristics of containment. Criterion 19 of iteration 1 provides the clearest definition of the orfginal AEC intent for containment:

\footnotetext{
"The maximum integrated leakage from the containment under the conditions described in Criterion 17 above must meet the site exposure criteria set forth in 10CFR100."
}

Thus, if an applicant could meet the 10CFR100 exposure guidelines with any type of containment (or no containment), the intent of these criteria would still be met.

In iteration 2, the criteria for containment became more explicit. Criterion 10 stated:

\footnotetext{
"Containment shall be provided. The containment structure shall be designed to sustain the initial effects of gross equipment failures, such as a large coolant boundary break, without loss of required integrity and, together with other engineered safety features as may be necessary, to retain for as long as the situation requires the functional capability to protect the public."
}

The phrase "as long as the situation requires" implies the duration of an accident condition, and protection of the public is required for the duration. From 10CFR100, exposure guidelines adequate for protection of the public over the duration of an accident are established. Hence, as with the intent in iteration 1 discussed above, if an applicant could meet the 10CFR100 exposure guidelines with any type of containment, the intent of this criterion would be satisfied. 
In iteration 3, the containment criteria stiffened for LWRs. Now, instead of "... containment shall be provided ..." (1teration 2 words), the "essentially leak-tight barrier" concept was imposed. At the same time, the change from "guidance" to "minimum requirements" for LWRs took place. Over the 5-1/2-year period of the GDC evolution process, LWR safety issues were becoming defined, and it became clear that an "essentially leak-tight barrier" was required to assure LWR satisfaction of 10CFR100. The developments in the technology and in the licensing process which led to this conclusion were clearly LWR-oriented and do not seem to be rigidly applicable to the HTGR or other types of reactors. In fact, for the HTGR, the critical safety issues are still in the process of definition. If it can be shown that the HTGR can meet 10 CFR100 guidelines without state-of-the-art containment, then it seems that this fact should be evaluated on its own merit, not on LWR precedent. Such a process clearly falls within the guidance originally intended for non-LWRs.

6.1.2.4. Conclusions from Study of GDC Evolution. This study of GDC evolution confirms that the overall AEC intent in development of the general design criteria has apparently been protection of the public. The criteria were not intended to establish new requirements, but were intended to document and clarify existing LWR practice. Thus, the fact that the GDC underwent an evolution process indicates that crucial LWR safety issues were not in all cases completely clear-cut. A parallel evolution process would allow derivation of separate HTGR criteria for protection of the public based on HTGR features. In lieu of a complete evolution process, however, proper airing of the evidence concerning alternate means for HTGR protection of the public appears to be a reasonable compromise, enabling consideration of the HTGR on its own merits. When specifically applied to the containment issue, this conclusion indicates that a nonconventional containment for the HTGR should not be disregarded merely on the basis of any specific criterion from the GDC; the evidence supporting various containment concepts should be properly evaluated. Demonstration that 10CFR100 exposure guidelines can be met is one reasonable and proper basis for acceptability of these concepts. 


\subsubsection{Potential Impact of Probab1listic Risk Assessment on Licensing of Containment Options}

Presently, deterministic safety analysis is employed in licensing U.S. nuclear power plants. For deterministic safety analysis, initiating events are selected on the basis of precedent or on the basis that their probability of occurrence is assessed above a certain threshold and, hence, they are deemed credible. These events are designated design basis events and their consequences are conservatively assessed assuming a single failure in the plant response sequence. This approach leads to a recognized dichotomy in the licensing process: acceptable consequences must be demonstrated for credible events while noncredible events are not considered (Ref. 6-7). However, to satisfy the siting criteria of $10 \mathrm{CFR} 100.11$, a source term is identified "that would result in potential hazards not exceeded by those from any accident considered credible." This arbitrary division between credible and noncredible events and arbitrary destgnation of a large source term for siting considerations leads to several inconsistencies. Two of the major inconsistencies are the following:

1. While dose consequence analysis presented in Safety Analysis Reports demonstrates that the source term identified for the siting event can be accommodated without exceeding the 10CFR 100 exposure guidelines, probabilistic analysis of low probability event sequences which could approximate the siting event source term shows that 10CFR 100 exposure guidelines can in fact be exceeded at some frequency level (see Fig. 5-18).

2. Since design basis events for non-LWRs are often based on LWR precedents or are arbitrarily defined, subsequent probabilistic analysis may demonstrate that design basis events have been improperly defined. Such appears to be the case, for instance, for the HTGR design basis depressurization accident (DBDA). The probability of failure of a PCRV penetration closure is sufficiently low that, based upon LWR precedents, it should not be 
designated as a design basis event. (Further information on a proposed design basis for HTGR penetrations and closures is given in Ref. 6-8.)

Probabilistic risk assessment (PRA) lends itself to solution of problems such as these. First, PRA brings recognition of the fact that there are some low probability event sequences for which consequences may exceed the 10CFR100 exposure guidelines, yet acceptability may be justifiable on the basis of overall risk. Ultimately, as PRA works its way into the licensing procedure, limits of acceptability based on risk may be established for such event sequences. Second, even within the traditional licensing framework, PRA lends itself to proper designation of design basis events so that their selection can be unencumbered by improperly chosen precedents. This can lead to uniform and economically balanced response to safety concerns. Engineered safety features can be designed to respond to the real safety issues rather than being concentrated in areas of plant design which may not contribute to the overall risk. Third, since PRA can lead to proper definition of design basis events, the siting event, which is intended to envelope all credible events, can be better defined.

While probabilistic risk assessment has thus far gained only limited acceptance in the licensing procedures, use of probabilistic techniques is currently being expanded by the NRC staff. At the American Nuclear Society Winter Meeting in San Francisco on November 17, 1975, a paper prepared by representatives of the NRC stated (Ref. 6-9) that the probabilistic risk approach was not expected to develop as a licensing basis in the near future. However, the paper went on to state:

"We do believe, however, that probabilistic methods will be useful for providing overall perspective of the licensing process and for determining the relative importance of selected concerns."

This belief was reiterated in testimony of a staff member before the ACRS (Ref. 6-10): 
"... insights from the study (WASH-1400) and the applicability of the methodology will provide in some areas another tool that can be used in the regulatory process ..."

These stated beliefs have also been manifested in a recent official staff report (Ref. 6-11) as follows:

\begin{abstract}
"Probabilistic and reliability methods are used, where appropriate, as one of a number of techniques in safety evaluation ..."

"In some instances, probabilistic and reliability methods have been used to aid our engineering judgment. This has been done on those problems where adequate relevant data were available from which applicable statistical information could be derived... . The staff will continue to use and endorse the use of such information in guiding and assisting our licensing decisions."
\end{abstract}

These statements are germane to consideration of licensing of HTGR containment options when the following facts are considered. First, licensing of containment designs which would experience licensing difficulty under present 10CFR100 rules may be possible with eventual establishment of PRA standards. Second, on the surface it appears that resolution of inconsistencies involving acceptability of the traditionally defined siting event must await future development of these PRA standards. However, the root of the problem, which is the proper definition of both design basis events and the siting event, can currently be clarified by application of PRA techniques and data. Finally, for events which can be shown to be within the 10CFR100 exposure guidelines, the relative merit of various design options (e.g., containment) can be placed in proper perspective by PRA. This latter fact supports the conclusion developed in Section 6.1.2.4 that if 10CFR100 exposure guidelines can be met without state-ofthe-art containment, then a basis for acceptability of these alternative containment concepts is established. 


\subsection{SEISIIIC DESIGN CONSIDERATIONS}

In 10CFR 100 are defined "criteria which guide the Commission in its evaluation of the suitability of proposed sites for stationary power and testing reactors subject to Part $20 \ldots "$ Thus, it appears that $10 \mathrm{CFR} 100$ is generally intended to be applicable to all types of reactors, including the HTGR. In addition, the historical developments discussed in Section 6.1 provide a strong indication that current licensing of HTGR containment options would take place within the framework of the 10 CFR 100 guidelines.

One factor which is considered in $10 \mathrm{CFR} 100$ and which must be addressed for nonconventional containment is the seismic behavior of such containment during the safe shutdown earthquake (SSE). The SSE is defined in Section III of Appendix A to 10 CFR 100 as that earthquake for which systems necessary to assure "... the capability to prevent or mitlgate the consequences of accidents which could result in potential offsite exposures comparable to the guideline exposures ..." (and certain other systems) are designed to remain functional. Traditionally, the SSE is accomodated by designing structures, systems, and components to Seismic Category I requirements. lleans of accommodating the SSE for a nonconventional containment have been investigated, and the results are reported in the following subsections.

\subsubsection{Design to Seismic Category I}

The first means of accommodating the definition of the SSE for a nonconventional containment is to design the containment to withstand the SSE, i.e., to maintain the practice of making the containment Seismic Category I. Section III, Division 2, of the ASIE code defines rules for steel-lined concrete containment which ensure that the containment can withstand the SSE and still maintain leak-tight integrity. Design of a non-steel-lined concrete containment to Seismic Category I would require an approach consistent with the intent of Section III, Division 2. For conventional containment the liner is considered ductile with no seismic failure. For nonsteel-1ined containment, the design must compensate for the absence of the 
liner. This could be accomplished by designing the containment to remain elastic for all loading combinations.

\subsubsection{Two-Tier Leak Rate Approach}

The second potential means of accomodating the SSE is to propose a somewhat different interpretation for "remaining functional" through the SSE. If the leak rate is allowed to increase following the SSE, but only to an extent that the 10CFR 100 guidelines could still be met, then it could be said that the basic function of the containment (i.e., to limit the release of fission products) has been retained, and it has therefore "remained functional." In this two-tier approach, a design leak rate would be proposed, and a higher leak rate would be allowed following the SSE.

\subsection{3. "Site Suitability Source Term" Approach}

A third means of addressing SSE applicability to the containment is derived from close examination of the definition of the SSE and use of a methodology employed in the Clinch River Breeder Reactor (CRBR) plant PSAR (Ref. 6-12). In the original version of this PSAR, a "site suitability source term" appropriate for CRBR was derived by studying the credible accidents and choosing a source term which bounded all the credible accidents. In this methodology, the intent of 10 CFR 100 was believed to be met by demonstration that the postulated fission product release was not exceeded by any accident considered credible. By similar methodology, an enveloping source term appropriate for HTGR release to containment could possibly be defined for which containment would not be necessary to reduce doses below the 10CFR100 exposure guidelines. For such a condition, any building that would be provided for missile and weather protection of internal systems and components would not have to be Seismic Category I with respect to leak-tightness because it would not be required to assure "... the capability to prevent or mitigate the consequences of accidents which could result in potential offsite exposure comparable to the guideline exposures ..." 


\subsubsection{Consideration of Alternate Factors}

Some latitude in regard to a rigorous adherence to all provisions of 10CFR100 is allowed under the provision of 10CFR100.1(b), which states:

"Any applicant who believes that factors other than those set forth in this guide should be considered by the Commission will be expected to demonstrate the applicability and significance of such factors."

Therefore, a fourth possible means of addressing SSE applicability to the containment is to take advantage of this latitude and argue that a nonSeismic Category I containment should be allowed insofar as leak-tightness is concerned on the basis of unique features of the HTGR. The unique features and the safety benefit they afford can be demonstrated through a probabilistic approach. Although this approach requires a change in the present NRC practice, it may be considered within the present regulations due to the statement from 10CFR 100.1(b) quoted above.

\subsubsection{Conclusions Regarding Seismic Considerations}

These four alternative means of accommodating the SSE were the subject of extensive internal consideration. The first approach, namely, designing the containment to be Seismic Category I so that the design leak rate is maintained during and beyond the SSE, was ultimately recommended. The other alternatives were assessed as possibilities in an evolving, maturing licensing process.

\subsection{LICENSING OF CONTAINMENT OPTIONS}

The following subsections discuss specific means for licensing of each of the containment options under current licensing requirements, including 10 CFR 100 .

To evaluate dose consequences for the various containment options on an equal basis, representative siting assumptions are required. For this 
study, the representative site geometry is defined [consistent with the AIPA study (Ref. 6-5) and Section 5 of this report] as having a 500-meter exclusion area boundary (EAB) and 2500-meter low population zone (LPZ). Conservative meteorology and breathing rates taken from Regulatory Guides 1.3 and 1.4 (Ref. 6-13) are also assumed in contrast to the median values employed in Section 5. The breathing rates, building wake factors, and atmospheric diffusion factors used in these evaluations are given in Table 6-2.

\subsubsection{Licensing of Unlined Containment}

In Section 3, an unlined containment is described as similar to a conventional containment except that the steel liner is replaced by a nonmetallic lining of vinyl or epoxy material. An unlined containment has pressure-retaining capability, and it provides an intact barrier for all postulated accident conditions. A containment recirculation system is provided as an engineered safety feature. It is the purpose of the following sections to demonstrate licensability of an unlined containment within the current licensing requirements.

\subsubsection{Requirements for Licensing of Unlined Containment. Licensing} requirements for an unlined containment can be readily defined, since this concept does not represent a radical departure from a present state-of-theart containment, and since previous GA/NRC discussions on unlined containments have taken place. In fact, the previously quoted NRC response to the GA 3800-MW(t) HTGR proposal provides a straightforward definition of licensing requirements (Ref. 6-4):

"... a containment building liner would not be necessary if it is established that the containment building will perform as designed and that the leak rate will not result in doses exceeding 10CFR Part 100 guidelines for the appropriate spectrum of postulated accidents. For any specific design, however, it would be necessary for us to establish by means of a detailed review that the Part 100 guidelines could be achieved with a satisfactory degree of margin." 
TABLE 6-2

DOSE CALCULATION PARAMETERS (Ref. 6-13)

Breathing rates $\left(\mathrm{m}^{3} / \mathrm{sec}\right)$

$$
\begin{array}{ll}
0-8 \mathrm{hr} & 3.47 \times 10^{-4} \\
8-24 \mathrm{hr} & 1.75 \times 10^{-4} \\
1-30 \text { days } & 2.32 \times 10^{-4}
\end{array}
$$

Building wake factors $(0-8 \mathrm{hr})$ assuming $0.5 \mathrm{~A}=1250 \mathrm{~m}^{2}$

$\begin{array}{ll}500 \mathrm{~m} & 3.0 \\ 800 \mathrm{~m} & 2.1 \\ 1000 \mathrm{~m} & 1.8 \\ 3000 \mathrm{~m} & 1.2\end{array}$

Atmospheric diffusion factors (with building wake factors included):

\begin{tabular}{l|c|c|c|c|c|c}
\hline \multirow{2}{*}{$\begin{array}{c}\text { Time } \\
\text { (hr) }\end{array}$} & \multicolumn{7}{|c|}{500} & 800 & 1000 & 3000 & 6000 \\
\cline { 3 - 8 } 0 & 8 & $7.0 \times 10^{-4}$ & $4.5 \times 10^{-4}$ & $3.6 \times 10^{-4}$ & $1.1 \times 10^{-4}$ & $4.2 \times 10^{-5}$ \\
8 & 24 & $5.0 \times 10^{-4}$ & $2.2 \times 10^{-4}$ & $1.5 \times 10^{-4}$ & $2.7 \times 10^{-5}$ & $8.3 \times 10^{-6}$ \\
24 & 96 & $1.8 \times 10^{-4}$ & $7.7 \times 10^{-5}$ & $5.3 \times 10^{-5}$ & $9.0 \times 10^{-6}$ & $2.8 \times 10^{-6}$ \\
96 & 720 & $4.1 \times 10^{-5}$ & $1.8 \times 10^{-5}$ & $1.2 \times 10^{-5}$ & $2.0 \times 10^{-6}$ & $5.9 \times 10^{-7}$ \\
\hline
\end{tabular}


In Section 6.3.1.2, industrial experience with unlined containments is discussed, indicating state-of-the-art performance for unlined containments and dictating appropriate design leak rate specifications corresponding to the past experience. In Sections 6.3.1.3 and 6.3.1.5, dose calculations are presented to demonstrate compliance with the 10CFR 100 guidelines for an appropriate spectrum of accident conditions. These subsections are concerned with the first two NRC requirements quoted above, namely, demonstration that the unlined containment will perform as designed and demonstration of dose consequences within the 10CFR 100 guidelines for the appropriate spectrum of postulated accidents. Input for a detailed NRC review of a specific design is beyond the scope of this report.

6.3.1.2. Leak Rate for Unlined Containment. The available evidence concerning leakage through an unlined containment indicates that a prestressed concrete structure can be designed and constructed with total leakage of 0.5 vol \%/day, and less when the presence of a plastic liner is accounted for. This conclusion is based on the results of recent French tests reported in ef. 6-14 and on the Canadian experience with plastic-lined containment reported in Ref. 6-15. The evidence is that the leakage occurs through minute cracks and imperfections around penetrations and construction joints and can be adequately controlled by high quality workmanship.

The containment structure is expected to retain its leak-tightness after an earthquake up to and including SSE, provided the structure is prestressed sufficiently so that, under combined pressure and earthquake loads, the concrete remains elastic. This assessment is based on the general understanding of the behavior of prestressed structures. The retention of similar leak-tightness in the reinforced-type construction is not considered feasible under combined loading conditions.

French Test Results. Significant testing of a prestressed, unlined concrete containment model was performed in France and was reported at a 1975 conference on containments at the University of York, England (Ref. 6-14). These tests were performed on a model of a cylindrical prestressed concrete containment, approximately $10 \mathrm{ft}$ high, $6 \mathrm{ft}$ in diameter, and 1.3 
ft thick, pressurized with air and steam. The structure had one purposely poor construction foint and one penetration consisting of a 2-ft-diameter pipe. The following were the conclusions of the test:

1. Leakage through the concrete was insignificant.

2. Leakage was concentrated in the poor construction joint.

3. Quality concrete had low permeability properties which, even without benefit of a plastic liner, kept total containment leakage to less than $0.5 \% /$ day.

4. Any lack of continulty caused by a crack or untreated construction joint or a poor penetration seal provides the easiest path for leakage.

5. Workmanship must be given particular care to keep the drying and thermal shrinkage to a minimum to avoid erratic density.

6. Cracks can be rendered leak-tight by infecting them with polyester resin.

Canadian Experience. From the experience with CANDU reactors (Ref. 6-15), which are provided with plastic-lined containment structures, the test results for the Gentilly Station and the Karach1 Nuclear Power Plant (KANUPP) are of particular interest. Gentilly is a 250-MW(e) plant with a containment design pressure of $0.22 \mathrm{MPa}(17 \mathrm{psig})$. A leakage test at 0.22 $\mathrm{MPa}$ (17 psig) indicated a net containment leakage rate of $0.25 \%$ vol/day for this vinyl-epoxy-lined building. For KANUPP, in which an epoxy-hypalon liner was provided, the containment leakage rate under test was $0.23 \%$ vol/day at $0.29 \mathrm{MPa}$ (27 psig).

In support of the use of these plastic-lined containment buildings, extensive laboratory testing was carried out (Ref.6-15). Tests indicated that the best vinyl system could be used up to an integrated gamma dose of 
$5 \times 10^{7} \mathrm{R}$; the best epoxy system could be used up to $10^{9} \mathrm{R}$. Samples of plastic liners were subjected to steam impingement tests. Epoxy appeared to be unaffected. Vinyl softened and blistered superficially, but apparently resisted further degradation by virtue of the self-insulating quality of the blistering. Finally, the ability of plastic liners to span a crack in concrete was investigated. It was observed that a 5-mm epoxy liner (which is less flexible than vinyl) did not crack over a concrete crack 7 mm wide. Thus, even if the containment building were designed to allow minute cracks under loading, the plastic liner would probably remain intact.

Based on actual containment tests and 1aboratory testing, it can be concluded that the Canadian experience with plastic-lined containment buildings has been most favorable. Use of a plastic liner makes it possible to construct a prestressed concrete containment with a leak rate of less than $0.5 \% /$ day, and the plastic liner can be shown to survive severe environmental conditions appropriate for accident events.

Conclusions Regarding Unlined Containment Leak Rate. A design leak rate of $0.5 \% /$ day will be assumed for an unlined containment. The French data indicate that a prestressed unlined containment can be designed and constructed for this leak rate criterion. The Canadian experience with actual containment structures shows that an appropriate degree of margin is then provided by the presence of a plastic liner. (Section 6.3.1.5 also includes consideration of $1.5 \%$ /day containment leak rate to show additional margin.)

\subsubsection{Accident Dose Calculations for Unlined Containment.}

DBDA. For the Summit and Fulton applications, a design basis depressurization accident (DBDA) was postulated with primary system depressurization occurring through a 100-sq-in. cross-sectional area. The DBDA dose consequences were calculated assuming release of (1) $100 \%$ of the design level circulating activity and (2) fractional liftoff of the design level 40-year plateout activity. The liftoff of plateout was based on primary 
system average shear force ratios due to depressurization through a 100-sqin. area. Subsequent to the Sumit and Fulton applications, determination of more accurate local primary system shear force ratios has been made possible by use of the RATSAM code (Ref. 6-16). Using the RATSAM shear force ratios for 100-sq-in. depressurization, DBDA dose consequences for unlined containment can be shown to be small fractions of the 10 CFR 100 guidelines. These results are shown in Table 6-3.

Siting Event. In Ref. 6-3, a means of meeting the 10 CFR 100 requirement for a site-suitability source term was proposed which was based upon:

1. The inherent capability of the HTGR, during core heatup, to delay release of fission product activity from the reactor core boundary to the primary coolant system boundary.

2. A hypothetical, nonmechanistic transfer of the appropriate fraction of fission product inventory to the containment building.

There is evidence that the "appropriate fractions of fission product inventory" for the HTGR should be different from the fractions established for LWRs via TID-14844 (Ref. 6-1). (See, for example, Table 4-9 of Ref. 6-19.) In addition, as an outgrowth of the AIPA study, subsequent 1icensing considerations may incorporate a more mechanistic treatment of core heatup and consequent fission product release. For the present considerations, however, a primarily nonmechanistic treatment consistent with Ref. 6-3 and TID-14844 is considered appropriate. A calculation of a timedependent release based on Ref. $6-3$ and the TID-14844 release fractions has been performed, and the fission product release is characterized by the data given in GASSAR-6, Table 2A.5-1 (Ref. 6-20). Dose results based on this time-dependent release to unlined containment are given in Table 6-4. The results in Table 6-4 demonstrate that a time-dependent release based on TID-14844 can be accommodated by an unlined containment well within the 10CFR 100 exposure guidelines for the specific assumptions stated in Table 6-4. For lower release fractions, the results would be even more favorable; greater margin would be demonstratable or smaller site boundaries could be utilized. 
TABLE 6-3

DOSE CONSEQUENCES FOR DBDA RELEASE TO UNLINED CONTAINMENT $(\mathrm{a})$

Assumptions :

Source terms: "Design" circulating and 40-year plateout activities from GASSAR-6, Table 11.1-5 (Ref. 6-17)

Fraction of circulating activity released: $100 \%$

Fraction of plateout released: Existing liftoff correlations from GASSAR-6 (Ref. 6-18) with shear force ratios predicted by RATSAM. code (Ref. 6-16)

Depressurization area: $100 \mathrm{sq}$ in.

Containment leak rate: $0-24 \mathrm{hr}, 0.5 \% /$ day

$1-30$ days, $0.25 \% /$ day

Containment cleanup: $\quad 1$ vol/hr recirculation system with $0.5-\mathrm{hr}$ ' startup delay; $\eta_{\text {halogens }}=0.95$,

$\eta_{\text {particulates }}=0.99$

Meteorology and breathing rates: Table 6-2

\begin{tabular}{l|c|c|c}
\hline Consequences: & $\begin{array}{c}\text { Whole Body } \\
\text { Gamma } \\
\text { (rem) }\end{array}$ & $\begin{array}{c}\text { Thyroid } \\
\text { (rem) }\end{array}$ & $\begin{array}{c}\text { Bone } \\
\text { (rem) }\end{array}$ \\
\hline 2-hr dose at $500 \mathrm{~m}$ & $7.7 \times 10^{-3}$ & $6.7 \times 10^{-2}$ & $3.0 \times 10^{-2}$ \\
30-day dose at $2500 \mathrm{~m}$ & $3.2 \times 10^{-3}$ & $1.5 \times 10^{-2}$ & $6.8 \times 10^{-3}$ \\
10CFR100 guide1ine & 25 & 300 & $150^{\text {(b) }}$ \\
\hline
\end{tabular}

(a) The dose consequences for representative site conditions in this table and in the following tables are compared to the 10CFR100 guidelines which are the governing legal requirements. Although it is recognized that the NRC genera11y requires reduced doses at the construction permit (CP) stage (20 rem whole body, 150 rem thyroid), it is felt that comparison with the full guideline values is more appropriate for a study of dose calculation parameters such as leak rate, meteorology, site boundaries, containment cleanup efficiency, etc. This precludes premature elimination of alternatives. However, one must bear in mind the CP 1imitations once an actual site (with actual meteorology) is chosen.

(b) Practiced guideline value. 
TABLE 6-4

DOSE CONSEQUENCES FOR TIME-DEPENDENT TID-14844

RELEASE TO UNLINED CONTAIMMENT

Assumptions :

Source terms: Time-dependent release characterized by data in GASSAR-6, Table 2A.5-1 (Ref. 6-20)

Containment leak rate: $0-24 \mathrm{hr}, 0.5 \% /$ day

$1-30$ days, $0.25 \% /$ day

Containment cleanup: $\quad 1$ vol/hr recirculation system with $0.5-\mathrm{hr}$ startup delay; $\eta_{\text {halogens }}=0.95$

$n_{\text {particulates }}=0.99$

Meteorology and breathing rates: Same as Table 6-2 except that the most conservative values are taken at the time of maximum release ( 7.5 to $15.5 \mathrm{hr}$ ), rather than 0 to $8 \mathrm{hr}$.

\begin{tabular}{l|c|c|c}
\hline Consequences: & $\begin{array}{c}\text { Whole Body } \\
\text { Gamma } \\
\text { (rem) }\end{array}$ & $\begin{array}{c}\text { Thyroid } \\
\text { (rem) }\end{array}$ & $\begin{array}{c}\text { Bone } \\
\text { (rem) }\end{array}$ \\
\hline 2-hr dose at $500 \mathrm{~m}$ & Insignificant & Insignificant & Insignificant \\
30-day dose at $2500 \mathrm{~m}$ & 2.4 & 170 & 4.3 \\
10CFR100 guideline & 25 & 300 & $150^{\text {(a) }}$ \\
\hline
\end{tabular}

(a) Practiced guideline value. 
6.3.1.4. Comparison of Licensing Versus Best Estimate Dose Calculations for Unlined Containment. Table 6-4 shows that of the various organ doses, the thyroid inhalation dose most nearly approaches its respective 10CFR 100 limit. To put this in proper perspective, however, it is informative to compare this arbitrarily determined thyroid dose with the best-estimate thyroid dose from a mechanistic core heatup event as assessed in the AIPA study. Median consequences of a mechanistic core heatup with intact conventional containment are reported in Section 3.2, Comment 1, Table 2, of Ref. 6-21. Multiplying by a factor of 5 to account for the difference in design leak rate between conventional and unlined containments, one can transform these conventional containment results from the AIPA study to approximate median consequences for an unlined containment. Thirty-day dose consequences derived in this manner are presented in Table 6-5. Comparison of the unlined containment thyroid doses from Tables 6-4 and 6-5 indicates that a factor of conservatism of approximately 600 is inherent in the time-dependent TID-14844 release thyroid dose calculation.

\subsubsection{Alternate Siting Considerations for Unlined Containment.}

Urban Siting. Potentially, a unique exploitation of inherent HTGR safety is urban siting. [In the context of this report, urban siting is taken to mean siting in a location where site meteorology and population distribution are such that exclusion area boundary/low population zone $(\mathrm{EAB} / \mathrm{LPZ}$ ) distances considerably less than the representative 500/2500 meters assumed in this study are allowable.] For a conventional containment, a design leak rate on the order of $0.1 \% /$ day is obtainable, giving doses lower by approximately a factor of 5 compared to an unlined containment with a design leak rate of $0.5 \% /$ day. Accordingly, for conventional containment, acceptable DBDA and siting event doses similar to the results in Tables 6-3 and 6-4 appear to be possible for an HTGR urban site.

It should be noted, however, that the choice of unlined containment does not preclude the possibility of urban siting. A survey of actual site 
TABLE 6-5

MEDIAN DOSE CONSEQUENCES FOR CORE HEATUP FROM CURRENT AIPA ANALYSIS (LOSS OF OFFSITE POWER, BRANCH BD)

\begin{tabular}{l|c|c|c}
\hline & $\begin{array}{c}\text { Whole Body } \\
\text { Gamma } \\
\text { (rem) }\end{array}$ & $\begin{array}{c}\text { Thyroid } \\
\text { (rem) }\end{array}$ & $\begin{array}{c}\text { Bone } \\
\text { (rem) }\end{array}$ \\
\hline $\begin{array}{c}\text { Conventional containment } \\
\text { (Section 3.2, Comment 1, } \\
\text { Table 2 of Ref. 6-21) } \\
\text { 30-day dose at 2500 m }\end{array}$ & $6.9 \times 10^{-2}$ & $5.9 \times 10^{-2}$ & $1.0 \times 10^{-3}$ \\
$\begin{array}{l}\text { Unlined containment } \\
\text { (5 times conventional } \\
\text { containment consequences) } \\
30-\text { day dose at 2500 m }\end{array}$ & $3.5 \times 10^{-1}$ & $3.0 \times 10^{-1}$ & $5.0 \times 10^{-3}$ \\
10CFR100 guideline & 25 & 300 & $150^{(\mathrm{a})}$ \\
\hline
\end{tabular}

(a) Practiced guideline value. 
meteorological conditions performed by Stone and Webster (Ref. 6-22) indicates that actual sites may have 0 to $8 \mathrm{hr}$ EAB meteorology which is favorable by a factor of two or more compared to Regulatory Guide 1.3/1.4 meteorology with building wake factor. Similarly, dispersion data used to calculate 30-day doses for some actual sites would be more favorable than Regulatory Guide $1.3 / 1.4$ values. Such favorable sites would allow unlined containment doses equivalent to the doses of Tables $6-3$ and $6-4$ for EAB/LPZ distances less than the 500/2500 meters assumed for this study. Thus, with specific site data, even an unlined containment could be shown to be compatible with HTGR urban siting.

Greater Containment Leak Rate. To this point, dose consequence considerations for an unlined containment (Tables 6-3 and 6-4) have been based on an initial containment design leak rate of $0.5 \mathrm{vol} \% / \mathrm{day}$, a value supported by experience and a value which allows some margin since the vinyl or epoxy containment lining would be expected to further reduce the actual leak rate obtainable (see Section 6.3.1.2). However, there is some thought that licensing considerations at this preliminary stage should be based on a greater containment design leak rate to give an even greater allowance for uncertainties in design, construction, and testing of an unlined containment. A value of 1.5 vol \%/day has been suggested. The following paragraphs discuss ways in which compliance with 10CFR100 can be demonstrated for a containment leak rate of $1.5 \%$ /day.

Examination of Table 6-3 shows that a factor of 3 increase in the DBDA doses (corresponding approximately to a factor of increase in the assumed unlined containment leak rate of from $0.5 \%$ day to $1.5 \% /$ day) would not result in unacceptable consequences. Therefore, further consideration of DBDA consequences with $1.5 \%$ /day leak rate is unnecessary. However, the consequences of a time-dependent TID release given in Table 6-4 are generally greater than maximum DBDA consequences, and careful consideration of alternatives is therefore required if the containment leak rate is assumed to be $1.5 \%$ /day instead of $0.5 \%$ /day. There are several means by which time-dependent TID-14844 dose consequences could be decreased to 
offset the adverse effect of assuming a $1.5 \% /$ day containment leak rate. The first means is to increase the efficlency of the containment cleanup system, a study of which would involve site-spectfic economic tradeoff considerations for a particular site that are beyond the scope of this study. This alternative, therefore, will not be considered further. A second possible means of decreasing siting event dose consequences is to site the plant where a larger low population zone is possible. Third, if meteorology and breathing rates were assumed strictly in accordance with Table 6-2 (i.e., in accordance with Regulatory Guides 1.3 and 1.4), rather than permuting the worst conditions with the worst time of release, then lower consequences would result. Finally, based on current studies of HTGR accident consequences, a finfte transport rate of fission products from the PCRV to the containment can be fustified. Gaining credit in the licensing process for this inherent HTGR phenomenon would result in lower siting event dose consequences. These alternatives are discussed in more detail in the following paragraphs.

If a containment leak rate of $1.5 \%$ /day and a larger low population zone of $6400 \mathrm{~m}$ are assumed, dose consequences for the siting event are as given in Table 6-6. Compared to the 10CFR100 guidelines, these doses are acceptable. This shows the effect of larger site boundaries.

The practice of permuting the meteorology and breathing rates for a time-dependent release arises from a past interpretation of the intent of LWR Regulatory Guides 1.3/1.4 (Ref. 6-13). However, this interpretation appears to be questionable since the practice of assuming LWR release fractions and meteorological data which do not account for helium buoyancy and then permuting as well may go beyond the original intent of the Regulatory Guides. In addition, permuting does not account for beneficlal effects which a time-dependent release actually makes possible. For instance, during the first few hours of an actual HTGR core heatup event, evacuation could be taking place, such that the maximum breathing rate would be applicable during these first few hours, and a lower breathing rate would be appropriate (and in fact conservative) thereafter. of 
TABLE 6-6

DOSE CONSEQUENCES FOR TIME-DEPENDENT TID-14844

RELEASE TO UNLINED CONTAINMENT ( $1.5 \% /$ day

containment leak rate and $6400-\mathrm{m} \mathrm{LPZ}$ )

Assumptions :

Source terms: Time-dependent release characterized by data in GASSAR-6, Table 2A.5-1 (Ref. 6-20)

Containment leak rate: Constant $1.5 \% /$ day

Containment cleanup: $\quad 1$ vol/hr recirculation system with $0.5-\mathrm{hr}$ startup delay; Thalogens $=0.95$,

$\eta_{\text {particulates }}=0.99$

Meteorology and breathing rates: Same as Table 6-2 except the most conservative values are taken at the time of maximum release ( 7.5 to $15.5 \mathrm{hr}$ ) rather than 0 to $8 \mathrm{hr}$.

\begin{tabular}{l|c|c|c}
\hline Consequences: & $\begin{array}{c}\text { Whole Body } \\
\text { Gamma } \\
\text { (rem) }\end{array}$ & $\begin{array}{c}\text { Thyroid } \\
\text { (rem) }\end{array}$ & $\begin{array}{c}\text { Bone } \\
\text { (rem) }\end{array}$ \\
\hline 30-day dose at $6400 \mathrm{~m}$ & 2.2 & 160 & 3.6 \\
10CFR100 guide1ine & 25 & 300 & $150(\mathrm{a})$ \\
\hline
\end{tabular}

(a) Practiced guideline value. 
course, meteorology cannot be controlled, yet it is predictable. Therefore, it is conceivable that an operator confronted with an HTGR core heatup could take steps to minimlze the contalnment leak rate (e.g., by reducing the pressure drfving force) prior to the onset of severe meteorology concurrent with maximum release. Assumption of nonpermuted meteorology and breathing rates would require further investigation of the intent of the Regulatory Guides and possible additional discussion with the NRC. However, the benefit is readily apparent from Table 6-7, which gives dose consequence results for a time-dependent TID-14844 release, assuming meteorology and breathing rates strictly in accordance with Table 6-2. Again, these doses compare favorably to the 10CFR100 guidelines.

In previous HTGR licensing calculations for the siting event, instantaneous transfer of fission products from the PCRV to the contalnment has been assumed. Instantaneous PCRV-to-containment transport was also assumed in the initial AIPA work, since computer codes were used which had been developed in a licensing background.

However, work subsequent to the original AIPA Status Report (Ref.6-5) has accounted for an additional inherent feature of the HTGR, namely, a finite transport rate of fission products from the PCRV to the containment for the core heatup event sequences. This work is reported in Ref. 6-21. A finite transport rate was first proposed and analyzed by Los Alamos Scientific Laboratory (Ref, 6-23). This phenomenon is based on the fact that on completion of the PCRV blowdown through the relief train, which occurs prior to appreciable fission product release from the fuel, the PCRV is connected to the containment by a single open flow path. The driving forces for transport through this single flow path from the PCRV to the containment are (1) heat transfer from the containment to equipment inside the containment, (2) heatup expansion of the gas in the PCRV, and (3) buoyancy which allows for potential exchange of helium in the PCRV and the mixed gas in the containment. These forces have been considered in the recent work at GA and have been found to be readily quantifiable, such that assumption of instantaneous transfer to the containment is inappropriate for the HTGR. The finite delay feature appears to be an inherent safety characteristic which is unique to the HTGR. 
TABLE 6-7

DOSE CONSEQUENCES FOR TIME-DEPENDENT TID-14844

RELEASE TO UNLINED CONTAINMENT ( $1.5 \% /$ day containment

leak rate with nonpermuted meteorology)

Assumptions :

Source terms: Time-dependent release characterized by data in GASSAR-6, Table 2A.5-1 (Ref. 6-20)

Containment leak rate: Constant $1.5 \% /$ day

Containment cleanup: $\quad 1$ vol/hr recirculation system with $0.5-\mathrm{hr}$ startup delay; $\eta_{\text {halogens }}=0.95$,

$n_{\text {particulates }}=0.99$

Meteorology and breathing rates: Table 6-2

\begin{tabular}{c|c|c|c}
\hline Consequences: & $\begin{array}{c}\text { Whole Body } \\
\text { Gamma } \\
\text { (rem) }\end{array}$ & $\begin{array}{c}\text { Thyroid } \\
\text { (rem) }\end{array}$ & $\begin{array}{c}\text { Bone } \\
\text { (rem) }\end{array}$ \\
\hline $\begin{array}{c}\text { 30-day dose at } 2500 \mathrm{~m} \\
\text { 10CFR100 guideline }\end{array}$ & 5.8 & 200 & 7.5 \\
25 & 300 & $150(\mathrm{a})$ \\
\hline
\end{tabular}

(a) Practiced guideline value. 
From the recent GA assessment of core heatup event sequences, a PCRVto-containment transport rate of $2 \% / \mathrm{hr}$ was determined to be appropriate for the HTGR following initial blowdown through the PCRV relief train. Applying this transport rate and others parametrically to a time-delayed TID-14844 release results in the dose consequences given in Table 6-8. These results demonstrate that gaining credit in the licensing process for this unique HTGR characteristic enables compliance with the 10CFR 100 guideline for a $1.5 \%$ /day containment leak rate. Even if, because of the more mechanistic nature of this approach, it were necessary to account for a dose contribution due to the initial primary system blowdown through the relief train, acceptable results would still be obtainable because the blowdown would appreciably affect only the 2-hr dose at the EAB, which is essentially insignificant for an HTGR time-dependent release.

6.3.1.6. Summary Regarding Licensing of Unlined Containment. From the previous discussion, several summary statements which established a basis for licensing an unlined containment are derived:

1. A prestressed concrete containment with a plastic liner can be designed and constructed with a leak rate of less than $0.5 \% /$ day.

2. With an unlined containment design leak rate of $0.5 \% /$ day and the representative site conditions assumed in this study, doses well within the 10CFR 100 exposure guidelines can be demonstrated for an appropriate spectrum of conservative accident conditions.

3. The choice of an unlined containment does not necessarily preclude the possibility of urban siting for the HTGR.

4. With more favorable siting conditions or via a more flexible interpretation of existing licensing practices, compliance with $10 \mathrm{CFR} 100$ can be demonstrated even for a containment design leak rate of $1.5 \% /$ day. 
TABLE 6-8

DOSE CONSEQUENCES FOR TIME-DELAYED TID-14844 RELEASE

TO UNLINED CONTAINMENT (finite PCRV-to-containment

transport rate and $1.5 \%$ /day containment leak rate)

\section{Assumptions :}

Source terms: Time-dependent release characterized by data in GASSAR 6 Table 2A.5-1 (Ref. 6-20)

PCRV-to-containment transport rate: Various

Containment leak rate: Constant $1.5 \%$ day

Containment cleanup: $\quad 1$ vol/hr recirculation system with $0.5-\mathrm{hr}$ startup delay; nhalogens $=0.95$,

$\eta_{\text {particulates }}=0.99$

Meteorology and breathing rates: Same as Table 6-2 except the most conservative values are taken at the time of maximum release $(7.5$ to $15.5 \mathrm{hr}$ ) rather than 0 to $8 \mathrm{hr}$.

\begin{tabular}{c|c|c|c}
\hline Consequences: & $\begin{array}{c}\text { Whole Body } \\
\text { Gamma } \\
\text { (rem) }\end{array}$ & $\begin{array}{c}\text { Thyroid } \\
\text { (rem) }\end{array}$ & $\begin{array}{c}\text { Bone } \\
\text { (rem) }\end{array}$ \\
\hline $\begin{array}{c}\text { 30-day dose at 2500 m for } \\
\text { PCRV-to-containment transport } \\
\text { 2\%/hr } \\
\text { 5ate: }\end{array}$ & 2.3 & 99 & 4.8 \\
$10 \% / h r$ & 3.5 & 180 & 6.8 \\
10CFR100 guideline & 4.4 & 260 & 8.1 \\
& 25 & 300 & $150(\mathrm{a})$ \\
\hline
\end{tabular}

(a) Practiced guideline value. 


\subsubsection{Licensing of Reclosable Vented Containment}

Recalling from Section 6.1.2 that accommodating accident conditions within the 10CFR100 exposure guidelines establishes a basis for acceptability of alternate containment, the following sections demonstrate that a reclosable vented containment [Fig. 3-1(c)] can accommodate HTGR accident events within these 10CFR100 exposure guidelines.

6.3.2.1. Leak Rate for Reclosable Vented Containment. A reclosable vented containment would allow venting of the activity release due to accidental depressurization of the primary coolant system. Although considerable fallout, plateout, and retention of fission products would realistically occur within the containment building, a traditional licensing-type calculation requires that no credit be taken for such depletion of the DBDA release. Hence, the DBDA dose consequences for this alternative design are evaluated assuming no containment, 1.e., a direct ground-level release. The containment building leak rate is not a parameter in this calculation.

Following depressurization of the primary coolant system, the vented reclosable containment building can be isolated or "buttoned up" to closely resemble an unlined containment building. This action would be accomplished by automatic or remote manual closure of the valve(s) through which venting is allowed. This building configuration would be available to contain long-term release of fission products. The containment leak rate following closure is dependent on the building design and the leakage through the vent system. In Section 6.3.1.2, it was established that $0.5 \% /$ day or less is an obtainable leak rate for a high-pressure unlined containment. A reclosable vented containment would be of similar prestressed design but with a design pressure of only $0.12 \mathrm{IPa}$ ( $3 \mathrm{psig}$ ), since it is not required to contain a primary or secondary system blowdown. At its lower design pressure, this containment building leak rate would be lower than that of a high-pressure unlined containment. Assuming the leak rate of the vent system in the reclosed configuration to represent a small incremental leak rate (possibly requiring redundant venting valves with pressurized interspace), then $0.5 \%$ /day would also represent a conservative estimate of the 
leak rate for the bullding and vent system combined. If a tight vent system cannot be developed, the leak rate for a reclosable vented contalnment would be substantially greater than $0.5 \% /$ day; hence, consequences for a $1.5 \% /$ day leak rate have also been evaluated.

\subsubsection{Accident Dose Calculations for Reclosable Vented Containment.}

DBDA. The most severe release of fission products which could occur with the containment vent system open is a depressurization of the primary system. For a DBDA source term assessed in the same manner as GASSAR-6 (Ref. 6-18) but with direct release to the environment, dose consequences are given in Table 6-9. Although considerable plateout and fallout of fission products in the containment building would occur, and a considerable fraction of the gasborne activity would be retained in the building, no credit for this depletion and retention has been taken in the Table 6-9 calculations.

The consequences in Table 6-9 exceed the 10CFR100 exposure guidelines and hence appear to be unacceptable in a traditional licensing setting; activity release must be reduced below the GASSAR-6 design levels in order to allow vented containment DBDA dose consequences within the traditional limits. One possible means of reducing the DBDA activity release is by owering the circulating and plateout activity via improved fuel design and/or manufacture. A second possible means is to develop a revised analytical basis for evaluating the activity released during a DBDA. To quantify these requirements, Fig. 6-1, which is a dose parameter tree for the DBDA, has been prepared. Four sets of source terms are evaluated, ranging from AIPA median source terms (Ref. 6-24) to current GASSAR-6 source terms (Ref.6-18). Similarly, four means of evaluating liftoff of plateout are employed parametrically, ranging from a 30-sq-in. depressurization with liftoff based on local shear force ratios predicted by the RATSAM code (Ref. 6-16) to a 100-sq-in. depressurization with liftoff based on primary system average shear force ratios. Combinations of these assumptions have been considered in Fig. 6-1, resulting in 9 branches on 
TABLE 6-9

DOSE CONSEQUENCES FOR DBDA RELEASE TO VENTED CONTAINMENT

OR CONFINEMENT (DIRECT RELEASE TO ENVIRONMENT)

Assumptions:

Source terms: "Design" circulating and 40-year plateout activities from GASSAR-6, Table 11.1-5 (Ref. 6-17)

Fraction of circulating activity released: $100 \%$

Fraction of plateout activity released: Existing 1iftoff correlations from GASSAR-6 assuming average primary system shear force ratios (Ref. 6-18)

Depressurization area: $100 \mathrm{sq}$ in.

Containment leak rate: Direct release

Meteorology and breathing rates: Table 6-2

\begin{tabular}{c|c|c|c}
\hline Consequences: & $\begin{array}{c}\text { Whole Body } \\
\text { Gamma } \\
\text { (rem) }\end{array}$ & $\begin{array}{c}\text { Thyroid } \\
\text { (rem) }\end{array}$ & $\begin{array}{c}\text { Bone } \\
\text { (rem) }\end{array}$ \\
\hline 2-hr dose at $500 \mathrm{~m}$ & 44 & 660 & 1100 \\
30-day dose at $2500 \mathrm{~m}$ & 12 & 130 & 220 \\
10CFR100 guideline & 25 & 300 & 150 (a) \\
\hline
\end{tabular}

(a) Practiced guideline value. 


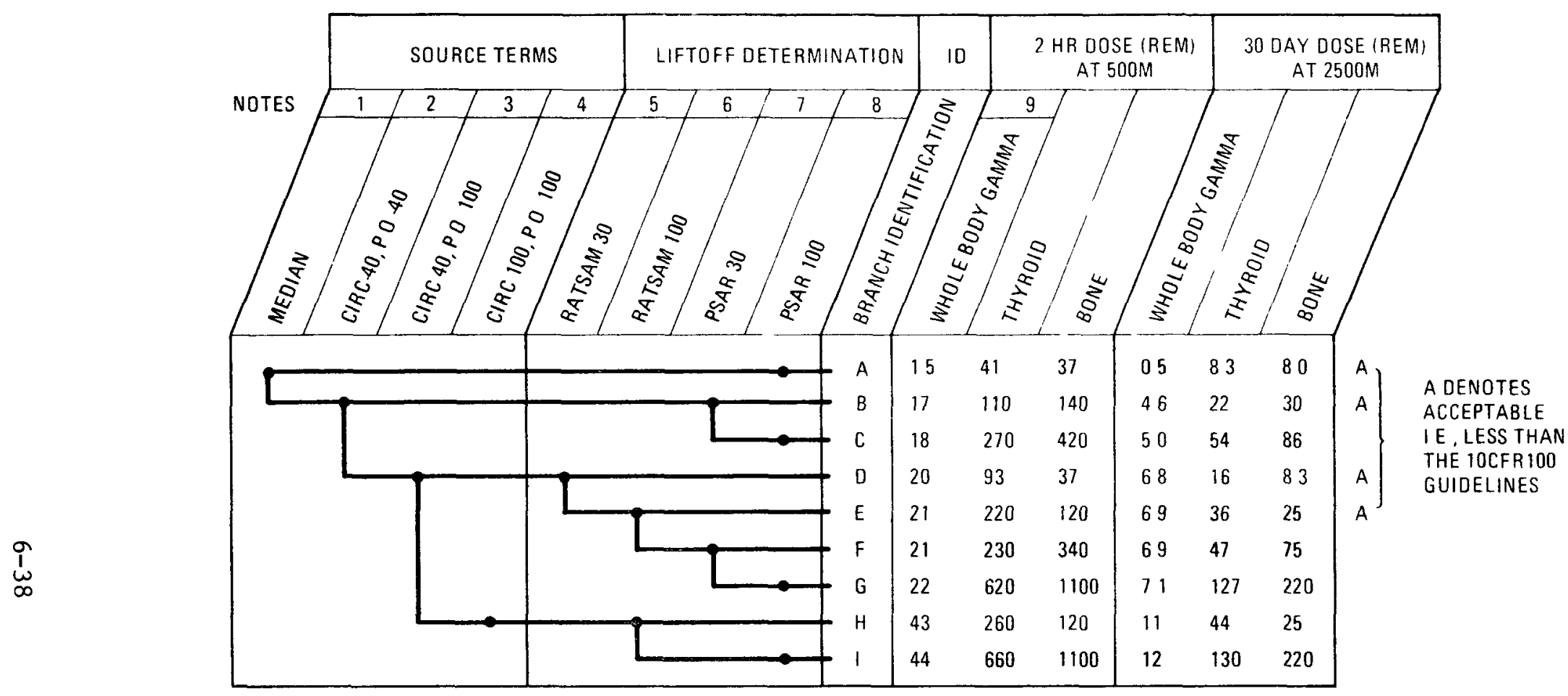

NOTES 1 MEDIAN CIRCULATING AND PLATEOUT ACTIVITIES (REF 6-24)

2 ACTIVITY EQUALS 40\% OF CIRCULATING \& PLATEOUT ACTIVITIES FROM GASSAR 6, TABLE 1115 (REF 6 15)

3 ACTIVITY SAME AS GASSAR 6, TABLE 1115 , EXCEPT CIRCULATING ACTIVITY $=40 \%$ OF TABLE 1115 VALUES

4 ACTIVITY SAME AS GASSAR 6, TABLE 1115

5 LIFTOFF BASED ON LOCAL SHEAR FORCE RATIOS PREDICTED BY RATSAM CODE (REF 6-16) FOR 30 SO IN DEPRESSURIZATION

6 LIFTOFF BASED ON LOCAL SHEAR FORCE RATIOS PREDICTED BY RATSAM CODE FOR 100 SO IN DEPRESSURIZATION

7 LIFTOFF BASED ON PRIMARY SYSTEM AVERAGE SHEAR FORCE RATIOS FOR 30 SO IN DEPRESSURIZATION

8 LIFTOFF BASED ON PRIMARY SYSTEM AVERAGE SHEAR FORCE RATIOS FOR 100 SO IN DEPRESSURIZATION

9 ALL DOSES BASED ON INSTANTANEOUS DIRECT GROUND LEVEL RELEASE, REG GUIDE $13 / 14$ METEOROLOGY AND BREATHING RATES (SEE TABLE 6 2)

Fig. 6-1. DBDA dose parameter tree for vented design options (direct release to environment assumed) 
the dose parameter tree. Branches for which consequences less than the 10CFR 100 exposure guidelines have been determined are denoted by the symbol " $A$ " in the right-hand column of Fig. 6-1.

Two branches, A and D, from Fig. 6-1 are well within the 10CFR 100 guidelines, and two branches, $B$ and $E$, are marginally acceptable, i.e., the doses for Branches $B$ and $E$ are less than the 10CFR100 exposure guidelines but greater than the practiced limits at the construction permit stage. In general, Fig. 6-1 demonstrates for a direct release to the environment the importance of reducing the activity released during a depressurization event. Compared to the GASSAR-6 basis (Ref. 6-16), a modest reduction in circulating activity can bring about acceptable whole body gamma doses, and a somewhat greater reduction in the amount of plateout released appears to be required in order to effect acceptable thyroid and bone doses.

lieans of Assuring Acceptable DBDA Results. For vented containment, Fig. 6-2 summarizes the restrictions which lead to acceptable rapid depressurization dose consequences for various combinations of analysis parameters. (It should be noted that the restrictions for the DBDA identified herein also apply to traditional licensing consideration of the other vented alternatives, namely reclosable vented confinement, discussed in Section 6.3.3, and vented confinement, discussed in Section 6.3.4.)

Acceptable Branch A of Fig. 6-1 represents a significant (factor of 10 to 1000) reduction in circulating and plateout activities compared to the GASSAR-6 design levels (Ref. 6-17). This could be accomplished by improved fuel design/manufacture and/or by justification of reduced margin between expected activity levels and the design level.

Acceptable Branch D of Fig. 6-1 represents a reduction in circulating activity to nominally $40 \%$ of GASSAR- 6 level with plateout activity maintained at GASSAR-6 level. (The reduction to precisely $40 \%$ circulation activity is not critical; it is merely given as an example.) In addition to a reduction in circuit activity, acceptability of this branch requires 


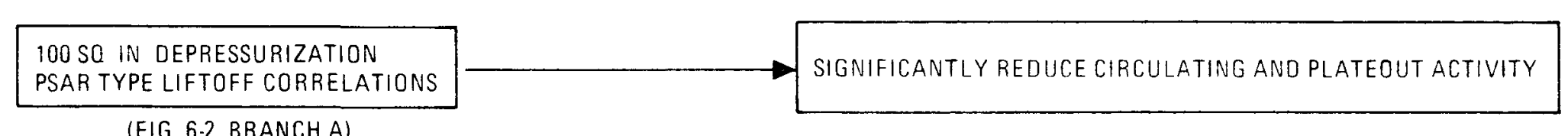

(FIG 6-2, BRANCH A)
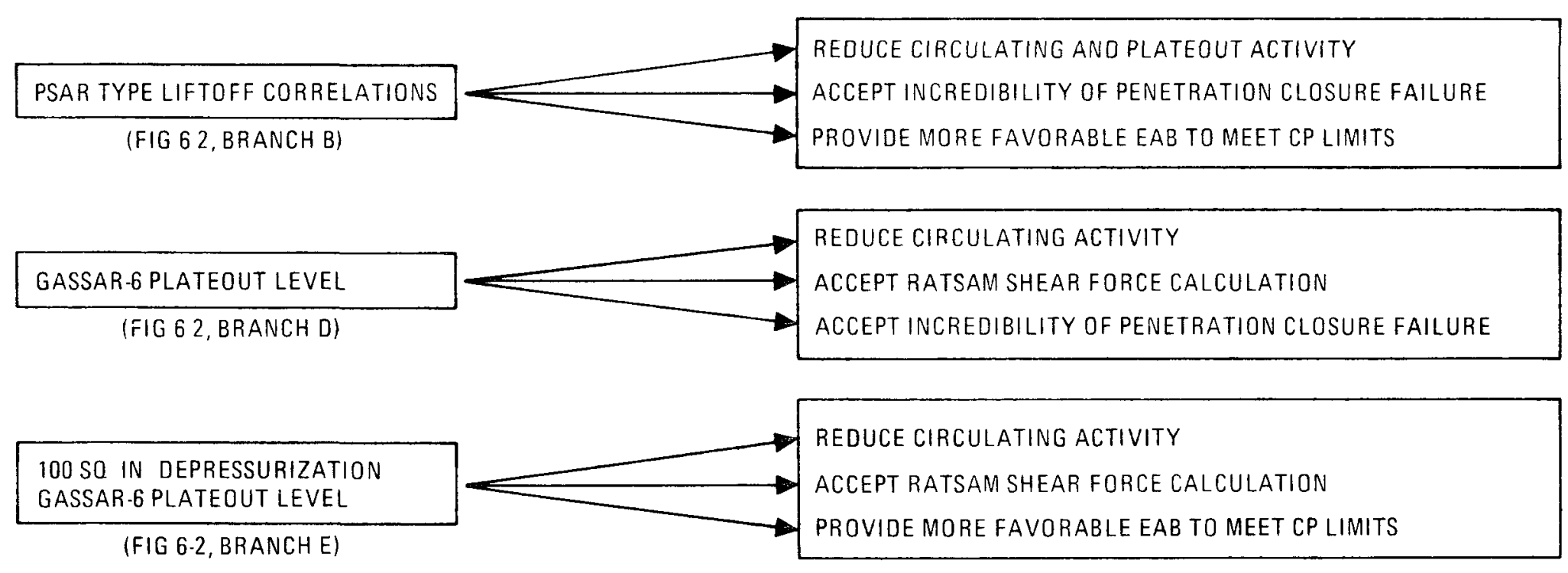

Fig. 6-2. Alternatives for acceptable DBDA results for vented design options 
acceptance of the RATSAl1-calculated shear force ratios and concurrence that PCRV penetration closure failure is incredible (hence, assumption of mechanistic fallures leading to depressurization through areas less than $30 \mathrm{sq}$ in.).

Branches B and E from Fig. 6-1 are less than the 10CFR100 guidelines, and, for the assumptions inherent in these branches, the doses could be shown to be acceptable at the construction permit stage for an exclusion area boundary (EAB) larger than 500 meters, or for a site with a 500-meter $\mathrm{EAB}$ and site-specific meteorology more favorable than Regulatory Guide $1.3 / 1.4$ meteorology.

Siting Event Considering 0.5\%/Day Leak Rate. As discussed in the portion of this report dealing with dose calculations for unlined containment (Section 6.3.1.3), the 10CFR 100 requirement for an HTGR siting source term can be met by postulating a time-dependent fission product release and a hypothetical, nonmechanistic transfer of the fission products to the containment building, as was originally proposed in Ref. 6-3. With a nonmechanistic approach, the doses for reclosable vented containment resulting from a time-dependent TID-14844 release would be essentially the same as those for unlined containment given in Table 6-4, owing to the same $0.5 \% /$ day containment leak rate. However, two slight adjustments are appropriate. First, a finite time delay must be allowed for closing the reclosable containment. Thus, instead of insignificant 2-hr doses as in Table 6-4, a 2-hr dose will be seen which is dependent on the closure time. Second, the unlined containment calculations in Table 6-4 assumed a lower leak rate after $24 \mathrm{hr}$. This is appropriate for high-pressure containment in which the leakage driving force will decrease as the internal gas volume cools and slowly escapes. For low-pressure containment, a leak rate constant with time is thought to be more appropriate. This will slightly increase the 30-day doses compared to Table 6-4. Considering these factors, the consequences for a time-dependent TID-14844 release to reclosable vented containment are given in Table 6-10. These doses are less than the 10CFR 100 limits. 
TABLE $6-10$

DOSE CONSEQUENCES FOR TIME-DEPENDENT TID-14844

RELEASE TO RECLOSABLE VENTED CONTAINMENT

Assumptions:

Source terms: Time-dependent release characterized by data in GASSAR-6, Table 2A.5-1 (Ref. 6-20)

Containment leak rate: Constant $0.5 \% /$ day

Containment cleanup: $\quad 1$ vol/hr recirculation system with $0.5-\mathrm{hr}$ startup delay following isolation;

$\eta_{\text {halogens }}=0.95, \eta_{\text {particulates }}=0.99$

Meteorology and breathing rates: Same as Table 6-2 except that the most conservative values are taken at the time of maximum release ( 7.5 to $15.5 \mathrm{hr}$ ) rather than 0 to $8 \mathrm{hr}$.

\begin{tabular}{c|c|c|c}
\hline Consequences : & $\begin{array}{c}\text { Whole Body } \\
\text { Gamma } \\
\text { (rem) }\end{array}$ & $\begin{array}{c}\text { Thyroid } \\
\text { (rem) }\end{array}$ & $\begin{array}{c}\text { Bone } \\
\text { (rem) }\end{array}$ \\
\hline 2-hr dose at $500 \mathrm{~m}$ & 0.02 & 1.3 & 0.02 \\
10-min isolation & 0.08 & 5.1 & 0.03 \\
30-min isolation & 3.2 & 200 & 5.3 \\
30-day dose at 2500 m & 25 & 300 & $150^{(\mathrm{a})}$ \\
10CFR100 guideline & & &
\end{tabular}

(a) Practiced guideline value. 
Siting Event Considering 1.5\%/Day Leak Rate. If the leak rate for reclosable vented containment is taken as $1.5 \% /$ day, consequences greater than those presented in Table 6-10 will result. Alternative means of reducing the dose consequences of the siting event source term must be considered, as was done for unlined containment in Section 6.3.1.5. In fact, the results presented in Section 6.3.1.5, namely Tables 6-6, 6-7, and 6-8, are equally applicable to reclosable vented containment w1th $1.5 \% /$ day design leak rate. These results show that consequences less than the 10CFR 100 guldelines can be demonstrated.

6.3.2.3. Summary Regarding Licensing of Reclosable Vented Containment. From the preceding sections, the following summary statements are derived for reclosable vented containment:

1. Doses within the 10 CFR 100 exposure guidelines can be demonstrated for a rapid depressurization although activity release must be reduced considerably from the GASSAR-6 leve1.

2. A redefinition of the DBDA as depressurization through a 30-sqin. area or less provides a more reasonable basls for licensing of reclosable vented containment. Such a redefinition is consistent with Ref. 6-8.

3. A siting event based on a time-dependent TID-14844 release can be shown to be acceptable if the leak rate of the closed containment is of the order of $0.5 \% /$ day. Containment leak rate of $1.5 \% /$ day requires more favorable siting or a more flexible interpretation of existing licensing practices.

\subsubsection{Licensing of Reclosable Vented Confinement}

As described in Section 3, reclosable vented confinement consists of a building which is normally slightly subatmospheric, allowing processing of slowly released radioactive materials through a filtration system, yet permitting venting of sudden activity releases from primary or secondary system depressurization. [Fig. 3-1(e) represents a conceptual diagram of

$$
6-43
$$


reclosable vented confinement. The Fort St. Vrain HTGR confinement building is an example of reclosable vented confinement.] The building design leak rate is not of consequence in the determination of accident consequences, as long as the effluent filtration system is of sufficient capacity to maintain the building subatmospheric such that only inleakage occurs. The DBDA consequences are determined assuming a direct release to the environment; the siting event is evaluated assuming processing through the effluent filtration system. The purpose of this section is to demonstrate that reclosable vented confinement can accommodate HTGR accident events within the 10 CFR 100 exposure guidelines.

\subsubsection{Accident Dose Calculations for Reclosable Vented Confinement.}

DBDA. Dose consequences for a rapid primary system depressurization to reclosable vented confinement are identical to the dose consequences for depressurization to reclosable vented containment, given in Section 6.3.2.2, since both alternatives are evaluated with a direct release to the environment. Specifically, the results presented in Fig. 6-1 are applicable, as are the restrictions identified for the acceptable cases from Fig. 6-1. Figure 6-2 summarizes the restrictions which lead to acceptable dose consequences for rapid depressurization to reclosable vented containment. The restrictions identified in Fig. 6-2 also apply to reclosable vented confinement.

Siting Event. Acceptable consequences for a time-dependent TID-14844 (Ref. 6-1) release can be demonstrated for reclosable vented confinement by means of analysis based on the Fort St. Vrain precedent. In the Fort St. Vrain Safety Analysis Report (Ref. 6-25), a permanent loss of forced circulation was analyzed as a hypothetical extension of the 30-min 1oss-ofnormal-shutdown-cooling accident. The analysis was partially mechanistic in that it was based on loss of forced circulation, and certain operator actions including depressurization of the primary system via the helium purification system were required. However, it was also partially nonmechanistic since the arbitrary TID-14844 release fractions and an arbitrary 
5-psig driving force for leakage from a hypothetical unlined PCRV were assumed, resulting in a PCRV leak rate of $0.2 \%$ /day. Assuming the same PCRV leak rate for a 3000-MNJ(t) IHTGR, the dose consequences are as given in Table 6-11. Even with the conservatively low filter efficiencles used in the analysis, these results are acceptable. It should be noted, however, that the consequences are quite dependent on the PCRV leak rate. In an actual licensing application, an appropriate PCRV transport rate for the present PCRV design would be evaluated.

\subsubsection{Summary Regarding Licensing of Reclosable Vented Confinement.} For reclosable vented confinement, summary statements are derived as follows :

1. Doses within the 10CFR100 exposure guidelines can be demonstrated for a rapid depressurization although activity release must be reduced considerably from the GASSAR-6 level.

2. A redefinition of the $\mathrm{DBDA}$ as a depressurization through a 30 -sqin. area or less provides a more reasonable basis for licensing of reclosable vented confinement.

3. Doses within the 10CFR100 exposure guidelines can be shown for a time-dependent TID-14844 release with conditions similar to those previously assumed for licensing of Fort St. Vrain.

\subsubsection{Licensing of Vented Confinement}

Section 3 describes vented confinement as an open bullding in which natural depletion of fission products could occur via decay, fallout, plateout, and holdup or retention in the PCRV or confinement building [see Fig. 3-1(f)]. This alternative is the most basic concept considered, and it has the largest potential for cost savings. However, as described below, licensing of this concept requires a departure from the traditional regulatory framework. 


\section{TABLE 6-11}

DOSE CONSEQUENCES FOR TIME-DEPENDENT TID-14844

RELEASE TO RECLOSABLE VENTED CONFINEMENT

Assumptions:

Source terms: Time-dependent release characterized by data in GASSAR-6, Table 2A.5-1 (Ref. 6-20)

PCRV leak rate: Constant $0.2 \% /$ day

Confinement evacuation rate: Parametric 0.5 vol/hr to 1.0 vol/hr

Effluent filter efficiencies: $\eta_{\text {halogens }}=0.90$,

$\eta_{\text {particulates }}=0.95$

Meteorology and breathing rates: Same as Table 6-2 except that the most conservative values are taken at the time of maximum release ( 7.5 to $15.5 \mathrm{hr}$ ) rather than 0 to $8 \mathrm{hr}$.

\begin{tabular}{|c|c|c|c|}
\hline Consequences: & $\begin{array}{l}\text { Whole Body } \\
\text { Gamma } \\
\text { (rem) }\end{array}$ & $\begin{array}{l}\text { Thyroid } \\
\text { (rem) }\end{array}$ & $\begin{array}{l}\text { Bone } \\
\text { (rem) }\end{array}$ \\
\hline $\begin{array}{l}2-\mathrm{hr} \text { dose at } 500 \mathrm{~m} \text {, } \\
0.5 \mathrm{vol} / \mathrm{hr} \text { evac. }\end{array}$ & Insignificant & Insignificant & Insignificant \\
\hline $\begin{array}{l}2-\mathrm{hr} \text { dose at } 500 \mathrm{~m}, \\
1.0 \mathrm{vol} / \mathrm{hr} \text { evac. }\end{array}$ & Insignificant & Insignificant & Insignificant \\
\hline $\begin{array}{c}30-\text { day dose at } 2500 \mathrm{~m} \text {, } \\
0.5 \text { vol } / \mathrm{hr} \text { evac. }\end{array}$ & 1.2 & 110 & 7.0 \\
\hline $\begin{array}{c}30-\text { day dose at } 2500 \mathrm{~m} \text {, } \\
1.0 \mathrm{vol} / \mathrm{hr} \text { evac. }\end{array}$ & 1.3 & 140 & 7.1 \\
\hline 10CFR100 guideline & 25 & 300 & $150^{(a)}$ \\
\hline
\end{tabular}

(a) Practiced guideline value. 


\subsubsection{Accident Dose Calculations for Vented Confinement.}

DBDA. As with the other vented alternatives considered in this study, a traditional licensing-type assessment of primary system depressurization to a vented confinement bullding requires assumption of a direct release to the environment. If a rapid primary system depressurization is taken as a design basis event, the consequences determined for other vented designs, presented in Fig. 6-1, apply also to vented confinement. The restrictions on plant design and analysis in Fig. 6-2 identified for the acceptable cases from Fig. 6-1 also apply to vented confinement.

Siting Event. A siting event based on a time-dependent TID-14844 release to a vented confinement building will result in doses which exceed the 10 CFR 100 exposure guidelines for the representative site because the traditional licensing approach would require a direct release from the confinement to the environment. With such an approach, acceptability cannot be demonstrated for any reasonable range of site conditions. Licensing of vented confinement therefore appears to require a new approach, as described below.

\subsubsection{Proposed Means for Licensing of Vented Confinement. One basic} impediment to licensing of vented confinement for the HTGR is that the consequences of traditionally assessed design basis HTGR accidents may appear higher than similarly assessed LiVR design basis accidents. Another impediment is the use of assumptions for siting evaluation which do not account for unique features of the HTGR. As pointed out in Section 6.1.3, probabilistic risk assessment (PRA) lends itself to proper definition of both design basis events and siting considerations. Section 5 of this report contains detailed probabilistic assessments of the risk to the public from a representative PWR and from the HTGR with vented confinement. The results presented in Section 5 show that the radiological risk from an HTGR with vented confinement appears to be less than that from a representative PWR with conventional containment for high consequence events and comparable for lower consequences. Due to the dichotomy in the present 
licensing process (Ref. 6-7), which is discussed in Section 6.1 .3 , the high-consequence, low-probability event sequences are not considered in the Iicensing process, and the advantage of the HTGR is therefore not credited.

Section 5.4 contains conclusions derived from the probabilistic comparison of PWRs and the HTGR with vented confinement. Briefly, these conclusions are as follows:

1. The safety issues in terms of risk to the public could be more uniformly addressed by employing probabilistic risk assessment techniques in the licensing process.

2. Because of the generally lower risk from the HTGR with vented confinement as compared with results from the Reactor Safety Study (Ref. 6-6), the HTGR with vented confinement appears to be a viable concept.

On the basis of these conclusions, PRA appears to be a means for licensing consideration of the HTGR with vented confinement. Through PRA, the HTGR with vented confinement can be evaluated and licensed on its own merits rather than on LWR precedents, and Inherent safety features unique to the HTGR can be properly credited.

Section 6.1 .1 .3 briefly discusses the acceptability in the present licensing process of a tradeoff between one type of engineered fission product retention versus another. A change in the licensing process to a PRA basis relates to this precedent in that PRA brings about recognition of inherent safety features; with credit for inherent safety features, engineered safety features (such as containment) for an alternate nuclear plant (such as the HTGR) need not be designed and constructed to state-of-the-art design requirements in order to arrive at the accepted level of safety. This would be a tradeoff between inherent safety features and engineered safety features. It is not a departure from the existing NRC policy of defense in depth; rather, it is recognition that inherent safety features are a valid means of providing defense in depth. 


\subsection{SURIARY OF LICENSING CONSIDERATIONS}

At appropriate points through the preceding text of Section 6, the specific subjects under consideration have been summarized. It is appropriate at this juncture to recall these discussions to put containment options licensing considerations into overall perspective.

First, the review of past HTGR experience (Section 6.1.1) showed no firm precedent requiring a speciflc containment design for the HTGR. In fact, studying the development of the general design criteria (Section 6.1.2.4) indicated that protection of the public has been the apparent underlying intent of the AEC (NRC), and therefore meeting the 10CFR100 guidelines is proposed as a proper basis for consideration of containment alternatives. The use of PRA in the licensing process was discussed (Section 6.1.3), and it was concluded that PRA may ultimately enable a more orderly, uniform, and economically balanced licensing process. Until appropriate standards are developed, PRA can be used to clarify the existing practice, PRA data and techniques can lead to consistent identification of design basis events and siting considerations, and PRA can be used in design optimization to assist in weighing the merits of one design versus an alternative design.

Based on appropriate design parameters, unlined containment, reclos$a b l e$ vented containment, and reclosable vented confinement have all been shown to restrict doses for an appropriate spectrum of accident conditions to within the 10CFR100 exposure guidelines. The conditions for which acceptability can be demonstrated become respectively more restrictive, however. This fact makes unlined containment the one option of these three which has the highest probability of acceptance in the current licensing climate. The final option, vented confinement, is less 11kely to gain initial acceptance under the current licensing regulations, owing to the need for evaluation on the basis of PRA. Nevertheless, the substantial savings possible with vented confinement plus the fact that vented confinement provides an apparently acceptable risk level for the HTGR suggests that it should be pursued as an ultimate objective. 
REFERENCES

6-1. DiNunno, J. J., et a1., "Calculation of Distance Factors for Power and Test Reactor Sites," USAEC Report TID-14844, March 23, 1962.

6-2. Goodjohn, A. J., and T. R. Moffette, General Atomic Company, "Preliminary Information on the Degign and Safety Characteristics of a Large HTGR with Conventional Containment," August 11, 1969, unpublished data.

6-3. Thornberry, R. C., et al., "Selected Safety Design Bases for a 3800 MW(t) High Temperature Gas-Cooled Reactor Power Plant," General Atomic Report GA-A13403, March 27, 1975.

6-4. Rusche, Ben. C., U.S. Nuclear Regulatory Commission, letter to E. W. O'Rorke of General Atomic, June 20, 1975.

6-5. "HTGR Accident Initiation and Progression Analysis Status Report," ERDA Report GA-A13617, v. I-VII, Genera1 Atomic Company, October 1975 to February 1976.

6-6. "The Reactor Safety Study -- An Assessment of Accident Risks in U.S. Commercial Nuclear Power Plants," USAEC Report WASH-1400, October 1975.

6-7. Hanauer, Stephen H., "Probabilistic Risk Assessment in the Nuclear Regulatory Process in the United States - History and Perspective," paper presented at the American Nuclear Soclety Winter Meeting, San Francisco, California, November 17, 1975.

6-8. Ricarde11a, P. C., "Design Basis for HTGR Penetrations and Closures," General Atomic Report GA-A13832, May 7, 1976.

6-9. Eisenhut, D. G., and R. C. De Young, "Current Plans of the Regulatory Staff for the Use of Probabilistic Assessment," paper presented at the American Nuclear Society Winter Meeting, San Francisco, California, November 17, 1975.

6-10. Meeting of the Reactor Safety Study Working Group of the Advisory Committee on Reactor Safeguards, January 4, 1977, testimony of Mr. Saul Levine, p. 207 of uncorrected stenographic transcript of the proceedings. 
6-11. Office of Nuclear Reactor Regulation, USNRC, "Staff Discusston of Fifteen Technical Issues Listed in Attachment to November 3, 1976 Memorandum from Director, NRR to NRR Staff," NUREG-0138, November 1976.

6-12. Project Management Corporation, "Clinch River Breeder Reactor Project Preliminary Safety Analysis Report," Docket 50-537, Section 15A.

6-13. "Assumptions Used for Evaluating the Potential Radiological Consequences of a Loss of Coolant Accident for Boiling (Pressurized) Water Reactors," USNRC Regulatory Guide 1.3 (1.4), Rev. 2, June 1974.

6-14. Costaz, J. L., and J. Picaut, "Multiple-Barrier Concrete Containment Without Steel Liner," International Conference on Experience in the Design, Construction and Operation of Prestressed Concrete Pressure Vessels and Containments for Nuclear Reactors, University of York, England, September 1975.

6-15. Smith, E. C., "Plastic Liners for CANDU Containment Structures," ASCE National Water Resources Meeting, Phoenix, Arizona, Meeting Preprint No. 1307, January 11-15, 1971.

6-16. Deremer, R. K., and T. Shih, "RATSAM: A Computer Program to Analyze the Transient Behavior of the HTGR Primary Coolant System During Accidents," General Atomic Report GA-A13705, May 1977.

6-17. "GASSAR-6, General Atomic Standard Safety Analysis Report, Table 11.1-5, February 5, 1975 (NRC Docket STN 50-535).

6-18. "GASSAR-6, General Atomic Standard Safety Analysis Report," Section 15.11, February 5, 1975 (NRC Docket STN 50-535).

6-19. "HTGR Accident Inftiation and Progression Analysis Status Report," ERDA Report GA-A13617, v. VI, General Atomic Company, January 1976.

6-20. "GASSAR-6, General Atom1c Standard Safety Analysis Report," Table 2A.5-1, February 5, 1975 (NRC Docket STN 50-535).

6-21. "HTGR Accident Initiation and Progression Analysis Status Report," ERDA Report GA-A13617, v. VIII, General Atomic Company, January 1977. 
6-22. Stone and Webster Engineering Corporation, "Stone and Webster Standard Safety Analysis Report (SWESSAR-P1)," Docket-STN-50495, Section 2.3, Amendment No. 5, December 2, 1974.

6-23. "HTGR Safety Research Program, April-June 1975," Los Alamos Scientific Laboratory, LA-6054-PR Progress Report, September 1975.

6-24. "HTGR Accident Initiation and Progression Analysis Status Report," ERDA Report GA-A13617, v. V, Section 4, General Atomic Company, February 1976.

6-25. Public Service Company of Colorado, "Fort St. Vrain Nuclear Generating Station Final Safety Analysis Report," Docket 50-267, Appendix D. 


\section{RESEARCH AND DEVELOPMENT SUGGESTIONS}

\subsection{INTRODUCTION}

A primary objective of the AIPA study has been to provide guidance for safety research and development (R\&D) programs for HTGRs. Such R\&D efforts can in general be directed at either identifying design changes or reducing the uncertainties involved in assessing the risk of HTGR accident events. This containment design options study itself is in part an R\&D effort of the former type, and as a result of this study additional R\&D suggestions have been identified, most of which are of the latter type, aimed at reducing the uncertainties.

The method chosen for Identification of R\&D guidelines from this study consists of reviewing the potential problems associated with licensing of each containment option and identifying means to obviate or reduce these potential problems. This process identifies areas where money could be invested to enable eventual licensing of containment options, providing overall cost savings in the long term via less expensive containment.

No attempt has been made to assign precise priorities to the various R\&D recommendations. However, one alternative, unlined containment, is judged to have a higher probability of current licensing acceptance. The R\&D suggestions associated with unlined containment the refore have a higher probability of short-term return.

\subsection{R\&D SUGGESTIONS DERIVED FROM UNLINED CONTAINMENT CONSIDERATIONS}

With due regard for past experiments which have been reported in Section 6, some uncertainty remains in the leak rate obtainable for unlined containment. Hence, an experimental program to verify the leak rate 
obtainable for typical HTGR unlined containment may be of prime importance. The results of the test program in France (reported in Section 6.3.1.2 of this report) indicated that high quality concrete has low permeability properties and that a lack of continuity caused by a crack or untreated construction joint or a poor penetration seal provides the easlest path for leakage. It may be appropriate for R\&D efforts to be directed at confirming these results, defining acceptable quality for the concrete, and verifying the location of greatest potential leakage. As a corollary to this effort, leakage of various gasborne fission products could be correlated with leakage of containment atmosphere gases such as nitrogen, oxygen, and helium in order to quantify the fission product transport mechanisms and the plateout which would occur during the leakage flow process. These corollary studies could lead to some credit in the licensing process for fission product decontamination factors which would apply to the unlined containment leak rate, and thus ease licensing of unlined containment.

To facilitate decontamination, the interior surface of unlined containment would be coated with a vinyl or epoxy material. Canadian data (Ref. 7-1) indicate that such nonmetallic liner materials are also quite effective as leakage barriers. A fruitful area of R\&D investigation therefore appears to be the validation of the Canadian results.

In their safety evaluations of the Summit and Fulton plants (Refs. $7-2,7-3)$, the NRC postulated a time-dependent fission product release for siting consideration which was different from the GA model and which did not fully account for all the mechanisms for delayed release of fission products from the HTGR core. Use of this NRC release model would complicate the consideration of unlined containment because predicted dose consequences would exceed the base case values given in Table 6-5. Hence, proving to the NRC the validity of a fission product release model that incorporates these time-delaying features is a requirement for licensing of unlined containment. This is not a new R\&D guideline; HTGR fission product release and plateout tests and development and verification of fission product release and plateout codes were previously identified as requisite 
R\&D areas in Section 5 of Volume IV of the AIPA Status Report (Ref. 7-4). Research and development in these areas is currently under way via the ERDA-funded Safety Research Program. Identification of these areas again in this contalnment design options study serves to emphasize their importance.

A phenomenon related to fission product release is the finite PCRV-tocontainment transport rate proposed in section 6.3.1.5. It is suggested that analytical and/or experimental studies be continued to further define this transport phenomenon which appears to be a unique feature of the HTGR.

Section 6.3.1.1 discussed requirements which have been identified by the NRC for licensing of unlined containment (Ref, 7-5). The R\&D suggestions discussed above are directed at satisfying these NRC-identified requirements. In particular, the R\&D suggestions are directed at (1) confirming that the contalnment building will perform as designed and (2) removing uncertainty from the dose calculations presented in Section 6.3.1.3 which demonstrate compliance with the 10 CFR 100 exposure guidelines.

\subsection{R\&D SUGGESTIONS DERIVED FROM OTHER CONTAINMENT OPTIONS}

Al1 of the options considered in this study except unlined containment involve some kind of direct release to the environment for depressurization events. For each of these options, therefore, the activity released during the design basis depressurization accident is very important. More specifically, the plateout activity lifted off and released during the DBDA is critical, yet some uncertainty must be presumed to exist in quantifying the released plateout. With conventional and unlined containment, uncertainty in liftoff of plateout is not a major concern, because DBDA doses for conventional and unlined contalnment are small fractions of their respective limits. With any type of vented containment or confinement, however, uncertainty in liftoff of plateout should be minimized. The shear force ratio correlation for determining liftoff of plateout has been used in the past (Ref. 7-6), and it now appears prudent to direct some R\&D efforts toward verifying and/or updating the shear force correlation. 
Another factor which affects the liftoff of plateout is the size of the depressurization area. A current effort which could lead to a reduction in the size of the design basis depressurization area is the GA report on PCRV penetrations and closures (Ref. 7-7). A smaller design basis depressurization area will result in lower liftoff of plateout activity. In the process of NRC review of Ref. 7-7, areas of the design which require clarification may be identified. R\&D efforts required to satisfy this NRC review process (for example, materials or fabrication research, or development of inservice inspection procedures) should also be considered as efforts supporting containment options licensing.

If a reclosable type of vented confinement is ultimately considered, $R \& D$ efforts to quantify the actual leak rate through the reclosing mechanism may be required.

Finally, Section 6 of this report concludes that PRA is a reasonable and logical basis for consideration of vented confinement. However, PRA has not yet gained full recognition and acceptance in the licensing realm. Therefore, efforts which further develop the methodology of PRA and which result in wider acceptance of PRA or efforts which serve to introduce PRA into the licensing process can be considered supportive for vented confinement. Consequently, continued development of PRA for the HTGR is a valid R\&D guideline.

\section{REFERENCES}

7-1. Smith, E. C., "Plastic Liners for CANDU Containment Structures," ASCE National Water Resources Engineering Meeting, Phoenix, Arizona, Meeting Preprint 1307, January 11-15, 1971.

7-2. U.S. Nuclear Regulatory Commission, "Safety Evaluation of the Summit Power Station," NUREG-75/004, January 1975.

7-3. U.S. Nuclear Regulatory Commission, "Safety Evaluation of the Fulton Generating Station," NUREG-75/015, March 1975. 
7-4. "HTGR Accident Initiation and Progression Analysis Report," ERDA Report GA-A13617, v. IV, Section 5, General Atomic Company, December 1975.

7-5. Rusche, Ben C., U.S. Nuclear Regulatory Commission letter to E. W. O'Rorke of General Atomic, June 20, 1975.

7-6. Delmarva Power and Light Company, "Summit Power Station Preliminary Safety Analysis Report," Section 15.3.11, Amendment 12, February 15, 1974.

7-7. Ricardella, P. D., "Design Basis for HTGR Penetrations and Closures," General Atomic Report GA-A13832, May 7, 1976. 
APPENDIX A

UNCERTAINTIES IN DOSE CONSEQUENCES

\section{A.1. PARAMETER UNCERTAINTIES}

Derivations of the dose consequence uncertainty factors are based largely on definitions and methodology presented in Volume VI of the Phase I AIPA Status Report, Section 3. Numerically, the uncertainties have been updated from Phase $I$ and are consistent with the interim position in Volume VIII. In summary, these uncertainties represent multiplicative factors corresponding to statistical 5 and 95 percentile bounds on an assumed lognormal distribution of the dose probability density function (pdf). As described below, the assumption of a lognormal shape for the dose distribution has been verified to be accurate by Monte Carlo computer analysis for representative parameter probability density distributions.

Basically, seven parameters can be identified (as listed in Table A-1) as important sources of possible deviation in the median dose consequences as these parameters take on values other than the median or nominal values. These parameters are discussed in the following paragraphs.

\section{A.1.1. Initial Fission Product Inventories}

There are three initial fission product inventories of possible conern: fuel body activity, primary coolant gasborne activity, and PCRV plateout activity. Median values and uncertainty distributions for these inventories are taken from Volume $V$ of the Phase $I$ report. The fuel body activity is known to within about $1 \%$ (p. 3-4 of Volume VI) so that its uncertainty effect may be neglected. Circuit gasborne and iodine plateout inventories have uncertainty factors of about 1.5 and 1.6 , respectively, as shown in Table 3-2 of Volume VI. This implies that for events where the 
TABLE A-1

UNCERTAINTY FACTOR SUMMARY

\begin{tabular}{|c|c|c|c|}
\hline Parameter & $\begin{array}{l}\text { Parameter } \\
\text { Distribution }\end{array}$ & $\begin{array}{c}\text { Dose } \\
\text { Uncertainty } \\
\text { Factor }\end{array}$ & Applicable Event Doses \\
\hline \multirow[t]{2}{*}{$\begin{array}{l}\text { 1. Initial fission product } \\
\text { inventories }\end{array}$} & Lognorma1 & $\begin{array}{l}1.5 \\
\text { (gasborne) }\end{array}$ & $\begin{array}{l}\text { Depressurization whole body } \\
\text { gamma }\end{array}$ \\
\hline & Lognormal & $\begin{array}{l}1.6 \\
\text { (plateout) }\end{array}$ & $\begin{array}{l}\text { Depressurization and steam } \\
\text { ingress thyroid }\end{array}$ \\
\hline $\begin{array}{l}\text { 2. Hydrolysis of failed } \\
\text { fuel }\end{array}$ & Lognormal & 3 & $\begin{array}{l}\text { Steam ingress whole body } \\
\text { gamma }\end{array}$ \\
\hline $\begin{array}{l}\text { 3. Liftoff during } \\
\text { blowdown }\end{array}$ & $\begin{array}{l}\text { Truncated near } \\
\text { lognorma } 1\end{array}$ & 5 & $\begin{array}{l}\text { Depressurization and steam } \\
\text { ingress thyroid }\end{array}$ \\
\hline $\begin{array}{l}\text { 4. PCRV plateout during } \\
\text { core heatup }\end{array}$ & $\begin{array}{l}\text { Truncated near } \\
\text { lognorma1 }\end{array}$ & 24 & Core heatup thyroid \\
\hline $\begin{array}{l}\text { 5. PCRV egress rate and } \\
\text { containment plateout }\end{array}$ & Lognorma 1 & 10 & Core heatup thyroid \\
\hline $\begin{array}{l}\text { 6. Containment leak } \\
\text { rate }\end{array}$ & Lognorma1 & 5 & A11 \\
\hline 7. Weather & Lognormal & 5 & A11 \\
\hline
\end{tabular}

Overal1 Uncertainty Factors Employed in Risk Evaluations:

Whole body gamma

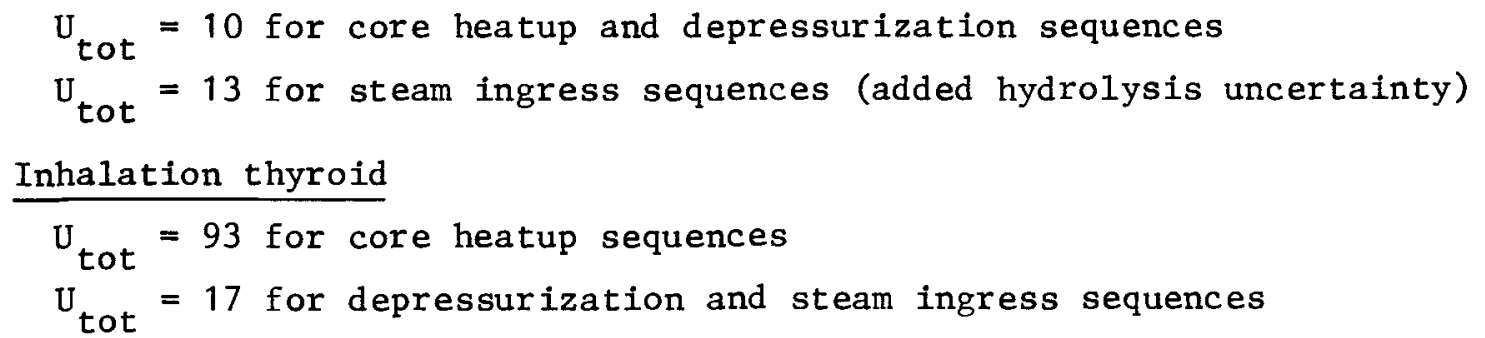


whole body dose stems largely from released noble gases in the primary coolant, such as depressurization events (but not for steam ingress events, where the primary contributors are noble gases from fuel hydrolysis), the corresponding whole body gamma dose uncertainty is 1.5. Likewise, for both steam ingress and depressurization events, where the inhalation thyroid dose is attributable to iodine lifted off PCRV surfaces or carried out on dust blown out of the PCRV (see Section 5.2 of Volume VI), the corresponding dose uncertainty factor is about 1.6 .

\section{A.1.2. Hydrolysis of Failed Fuel}

Specifically for steam ingress sequences, a major contributor to whole body doses is the release of noble gases due to chemical reaction of the steam with carbide fuel kernels, a reaction called fuel hydrolysis. Since intact fuel particle coatings are impervious to steam, only particles with failed coatings at the time of the accident are available to hydrolyze. Multiple parameters which affect hydrolysis were identified and their sensitivity effect on the whole body gamma dose was calculated as presented in Section 5.1 of Volume VI. Considering all such parameters combined, an overall whole body gamma dose uncertainty factor of 3 can be specified for hydrolysis. Note that this uncertainty is applied to all steam ingress sequences including cases where all failed fuel becomes hydrolyzed, releasing stored noble gases, because a major constituent of this uncertainty is the uncertainty of knowing what fraction of failed fuel exists in the core at the time of the accident (see Table 5-6 of Volume VI). The distribution of the release due to hydrolysis is taken to be lognormal.

\section{A.1.3. Liftoff During Blowdown}

The amount of fission products initially plated out in the primary coolant circuit released during blowdown includes fission products associated with loose dust that can be blown out along with the hellum and liftoff of activity sheared off from PCRV surfaces. Median values and methods of calculation for these releases are taken to be those used in the AIPA Phase I analysis. In these methods, blowdown of activity associated with 
loose dust is the major contributor for lodine release, as shown in Tables 5-13 and 5-14 of Volume VI. An uncertainty factor of 5 was assigned to this iodine release based largely on engineering judgment considering the difficulties in predicting the amount of loose dust and the fraction of iodine associated with this dust as compared to the fraction on fixed PCRV surfaces. The distribution of the release of plateout activity is taken to be lognormal, except that the upper tail of the distribution is truncated at $100 \%$ release to comply with physical reality.

\section{A.1.4. PCRV Plateout During Core Heatup}

An important parameter specifically for the thyroid dose in core heatup sequences is the amount of iodine released from the core which escapes the PCRV without plating out on metal surfaces. The median value and distribution of this iodine escape factor are taken to be as shown in Fig. A-1 (taken from Section 3.2 of Volume VIII). This is the interim position for the iodine PCRV plateout, which has been adopted until further test results are obtained. The technical basis for this position is described in detail in Section 3.2 of Volume VIII. The distribution is somewhat non-lognormal in that it is slightly skewed (on a $\log$ scale) to the low (left) side and is truncated at $100 \%$ release. An equivalent uncertainty factor of 24 is derived as described in Volume VIII and used in the report.

\section{A.1.5. PCRV Egress Rate and Containment Plateout and Fallout}

The containment can be treated as a control volume with the source, depletion, and release mechanisms as illustrated in Fig. A-2. In the interim analysis, a constant rate (in terms of fraction of PCRV inventory) of egress of helium and entrained fission products from the PCRV is assumed with median value $2 \% / \mathrm{hr}$. Parametric calculations using the TDAC computer code indicate that an increase of a factor of 3 in PCRV egress rate increases the doses by a factor of about 1.5 for a nonisolated containment with no cleanup and by a lesser amount for an isolated containment with cleanup. The factor of 3 appears to reasonably cover inaccuracies in the 


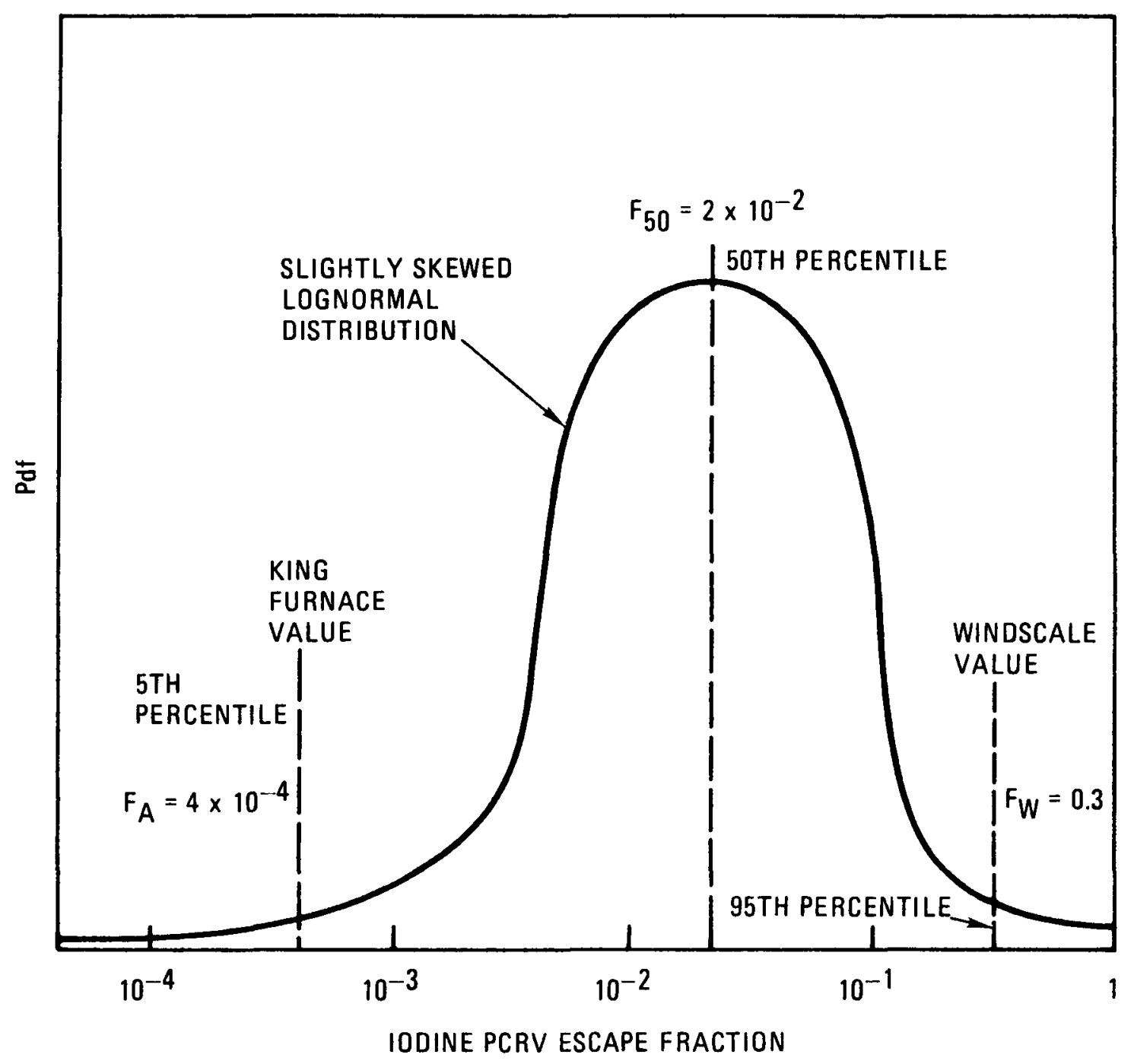

Fig. A-1. Probability density function (pdf) for iodine escape (nonplateout) fraction from PCRV 


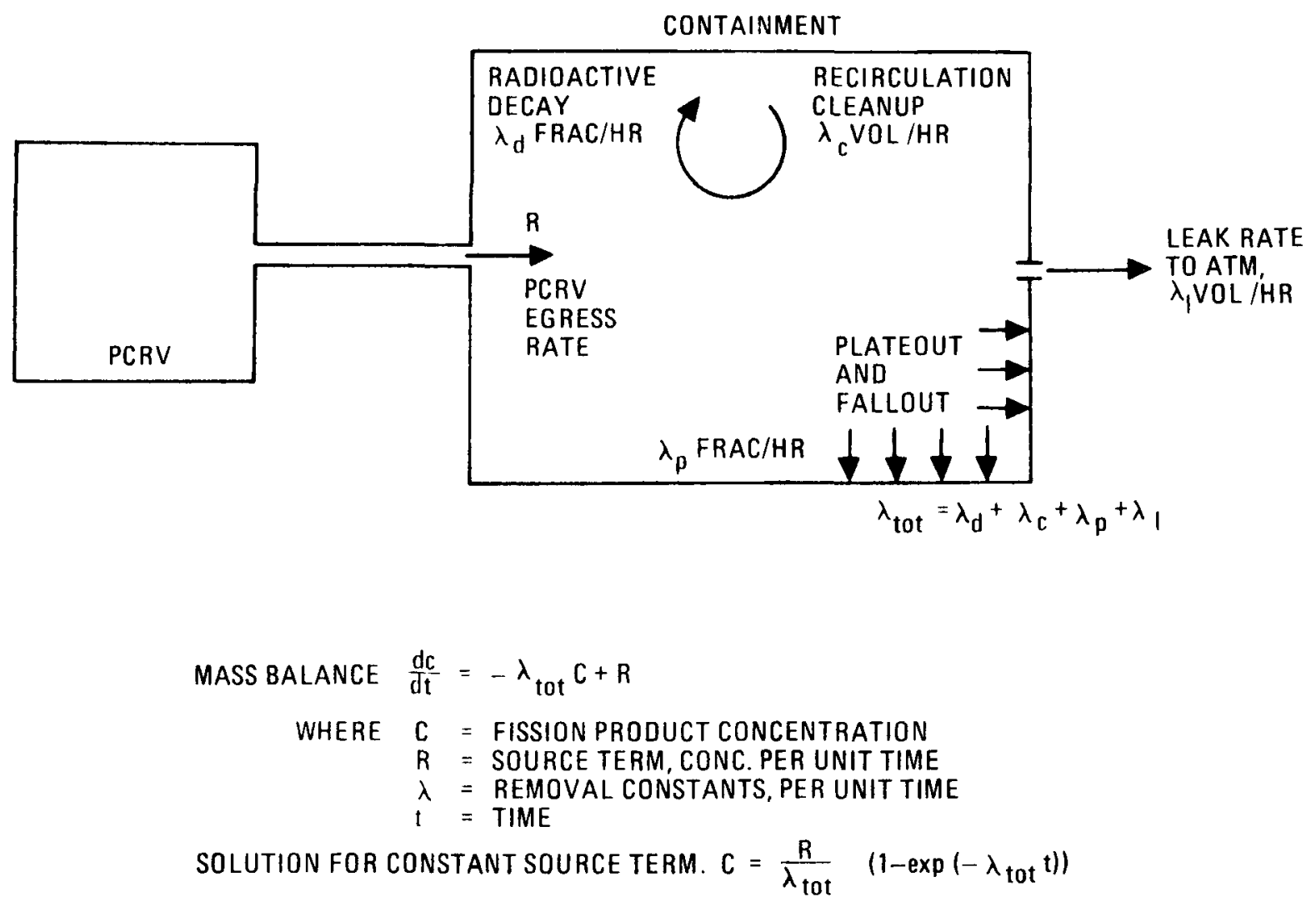

Fig. A-2. Representation of fission product processes in the containment 
calculation of PCRV egress rate so that the dose uncertainty estimate is taken to be 1.5 .

The uncertainty for containment plateout can be determined considering the competing containment processes illustrated in Fig. A-2. The onecompartment containment equations are also presented in Fig. A-2. Basically, the containment fallout and plateout process is an exponential depletion mechanism of the same form as radioactive decay, recirculation cleanup (if any), and leakage to the atmosphere. This implies that the rate of depletion is proportional to the concentration. These analytical relationships are identical to those presented in WASH-1400, Section 3 of Appendix VII.

The median value for the natural deposition removal rate constant $\left(\lambda_{p}\right)$ was assumed in the AIPA Phase $I$ and interim analyses to be $0.14 \mathrm{hr}^{-1}$. This value is the same as that used in the RSS for particulate settling in a large PWR containment volume (see Appendix VII of WASH-1400). An uncertainty factor of 10 in the removal rate constant was assigned in the AIPA study, based on engineering fudgment. Thus, using the median value, it is found that the amount of particulate species plating out or falling out in the containment is $15 \%$ in the first hour and $75 \%$ in $10 \mathrm{hr}$. For the lower bound $\left(\lambda_{p}=0.014 \mathrm{hr}^{-1}\right), 1.4 \%$ is removed in the first hour and $15 \%$ in $10 \mathrm{hr}$.

The solution of the fission product mass balance differential equation is shown in Fig. A-2 for a source term $\mathrm{R}$, which is constant with time. In actuality, the source term is a constant fraction of the PCRV inventory which changes strongly with time and the complex solution is made with the TDAC code. The simplified solution, however, illustrates the fact that the concentration of a fission product species in the containment varies proportionally to the total removal rate constant, $\lambda_{\text {tot }}$. For no circulation cleanup, $\lambda_{1}$ and $\lambda_{d}$ are small (for 1sotopes of interest) compared to $\lambda_{p}$ and thus $\lambda_{\text {tot }} \approx \lambda_{\mathrm{p}}$. From these considerations it follows that the dose increases approximately proportionally to the decrease in the plateout and fallout removal rate constant $\lambda_{p}$. A more precise calculation yields an 
increase in dose between a factor of 9 and 10 for a factor of 10 (uncertainty) decrease in $\lambda_{\mathrm{p}}$. Combining this statistically with the PCRV egress rate uncertainty factor of 1.5 results in a final uncertainty factor of 10 for both PCRV egress and containment natural deposition. The distribution is assumed to be lognormal.

\section{A.1.6. Containment Leak Rate}

Median values, uncertainty factor, and distribution of the containment leak rate parameter are taken from the AIPA Status Report, Volume VI. An uncertainty factor of 5 is assumed with a lognormal distribution.

\section{A.1.7. Weather}

Consistent with the AIPA interim analysis in Volume VIII, an uncertainty factor of 5 is assigned for meteorological conditions with a lognormal distribution. This uncertainty factor is significantly lower than the value used in Phase $I$ analysis and is based on statistical analysis of meteorology data from 68 licensed LWR sites. Median values are essentially unchanged from Phase $I$.

\section{A.2. COMBINATION OF UNCERTAINTIES}

Parameter uncertainties were combined statistically using the lognormal form of the law of propagation of errors:

$$
\exp \left[\sum_{i}\left(\ln U_{i}\right)^{2}\right]^{1 / 2}
$$

Table A-1 summarizes the parameter uncertainties and distributions. It is noted that several parameters deviate slightly from a lognormal distribution so that the above formula is approximate. To check the accuracy, two calculations were made with the STADIC computer code (Ref. A-1), which uses a Monte Carlo technique to combine different statistical distributions. In 
one calculation, a table of the truncated liftoff distribution for lodine liftoff ( $U=5$ ) during DBDA was Input to STADIC and comblned with lognormal distributions of initial lodine plateout inventory $(U=1.6)$, containment leak rate $(U=5)$, and weather $(U=5)$. The computer-combined uncertainty factor was within $6 \%$ of the value ( $U_{\text {tot }}=17$ ) using the above analytical formulation. In the second calculation, a table of the truncated PCRV plateout distribution (FIg. A-1) was combined with other (lognormal) distributions for parameters affecting the core heatup thyroid dose. The computer uncertainty was within $8 \%$ of the combined analytical uncertainty factor $\left(U_{\text {tot }}=93\right)$.

Based on the STADIC code verifications, the analytically combined uncertainties were used in the cumulative dose calculations. Resulting overall uncertainties are shown at the bottom of Table A-1.

\section{REFERENCE}

A-1. Cairns, J. J., and K. N. Fleming, "STADIC: A Computer Code for Combining Probability Distributions," General Atomic Report GAA14055, March 1977. 
APPENDIX B

ATMOSPHERIC DISPERSION ASSUMPTIONS AND PARAMETER SELECTIONS

FOR PWR CONSEQUENCE ANALYSIS

Representative Atmospheric Conditions Selected

Pasquill atmospheric stability category

Type C

Mean wind velocity

$1 \mathrm{~m} / \mathrm{sec}$

Persistence of meteorological condition

Constant persistence during release duration

Dose receptor location $2500 \mathrm{~m}$ downwind

Turbulent Diffusion Mode1

Gaussian diffusion model simplified to replace the Gaussian crosswind shape with a uniform function (i.e., "top-hat" distribution)

Gaussian diffusion expression:

$$
x=\frac{Q^{\prime}}{\pi \sigma_{y} \sigma_{z}} \exp \left[-\frac{y^{2}}{2 \sigma_{y}^{2}}-\frac{h^{2}}{2 \sigma_{z}^{2}}\right]
$$

where $\quad x=$ cloud concentration at point $x, y$, and $z=0\left(\mathrm{Ci} / \mathrm{m}^{3}\right)$,

$Q^{\prime}=$ source strength $(\mathrm{C} i / \mathrm{sec})$,

$\mathrm{u}=$ wind speed $(\mathrm{m} / \mathrm{sec})$,

$\sigma_{y}, \sigma_{z}=$ standard deviation of the material in the plume in the respective $y$ and $z$ directions $(m)$,

$h=$ height of release $(m)$. 
"Top-hat" distribution simplification replacement:

$$
\left[(2 \pi)^{1 / 2} \sigma_{y}\right]^{-1} \exp \left(-y^{2} / 2 \sigma_{y}^{2}\right)=\left(3 \sigma_{y}\right)^{-1}, \quad\left(-1.5 \sigma_{y} \leq y \leq 1.5 \sigma_{y}\right)
$$

Resultant "top-hat" diffusion model:

$$
\frac{x}{Q^{\prime}}=\frac{2}{\sqrt{2 \pi}\left(3 \sigma_{y}\right) \sigma_{z} u} \exp \left[-\frac{h^{2}}{2 \sigma_{y}^{2}}\right]
$$

Note: $3 \sigma_{\mathrm{y}}$ is the lateral width (m) of the assumed rectangular uniform distribution.

Buoyant Plume Rise Mode1

Ref: G. A. Briggs, "Plume Rise," USAEC Report TID-25075, November 1969, also see Appendix VI to Reactor Safety Study, Appendix A, October 1975.

For unstable or neutral atmospheric stability (i.e., Pasquill categories A through D inclusive):

$$
\Delta \mathrm{h}=1.6 \mathrm{~F}^{1 / 3} \mathrm{u}^{-1} \mathrm{x}^{2 / 3}
$$

where $\Delta \mathrm{h}=$ plume centerline height above its initial emission height (m), $\mathrm{F}=3.7 \times 10^{-5} \mathrm{Q}_{\mathrm{H}}=$ buoyancy $\mathrm{flux}\left(\mathrm{m}^{4} / \mathrm{sec}^{3}\right) /(\mathrm{cal} / \mathrm{sec})$, $Q_{H}=$ thermal energy release rate (cal/sec),

$\mathrm{X}=$ downwind distance (m); plume rise takes place until a distance $\mathrm{X}=5 \mathrm{X}^{*}$ is reached, at which point atmospheric turbulence dominates and no further buoyancy rise is allowed, where $X^{*}=0.25 Q_{H}^{0.4}$ 
The plume is conservatively assumed to remain in contact with the ground (i.e., no liftoff). However, the plume rise $\Delta h$ is assumed to increase the vertical atmospheric diffusion in the following manner:

$$
\sigma_{z}^{\prime}(x)=\left[\sigma_{z}^{2}(x)+\Delta h^{2}\right]^{1 / 2}
$$

$$
\begin{aligned}
\text { where } \sigma_{z}^{\prime}(\mathrm{x})= & \text { enhanced vertical standard deviation parameter }(\mathrm{m}), \\
\sigma_{z}(\mathrm{x})= & \text { vertical standard deviation parameter at distance } \mathrm{X} \text { for no } \\
& \text { buoyancy effects }(\mathrm{m}), \\
\Delta \mathrm{h}= & \text { plume rise }(\mathrm{m}) .
\end{aligned}
$$

No penetration of the elevated inversion (mixing layer) is allowed.

Vertical and Lateral Standard Deviations

Ref: Appendix VI to Reactor Safety Study, Table VI A-1.

For Pasquill stability category, Type C:

$$
\begin{aligned}
& \sigma_{y}(x)=0.11 x(1+0.0001 x)^{-1 / 2} \\
& \sigma_{z}(x)=0.08 x(1+0.0002 x)^{-1 / 2}
\end{aligned}
$$

where $\sigma_{y}, \sigma_{z}=$ standard deviation of the material in the plume in the respective $y$ and $z$ directions $(m)$,

$x=$ downwind distance $(m)$.

Values of $\sigma_{z}$ are allowed to increase until $\sigma_{z}$ equals $0.8 \mathrm{~L}$ where $\mathrm{L}$ is the prevalling mixing height. Thereafter, $\sigma_{z}$ is maintained equal to $0.8 \mathrm{~L}$. 
Mixing Layer Height

$\begin{array}{ll}\text { Stable stratifications*, } & \text { L }=550 \mathrm{~m} \\ \text { Unstable stratifications*, } & \mathrm{L}=1400 \mathrm{~m}\end{array}$

Building - Wake Effects

Building-wake effects are excluded; atmospheric turbulent expansion is assumed to start immediately at the discharge point. (Building-turbulent wake corrections are minor at a dose receptor point located $2500 \mathrm{~m}$ downwind.)

Plume Depletion

No dry or wet aerosol deposition is assumed. (Preliminary estimates indicate scavenging effects to be minimal at $2500 \mathrm{~m}$.)

Radioactive decay enroute is considered.

Release Duration Correction

Releases of durations greater than $0.5 \mathrm{hr}$ (PWR-3, $-4,-5,-6$, and -7) are corrected for plume meander by the following approximation:

$$
C F=\left(\frac{\Delta t}{0.5}\right)^{-1 / 3}
$$

where $C F=$ correction factor to account for plume meander with time, $\Delta t=$ release duration $(h r)$.

Ref: Appendix VI to the Reactor Safety Study, October 1975.

*Average of site types A through $G$ for winter through fall seasons. Ref: Appendix VI to Reactor Safety Study, Table VI 5-3. 